Portland State University

PDXScholar

\title{
Freedom vs. Security: Analyzing the Connection between States' Prioritization of Security over Civil Liberties and Citizen Support for Democratic Norms
}

Carlyn Trumbull Madden

Portland State University

Follow this and additional works at: https://pdxscholar.library.pdx.edu/open_access_etds

Part of the Other Political Science Commons

Let us know how access to this document benefits you.

\section{Recommended Citation}

Madden, Carlyn Trumbull, "Freedom vs. Security: Analyzing the Connection between States' Prioritization of Security over Civil Liberties and Citizen Support for Democratic Norms" (2021). Dissertations and Theses. Paper 5816.

https://doi.org/10.15760/etd.7687

This Thesis is brought to you for free and open access. It has been accepted for inclusion in Dissertations and Theses by an authorized administrator of PDXScholar. Please contact us if we can make this document more accessible: pdxscholar@pdx.edu. 
Freedom vs. Security:

Analyzing the Connection between States' Prioritization of Security over Civil Liberties and Citizen Support for Democratic Norms

by

Carlyn Trumbull Madden

A thesis submitted in partial fulfillment of the requirements for the degree of

Master of Science

in

Political Science

Thesis Committee:

Melody Valdini, Chair

Lindsay Benstead

Safia Farole

Portland State University

2021 
(C) 2021 Carlyn Trumbull Madden 


\begin{abstract}
Is global democracy declining? This is a question many have argued over, leading to multiple, oftentimes contradictory, answers regarding causes and potential solutions. This thesis seeks to explore the question of democratic decline by analyzing changes over time in public opinion survey data in three states- New Zealand, Turkey, and the United States- looking specifically at how the government has balanced the tradeoff between security and civil liberties in the post-9/11 world. I argue that long-term government prioritization of security over freedoms has eroded support for fundamental democratic norms, as citizens willingly accept restrictions to their rights in exchange for a sense of security, causing gradual democratic decline. The evidence from an analysis of survey data over the past ten years supports this theory, with New Zealand emerging as a bestcase scenario that always prioritized freedom, and remains a strong democracy, Turkey as a worst-case scenario that strongly supported security over all else and quickly transitioned away from the fledgling democracy they were into full autocracy, and the US gradually, and worryingly, slipping deeper into hybridity with enduring restrictions on civil rights. Further, the gap between citizen perceptions of the abstract and reality of democracy appears to be growing, resulting in a general inability (or unwillingness) among citizens to see an increase in security policy as counter to democracy, in either an abstract or practical sense, despite evidence that expanding security is balanced out by a decrease in freedoms. While not the only factor leading to democratic decline, government prioritization of security policy over civil liberties has long term consequences for democratic survival and serious implications for the future.
\end{abstract}




\section{Acknowledgments}

It took a village to get this project off the ground, and there are so many wonderful people whose support and guidance I am so grateful for. The entire political science department at PSU has been an incredible support system, particularly in such a crazy year that required so much change and flexibility, A very special thanks goes to professor Valdini for her endless support and encouragement and introducing to me a love for comparative political systems I didn't know I had- this thesis would have never seen daylight if not for you. Also, a huge thanks goes to Professor Yeşilada for a great deal of assistance with research methods and design and for all his advice on how best to narrow down and solidify my ideas into researchable arguments. My cohort as well deserves a special thanks for the constant guidance and discussion, not to mention the much-needed friendship and board game nights. Thanks to my friends, near and far, for encouragement and positive affirmation throughout this entire year; with extra love and gratitude to $\mathrm{J}, \mathrm{R}$, and $\mathrm{L}$ for the weekend adventures and the free use of their Wi-Fi when mine decided to stop working (multiple times!). Love and thanks as well to $\mathrm{N}$ and $\mathrm{T}$ for happily reading my first draft and offering so much helpful advice and reassurance, and to $\mathrm{C}$ for calming my nerves as my defense loomed. Finally, to my family for unending support and encouragement and for instilling in me from a very young age a deep passion for the pursuit of knowledge- I love you all, thank you. 


\section{Table of Contents}

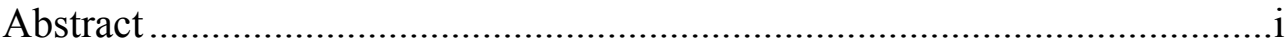

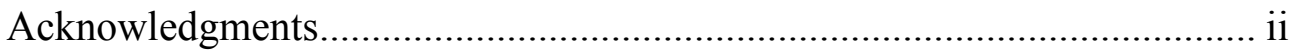

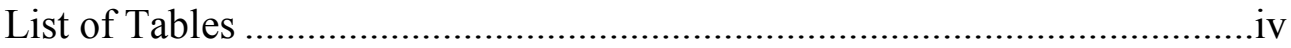

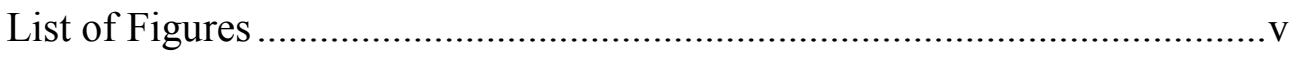

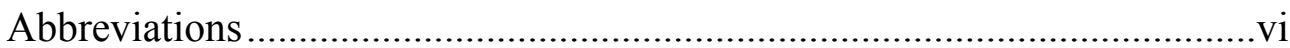

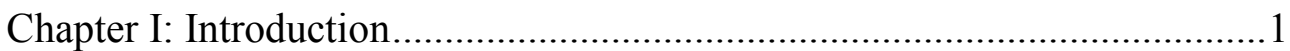

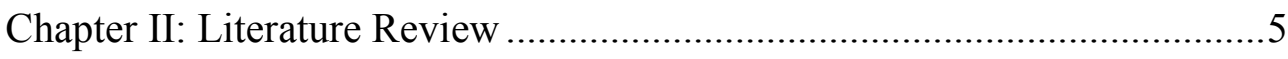

Chapter III: Research Design...............................................................24

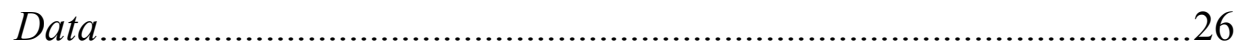

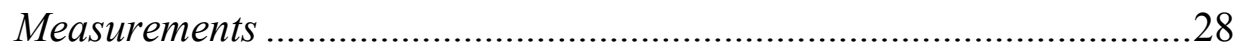

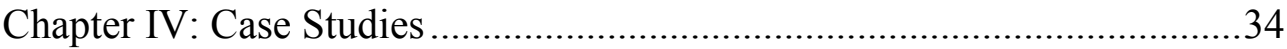

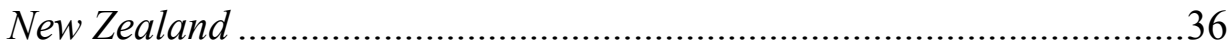

United States ..................................................................................44

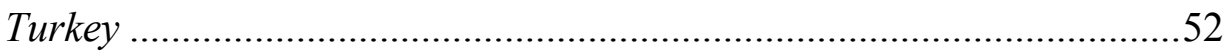

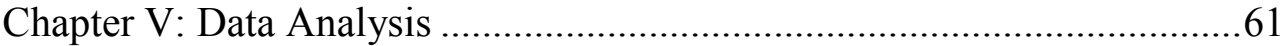

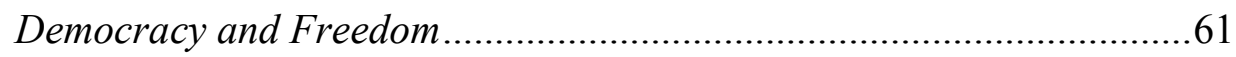

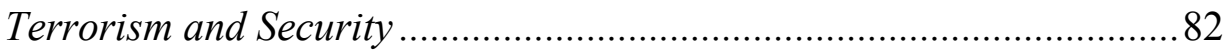

Regression Analysis ................................................................... 90

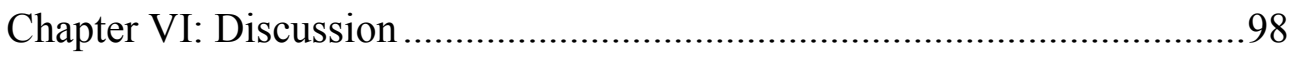

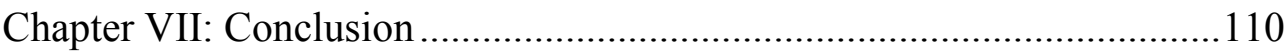

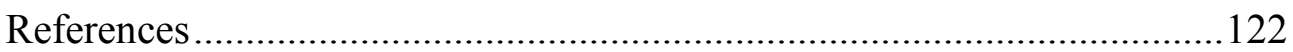

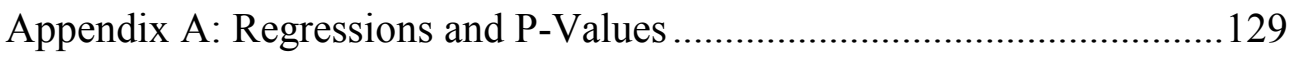

Appendix B: Graphs of Full Data ........................................................ 133 


\section{List of Tables}

Table 1- Framework for Measuring Political Support ..................................................29

Table 2- Relationship Between Importance of Democracy and Security vs. Freedom .....92

Table 3- Relationship Between Importance of Democracy and Security in

Neighborhood

Table 4- Relationship Between Importance of Democracy and Worry of a Terrorist

Attack.

Table 5- Relationship Between Perceived Democraticness of Country and Freedom vs. Security

Table 6- Relationship Between Perceived Democraticness of Country and Security in Neighborhood

Table 7- Relationship Between Perceived Democraticness of Country and Worry of a Terrorist Attack 


\section{List of Figures}

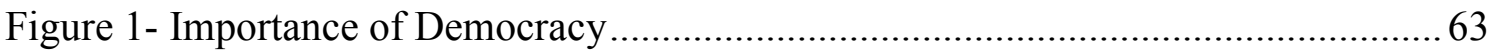

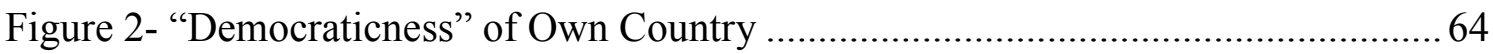

Figure 3- Support for Having a Democratic Political System ..........................................66

Figure 4- Satisfaction with Current Political System ......................................................67 67

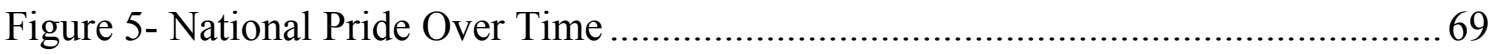

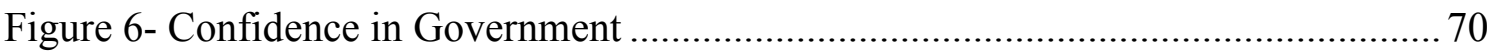

Figure 7- Support for Having A Strong Leader ......................................................... 72

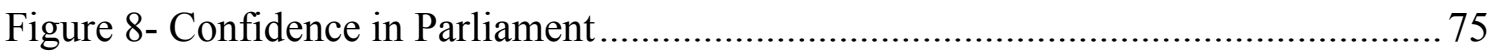

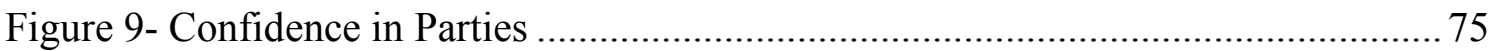

Figure 10- Essential Characteristics of Democracy: Civil Rights ..................................... 81

Figure 11- Essential Characteristics of Democracy: Elections ........................................ 81

Figure 12- Essential Characteristics of Democracy: Gender Equality ……………….... 81

Figure 13-Which is More Important: Freedom vs. Security ............................................ 83

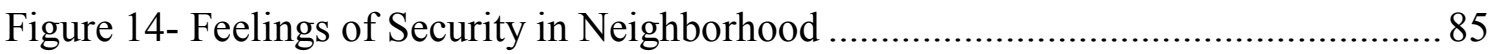

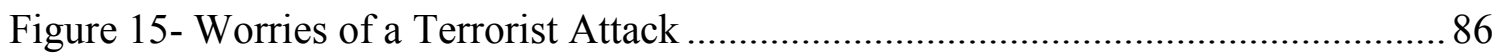


Abbreviations

AKP: Adalet ve Kalkınma Partisi (Justice and Development Party)

CHP: Cumhuriyet Halk Partisi (Republican People's Party)

DHKP/C: Devrimci Halk Kurtuluş Partisi-Cephesi (Revolutionary People’s Liberation Party Front)

EIU: The Economist Intelligence Unit

ESS: European Social Survey

GTI: Global Terrorism Index

HDP: Halklarin Demokratik Partisi (People's Democratic Party)

ISIL: Islamic State of Iraq and the Levant (also known as ISIS or Daesh)

MiT: Millî İstihbarat Teşkilatı (National Intelligence Organization)

PKK: Partîya Karkerên Kurdistanê (Kurdistan Worker's Party)

SDF: Syrian Democratic Forces

TBMM: Türkiye Büyük Millet Meclisi (Grand National Assembly of Turkey)

USA PATRIOT Act: Uniting and Strengthening America by Providing Appropriate

Tools Required to Intercept and Obstruct Terrorism

WVS: World Values Survey

YPG: Yekineyên Parastina Gel (People’s Protection Units) 


\section{CHAPTER I}

Introduction

Is the world truly experiencing a widespread decline of democracy? While the scope and seriousness of this phenomenon remain contested, it seems nearly certain that change of some sort is occurring. According to Freedom House, there are currently fewer democracies in the world than at any point in the organization's existence and 2020 marked the $15^{\text {th }}$ consecutive year of a general decline in global freedom. These concerning trends, marked by the rise of strongman autocrats across the globe and weakening support for democracy in key regions are very worrying for the long-term survival of democracy. There have been, of course, many attempts to explain this phenomenon and to offer potential solutions to stop the supposed decline, but, as it is such a multifaceted and ever evolving issue, there has been no definite consensus as to causes or even an agreement on if decline is truly happening. Most existing studies into democratic survival focus on the political actors (almost exclusively elite-centric), on autocratic states' role in exporting authoritarianism, or on institutional and economic factors. These are then juxtaposed with a number of other authors who argue that this threat of decline is in fact overexaggerated, leaving us with a very murky pool of contradictions that encompasses the vast field of democratic survival.

Democracy as a concept is already a tricky one, understood differently based on context and intended usage, although very generally defined as meaning "government by the people" (OED). Interestingly enough, while any average citizen could probably recognize the key ingredient of "the people" to a democracy, until recently there have been relatively few analyses that actually explore the role of citizens in democratic 
strength. In the academic world, stemming all the way back to the time of Plato, it was simply an accepted fact that public support is critical for a democracy, without much empirical evidence to back up this claim. While this has begun to change in the past few years, there remain many more avenues available for further research into the actual affect public support, and the loss or gain of it, has on long-term democratic survival. Public support for democracy rises and falls for many reasons, some normal fluctuations, and others with lasting effects, but an important and relatively unexplored field is the effect government security policy has on democratic values.

Since the devastating attacks in America on September 11, 2001, global governments have swiftly transitioned to prioritizing security over civil liberties, ostensibly because of the growing threat of terror related activity, and quite often with general public approval. In the tradeoff between security and civil liberty, it seems most often security wins out as citizens are very willing to accept restrictions on freedoms if this comes with a promise of safety. However, because commitment to protecting and upholding civil liberties and freedoms is a foundation of democracy, this raises question of if public approval of security prioritization has long-term effects on public support for these democratic norms. Thus, the question driving this research is: How has a global prioritizing of security over freedom and civil liberties in the post-9/11 world affected citizen support for democratic norms?

If democratic decline is indeed occurring (which I will later argue it selectively is), understanding the factors that may be driving this decline is crucial to slowing or reversing this trend. If we are to combat rising autocracy we must first address possible causes for its endurance and continued growth. The increased security environment of the 
$21^{\text {st }}$ century potentially has further answers as to why democratic decline persists, and thus presents an important avenue for research. While a number of prior studies have indicated people are overwhelmingly comfortable giving up some freedoms in exchange for safety, these have primarily focused on the United States in the immediate aftermath of the 9/11 attacks, and thus there is opportunity to expand and broaden these arguments for a more comparative perspective over a greater time period. Critical to this analysis is how public opinion has shifted over time, as the prioritization of security has persisted in many states since the attacks on 9/11, despite a decrease in the actual threat of terrorism. If the prioritization of security is found to decrease citizen support for fundamental norms, and this has remained steady government policy for the past decade, this could have much broader implications for the hopes of democratic survival. Furthermore, if this loss of support is due to citizens willingly giving up rights they view as unimportant or unnecessary, rather than out of apathy or frustration, this paints a worrying picture of the future existence of these fundamental norms.

Previous authors have recognized a gap or deficit between citizens evaluations of the performance of their democracy and their perception of the ideal of democracy but have overwhelmingly found no need to worry about this "democratic paradox" (Dahl, 2000). However, due to a continuously negative view of performance, coupled with a persistent fear of terrorism, it seems a spillover has begun to occur as the fundamental norms themselves are beginning to be questioned or turned away from. Even the ideal of democracy is losing support in citizen evaluations, indicating that there is certainly more going on than a normal fluctuation in performance evaluation of the incumbent government. Using New Zealand, Turkey, and the United States as case studies this 
analysis examines how support for these fundamental norms has changed over the past decade and explores the governments' security prioritization as a potential cause for the differences we can observe in the outcomes of these three cases.

With that goal, this thesis begins with a review of the very rich field of literature on public opinion and democratic decline before moving into an explanation of the method of analysis, data, and measurements used for this project. From there I offer a detailed summary of the current status of terrorism and democracy in Turkey, New Zealand, and the United States, and then present my analysis of survey data gathered from the World Values Survey, focusing initially on indicators related to freedom and civil liberties and then tying in measures of terrorism and security. Finally, I conclude with a discussion of what patterns this analysis has revealed as well as the implications and significance of this project and avenues for further research. 


\section{CHAPTER II}

\section{Literature Review}

The study of democratic decline is a rich field, which has only grown richer in recent years, producing a wide range of voices and explanations for what we are seeing in the world today. Arguments for democratic decline generally fall into four (relatively flexible) categories: those focusing on the role of elites and elected officials in causing a backslide, those that focus on autocratic regimes exporting their influence across borders, those that encompass the very broad field of economic factors, and those that focus more specifically on institutions and norms. These are, of course, very general categories and many previous works can be classified as falling into more than one, as most discuss a mixture of factors and situations that may cause democratic decline, although all generally put the ultimate blame on one specific factor or cause. Important to recognize right away however, are the explanations that are often left out or overlooked, particularly in this case, the critical role public opinion plays.

Some of the most prominent arguments in the field focus almost entirely on the role of actors in bringing about or causing this democratic backslide, in direct or indirect ways, however they most often center on political elite alone. In setting the stage for these arguments Juan Linz (1978) argued that all democratic regimes have the same reasonable chance of survival, but certain characteristics of relevant actors (both individuals and institutions) decrease the probability of this development and increase the probability of breakdown. This is expanded on by Ziblatt and Levitsky (2018) who argue that democracy fails because the democratically elected leaders gradually subvert democratic norms and use the regime's own institutions to slowly pull it apart. Likewise, 
Applebaum (2020) notes that political elites use emotive and manipulative strategies grounded in a "restorative nostalgia," to help promote an easy transition away from democracy by making citizens fear for their safety and stability (56). In general, these arguments see elite actors as opportunistic and self-interested, using every tool at their disposal to consolidate power, regardless of how it may hurt democracy. There are also those like Klaas (2017) who notes that, while elites are responsible for this backslide, it is somewhat unintentional as western governments put short-term economic interests over long-term foreign policy goals. Diamond et al (2016) meanwhile take the blame off of democratic political elites entirely and put it on existing autocracies themselves for "taking coordinated and decisive action" to contain and rollback democracy on a global level (4).

Diamond, like many other scholars of democratic decline and conflict [Przewoski (2005), Klaas (2017), Tilly (1978), Raskin (1976), Pavlovic (2019)] assumes that one of the primary causes of democracy "losing its luster" can be traced back to the perception among many that advanced democracies are in trouble due to economic inequality and other economic concerns. Whether looking at the 2008 financial crisis and its lingering consequences (Diamond 2015, Diamond 2016), Western government's putting short-term economic goals above long-term foreign policy goals (Klaas 2017), or the rising danger of capitalism (Raskin 1976), a common thread in the literature is the deep ties between democracy and state wealth. Adam Przeworksi (2005) perhaps stated it most clearly with his bold claim that "democracy always survives when a society is sufficiently developed," and "constitutions are neither necessary nor sufficient for democracy to survive;" it's ultimately all about the state's per capita income (265). 
As should be clear just from this brief overview, democratic decline is a heavily researched field, yet one with little consensus as to cause. It's quite likely, as others have noted, that a mixture of factors is ultimately responsible, and each case study has the potential to reveal more variables worth examining. It seems reasonable to assume that "ambivalent and indecisive policies of leaders have often been a major factor in the probability of breakdown" (Linz 1978, 13), but just as reasonable to assume that a lack of state wealth or fundamental institutions have a role to play as well. There are also countless other explanations in existence, many that echo or expand on each other, and many others beside that contradict one another. It is notable however, that, while we all understand democracy to be "rule by the people," there are comparatively fewer studies looking at the potential role of public opinion in democratic decline or consolidation. This is a confusing oversight, as nearly all the above-mentioned studies acknowledge public support or the role of people in some form or another, yet none chose to focus on it specifically as a cause or to fully examine the effect this variable may have.

Although it has been recognized as an important factor since the time of Plato, only in recent years has public opinion seriously been examined in terms of democratic strength and survival. Further, while it is generally acknowledged that public opinion is important for democratic survival, researchers disagree on the extent of this importance, leading to frequent contradictions in the literature. Until very recently, the idea of political support was simply assumed to be important, with very little empirical evidence to back this up, due primarily to the fact that the data required for these sorts of analyses were very difficult to obtain and required large, nationally representative public opinion surveys. Within the past two decades more in-depth waves of the World Values Survey 
and regional Democracy Barometer datasets have allowed for greater analysis of public opinion, however these studies still often came to inconsistent conclusions. For instance, in 2003, using the $4^{\text {th }}$ wave of the World Value Survey, Ronald Inglehart found public support to be modestly and positively correlated with democracy, and again in 2005, along with Welzel, found the same positive association, even when controlling for the number of years a regime was under democracy. In contrast however, Hadenius and Teorell (2005) and Welzel (2007) found that support has little to no relationship with subsequent democracy once you adjust for the initial level of regime democracy. In 2010, controlling for a number of different variables, Fails and Pierce found no evidence that support is associated with democratization or democratic survival. Similarly, Qi and Shin (2011) show that the level of public support for democracy is not associated with subsequent democratization when controlling for prior democracy, but the level of "critical support" is.

A recent study by Christopher Claassen (2020) seeks to remedy the confusion over the contribution citizen support has on democracy by producing a very broad empirical analysis of public opinion. Noting the limitations of relying on smaller datasets (as most previous works had done), Claassen's analysis utilizes a significantly larger pool of data- 1,390 nationally representative public opinion surveys, gathered by 14 different survey projects in 150 countries over a period of 30 years- and then creates a dynamic Bayesian latent variable model to combine all the pieces into one cohesive measure of support. He ultimately determined that classic theory on democratic strength is correct: public opinion helps democracy survive and if support is low emerging democracies may fail to consolidate or even descend into autocracy. Furthermore, the evidence he finds 
also indicates that declining support for democracy among the public can affect even the most established western democracies, weakening their legitimacy (Claassen 2020). While this analysis doesn't necessarily lead to any unexpected results, it provides strong empirical evidence and justification for the assumptions most other works simply make, and thus serves as an important path to connect my findings on public opinion to the broader question of democratic legitimacy.

Thanks to Claassen and some of these other scholars, we can safely conclude that public support is an important part of democratic strength, but there still exists a need to understand the why and how. Even before the existence of empirical evidence, most previous works in this field chose to analyze case studies or specific scenarios to determine what possible variables, factors and situations may cause public support for democracy to decline. Robbins and Tessler (2012) use survey data to examine the effect of elections and find that when people support candidates, platforms, or parties that are excluded from elections, or when they perceive of the elections as unfree or unfair, their support for democracy will decrease. When institutions are seen as corrupt or unfair, general attitudes towards democracy will decline, particularly in nondemocracies or hybrid regimes where citizens may be experiencing elements of the democratic process for the first time, allowing attitudes towards democracy to vary as a function of the perception of these experiences. As they note, for democracy to consolidate and survive all actors must believe that "the democratic regime is most right and appropriate for their society" and "better than any other realistic alternative" (Robbins and Tessler 2012, 1256). 
Similarly, through a detailed exploration of Latin American democracy, Steven Levitsky (2018) finds that the structural characteristics of states and politics are eroding public support for democracy, leading to declining legitimacy in the region. The three main characteristics explored in this analysis are: the persistent and extreme levels of social inequality, general state weakness leading to inability to uphold rule of law or tax effectively, and widespread party weakness as corruption, scandal and numerous policy failures have eroded partisan identities and encouraged voting against the political establishment (Levitsky 2018, 103). These structural characteristics combined have rapidly increased public discontent and created the perception that elected officials are not responsive to ordinary citizens, don't care about providing essential public goods, and are likely to be involved in numerous self-serving scandals. Therefore, even while more of the region is democratic than ever before, overwhelmingly the public are not happy with these regimes and this has caused many citizens to hold lower views of democratic norms and values in general as they no longer view democracy as the "only game in town" (Robbins and Tessler 2012, 1256). Levitsky's findings are essential, for they emphasize the fact that these changes in public opinion can be long-term, rather than just an immediate response to a specific event such as an election or natural disaster.

It's also important to note that, in spite of the existing evidence, there are some scholars who disagree on the extent that public support is actually critical to democratic survival. In his examination of the $4^{\text {th }}$ wave of the World Values Survey (1999-2001) Inglehart (2003) concluded that, although lip service to democracy was almost universal, "it is not necessarily an accurate indicator of how deeply democracy has taken root in a given country" (51). Like Levitsky and Robbins and Tessler, his focus is primarily on the 
establishment of institutions, although he differs in his approach to public support. Inglehart's key finding is essentially that institutions are crucial to survival and that public support for democracy is a necessary condition for their establishment, but it is not sufficient unless a wide range of other variables are also in place. Thus, just because public support exists, doesn't necessarily mean the democracy is healthy. This conclusion contrasts interestingly with that of Robbins and Tessler (2012) who also argue that democratic institutions are critical to democratic survival, however, ultimately conclude that institutions and public support go hand in hand and survival is only possible with both bolstering each other. They see institutions and public support as more of a hardware/software relationship, rather than see institutions as the ultimate end goal for survival and public support as simply one of the variables that bring them about (Robbins and Tessler 2012, 1256). Therefore, while both agree public support is important, Robins and Tessler view it as a much more crucial part of the equation than Inglehart who views it more as a means of bringing about the intended institutional goals.

Others choose to look beyond the effect structural and political factors may have on public opinion, and instead focus on events or scenarios beyond the control of actors or groups. In this area, one of the most frequently cited explanation for public opinion changes are crises and their aftermaths, as it's long been recognized that shocks to a system can spark major changes or disruptions in society. The argument here is that, when crises overwhelm states, they can damage democratic legitimacy as decreasing public opinion of regime response or management can "spur polarizing and possibly violent political and social conflicts; embolden cavalier political leaders who disregard checks and balances or remove elected rivals by unconstitutional means; and/or fuel 
public acquiescence to a 'gradual erosion of political rights and civil liberties"' (Norris 1999, quoted in Carlin et al 2014, 3). These "shocks" to the system range from economic downturns, to security threats, to domestic uprising or rebellion, to natural disaster, and even to much more localized disruptions such as crime waves (Carlin et al 2014). Carlin et al analyzed the effects of the devastating 2010 earthquake on Chilean public opinion to see whether an "act of god" could still undermine support for the democratic rules of the game. Through an analysis of national survey data, they found that, as expected, the natural disaster and the damage resulting from it strongly decreased victims' specific support for their municipal governments. More worryingly however, they also found that this negatively affected victims' support for broader democratic norms and values, in particular they were more supportive of military and executive coups and less politically tolerant (4). Therefore crisis, either man-made or acts of nature, can be seen to have a strong negative effect on public opinion, not only towards the incumbent government, but towards the foundations of the regime itself.

These findings, and those of others who've examined the effect of crisis on public opinion in democracy, could reasonably be extended to my question, for terror attacks and threats certainly fall into the overarching category of national crisis. If the response of governments towards disaster has ultimately been found to decrease victims' support for broader democratic values, it seems plausible to apply this same logic to acts of terror. It is true, as many have noted before, that terrorist acts often produce a "rally-round-theflag" effect wherein there is a "temporary burst of government popularity," (Norris 2011, 15), but how do these attitudes persist over time? It's well established that citizens are relatively pro-government and pro-security in the aftermath of a terrorist attack and 
therefore more open to potentially right-restricting policy (see Davis and Silver 2004), but the longer-term effects are what I'm most interested in here. How does citizen attitude and support for these policies change as time passes, and what long-term effect does this have on the strength of the regime? There seems to be a dearth in the literature examining how terrorism and the resulting government policy affects public opinion in the long run, and thus this analysis will attempt a comparison across several waves of public opinion survey data to help find an answer to this question. It will also become important to distinguish if support for democracy is decreasing because people are supportive of the government's prioritizing and think security is more important than civil liberties or if it's that support for democracy is decreasing because people are not supportive of the government's prioritizing and become disenchanting with the whole system as a result. In other words, is it acceptance or apathy?

A small bed of research exists looking directly at the effect terror attacks have on public opinion, with some very interesting findings, although unfortunately nearly all these studies focus very specifically on the United States in the immediate aftermath of 9/11. Jackson (2005) examines the language of the US "war on terror" to argue that it was "carefully and deliberately constructed" in a way "to make the war seem reasonable, responsible and inherently 'good"' (147). This served to normalize and legitimize counter-terrorism institutional practices, but also poses severe challenges to the healthy functioning of a democratic society by narrowing civic culture and political life while creating a general moral panic. By deliberately constructing a very real fear of terrorism among the public the government was encouraging individuals to give the "war" their full support and thus fully accept limits on their civil liberties if meant they would be safe. 
This is demonstrated perfectly in Davis and Silver's 2004 study that found Americans to be overwhelmingly willing to trade some civil liberties for greater personal safety. Ultimately, their findings indicate that Americans' commitment to democratic values is highly contingent on other concerns and that the context of large-scale threats to national or personal security can induce a substantial willingness to give up rights (Davis and Silver 2004). Basically, Americans care more about their safety than civil liberties and will happily make this tradeoff in the name of security, with greater support relative to the degree of perceived threat. Furthermore, when you consider Jackson's findings that this intense fear and sense of threat was purposely cultivated and constructed by political actors to justify their actions, this trade off becomes a little more worrying in the longterm context.

The idea that this intense fear and sense of threat was purposely cultivated by political elite to justify their actions was also examined by Baker's 2003 study that found civil liberties in the US were increasingly seen as a vulnerability after the 9/11 attacks. In the aftermath of the attacks many markers of an open, free society- free press and speech, privacy from government, individual protection in criminal proceedings, etc.- were suddenly transformed into opportunities for the enemy to do us harm and thus their restriction was not only a byproduct of this tradeoff but a very specific goal (Baker 2003, 563). Jackson and Baker would thus agree that elite manipulation and framing post-9/11 created a very strong environment of fear, giving them greater leeway to pass and justify policy restricting civil liberties. And Davis and Silver would note that, at least in regard to the US, citizens were generally accepting and even happy with this prioritization, for they recognized their safety as ultimately more important than freedom. While these 
findings are critical to my analysis, they all focus on the immediate aftermath of the $9 / 11$ attacks, and thus still leave us with the question of if these attitudes persist in the longterm.

Before diving too deeply into the debate between security and freedom, it's necessary to note that not all authors agree that democracy is in fact in danger, and an important subfield in the literature argues that there is currently not a legitimacy crisis of democracy, and no real evidence of declining support for democracy. Authors such as Weßels (2015), Norris (2011), Thomassen and van Ham (2017), and Ferrín and Kriesi (2016) focus on public opinion but all essentially argue that, while evaluations of democratic performance are decreasing, this must be differentiated from perceptions of democratic norms, which remain stable. Basically, these works all recognize that there is a gap between norms and practice of democracy, and just because support for regime performance is decreasing doesn't mean support for the fundamental norms and values that underlie it are. This is reflective of Robert Dahl's (2000) "democratic paradox," wherein citizens think of democracy in two different ways: as "an ideal to be attained" and as "a set of actual practices and institutions" (Dahl 2000, 37). Thus, according to Dahl, it is in no way surprising that citizens can be both dissatisfied with democracy and value its ideals simultaneously, a trend that has been exposed countless times over the past 20 years. In analyzing democratic decline then, it becomes important to look at how citizens understand and define democracy in general while also looking at how they evaluate their own regime, for, many would argue, as long as the actual foundations of democracy remain strong, we need not overly fear widespread democratic decline. 
In an examination of the strength of these democratic foundations, Norris (2011) confidently concludes that the worry of democratic decline has been greatly overstated. In her challenge of the conventional diagnosis of legitimacy crisis, she notes that this "crisis myth, while fashionable, exaggerates the extent of political dissatisfaction and too often falls into the dangers of fact free hyperbole" (241). She focuses on the idea of a "democratic deficit," which explores this same concept of a gap existing between satisfaction with the performance of democracy and public aspirations towards these norms and values. However, unlike some of her contemporaries, Norris ultimately doesn't see the existence of this gap as potentially ominous and notes the greatest possible causality of this democratic deficit being negative consequences for political activism and future democratization (Norris 2011, 8). Thus, while there are certainly consequences of this deficit that need to be addressed to maintain the long-term health of the democracy, they aren't necessarily dire.

Likewise, Thomassen and van Ham (2017) argue that exaggeration is rampant in discussions of the strength of democratic legitimacy. They note that current data provides no evidence of an actual legitimacy crisis because there is no consistent decline in public support and, furthermore, there exists a great deal of variation both between countries and over time. They also discuss another, more straightforward reason to doubt this "story of democratic malaise" being the simple fact that this concept is "anything but new" (Thomassen and van Ham 2017, 3) Since the 60s crisis theories of democracy appear regularly, often blaming different factors and complexities of modern society, and yet, despite all this doom and gloom, a complete breakdown of democracy has not yet occurred in any of the older, more established democracies. Thus, they are in agreement 
with Norris that, yes legitimacy is crucial to regime survival, and yes, "critical citizens" may indicate the rise of a democratic deficit between satisfaction and aspirations, but ultimately legitimacy itself is not in danger and the "crisis myth" has been blown way out of proportion.

Thomassen and van Ham do acknowledge that a regime requires stable and high level of support to survive, but even if this support declines, it will do little to weaken legitimacy unless this dissatisfaction persists for long periods of time and shifts away from authorities to the political regime as a whole (a conclusion somewhat more consistent with a classic Easton framework for understanding political support ${ }^{1}$ ). Therefore, they argue a legitimacy crisis is only a possibility when: 1 . Political support is lacking for political institutions and the political regime (rather than the incumbent political authorities) and 2. Levels of political support follow a trend of continuous decline rather than fluctuation (Thomassen and van Ham 2017, 6). Based on current evidence then, they very confidently assert that there is no imminent crisis of legitimacy and public opinion for democracy fluctuates slightly but ultimately remains stable.

Working with these same ideas of a democratic paradox, Weßels (2015) and Ferrín et al (2016) explore this potential deficit by looking specifically at Europe, using data from Round 6 of the European Social Survey, conducted in 2012. Ferrín et al very specifically want to know if democracy remains a universal value for Europeans and how legitimate citizens perceive their own regimes' to be. Noting that democracy is a "multidimensional concept" inherently hard to measure, the authors examine evaluations

\footnotetext{
${ }^{1}$ Easton's framework for understanding public support, while incredibly influential, has been heavily criticized and revised upon since its publication; see below for more explanation
} 
of a broad list of attributes covering a wide range of principles people may associate with democracy, based on three different "versions of democracy"- liberal, social, and direct (Ferrín et al 2016,3). Working off of Easton they recognize that public support "is fundamental to ensure the stability of the different objects of the political system, namely: the political community, the political regime, and the political authorities" (Easton 1965, 9), however they believe a more subtle conceptualization is required for such an important idea. Easton's theory suggests that there is crossover and shifts between these dimensions, with both positive and negative spillover possible as support for the performance of authorities can lead to decreased or increased support for the regime.

It's necessary to note here that Easton's framework, while undeniably important and influential, is quite complex, and thus has proven incredibly difficult to operationalize, leading most researchers to create simplified or more nuanced versions. In order to properly operationalize the full framework, you would have to distinguish between the three different objects of support (authorities, regime, and community), between specific and diffuse support, and between three different sources of support (long-term utility, moral norms, short-term utility) (Thomassen and van Ham 2017). Furthermore, one of the biggest downfalls of Easton's original outline is that the distinction between legitimacy and political support is somewhat blurred because it's not clear to what extent the sources of political support should be interpreted as causes or as defining characteristics of political support. Easton seems to opt for the latter interpretation; however, it can be messy to define a phenomenon by its causes, which is why many researchers have grounded their work in Easton but ultimately utilized a framework more akin to that of Norris (2011) (Thomassen and van Ham 2017). 
Thus, echoing some of these common criticisms of Easton's work, Ferrín et al note that there is some confusion between how political support is defined and explained and therefore propose two alternative concepts that are easier to identify empirically: views and evaluations of democracy. They begin this analysis by exploring how Europeans understand and define democracy in the abstract, dividing it into electoral, liberal, and social justice elements. In measuring the "democratic awareness" of citizens, they ultimately find that Europeans as a whole have a "very broad and far-reaching understanding of democracy," with little variation across countries (Ferrín et al 2016, 63). Basically, they determine that, overall, Europeans strongly understand the concept of democracy and are easily able to recognize which elements are most important (in this case, free and fair elections, and rule of law).

However, even while citizens in Europe understand and support democracy, when they go about evaluating their own, they have in mind a broad range of democratic elements and values that their own institutions and system often fail to live up to (Ferrín et al 2016, 164). Particularly when it comes to elements they regard as the most essential for democracy, such as rule of law and government accountability, Europeans are incredibly critical of their own regimes and often find them lacking. Evaluations are made on a 10-point scale, so the authors consider anything above 5 to be "passing" while anything below it "fails," and the overall mean for all the elements is only 5.6. While this does vary quite a bit by country, with a low of 3.8 in Ukraine and a high of 7.4 in Sweden, it still strongly indicates that there is a growing gap between the ideal and the perceived performance of democracies in Europe. 
Using the same dataset, but further confirming with data from the Eurobarometer and European Commission, Weßels (2015), in addressing claims of a "rollback" of European democracy, essentially reaches the same conclusion. He finds that, while performance related measures of democratic practice reveal significant negative developments, the normative foundations of democracy remain largely unaffected and thus, he concludes there is no current threat of democratic decline. However, while Ferrín et al end more optimistically with the note that this democratic deficit has not extended to all elements of democracy and, crucially, doesn't really affect the electoral elements, Weßels warns that this may not always be the case. He cautions that continued negative performance ratings may eventually "spillover" as dissatisfaction continues, beginning to erode the support for the fundamental values and norms that are the building blocks of democracy. If people continue to view the performance of their democracy negatively, this will begin to affect the norms themselves, which echoes Inglehart's (2003) conclusion that just because a regime seems to have public support doesn't guarantee long-term survival. Thus, democratic legitimacy isn't necessarily safe just because at the moment dissatisfaction remains concentrated on performance, and we should be a little more warry of this gap between norms and practice than others have concluded. If this gap is indeed growing, it could indicate that this spillover has begun as the abstract and the reality of democracy no longer meet, which has serious consequences for democratic regime survival.

This deficit and its affects are further analyzed in Shin and Kim's (2018) global analysis that finds, overwhelmingly, citizens are able to define democracy, point out its principles, and recognize it as a "preferred form of government," yet at the same time are 
often unable to correctly identify their own system as being autocratic or democratic (244). Importantly, they find that, although most citizens define democracy in terms of freedom and liberty, "they do not find these aspects to be highly salient components of democracy," and prioritize other elements when evaluating their own regime successes and failures (Shin and Kim 2018, 237). The $6^{\text {th }}$ Wave of the World Value Survey $(2010-$ 2014) for instance shows that citizens in Europe rank civil liberties behind many other regime characteristics, such as free elections and gender equality. This is similar to Ferrín et al.'s findings that elections and rule of law are top elements in the abstract ideal of democracy. Close analysis of both the Arab and Asian Barometers revealed similar findings- across the regions, when respondents were asked to select the most important feature of democracy, they consistently prioritized elections (at 33\% in East Asian countries, 29\% in MENA states) and economic security (at 32\% and 28\%), with political freedom falling last in East Asia (14\%) and freedom of speech last in Arab states (20\%) (Shin and Kim 2018, 238). This indicates that many citizens, particularly in non-western countries, view democracy as a form of government that works "for the people" rather than "by the people" (238).

While Shin and Kim's work serves more as a comprehensive literature review than as an empirical analysis, some disturbing points can be drawn from their research. Critically, if citizens don't actually recognize civil liberties to be as important as other characteristics, it's easier to see how they would perhaps be more accepting of those rights being restricted. Shin and Kim, like many others before them, recognize a disconnect between ideals and practice and find strong empirical evidence to support its existence, but they are more akin to Weßels (2015) or Inglehart (2003) in indicating the 
situation may be more dire than some of their contemporaries note. It doesn't really matter if citizens can define democracy if they aren't able to truly recognize it in practice, particularly when they are ultimately basing their evaluations on elections and economic considerations about all else, with seemingly little care for fundamental democratic norms such as freedom of speech.

As long as citizens remain overly critical about their own regimes (and often overly critical of arguably the wrong aspects of these regimes), it seems Weßels may be right to worry of a spillover onto norms. The gap between norms and practice of democracy is seemingly worsening every year, and it's quite possible that we have reached this tipping point where performance is no longer the only thing viewed negatively. We have long ignored or overlooked the importance of public opinion in gauging democratic strength, and even the existing studies that do either don't seem to afford it as much power as they should, or they focus on a specific, somewhat limited timeframe. As many of the above studies have made clear however, we must pay more attention to shifts and changes in public support, for if negative opinions have indeed started to spillover onto support for norms, the situation is much more dire. This project does not seek to reject any of these previous findings of a democratic paradox that isn't a real cause for alarm but instead a normal fluctuation of a democratic regime. Rather, it seeks to expand on them and consider what could have changed to make it so performance evaluations aren't the only thing losing support. How has the world shifted in ways that may have resulted in Weßels' spillover occurring? With globalization and rapid change a near constant, even these studies from 2015/6 are potentially outdated and it is thus worth re-exploring the dangers this deficit holds and how norms may already be 
eroding. Of course, this question is far too large to fully explore in this project, instead I will analyze one possible explanation that may shed light on why (or if) this spillover has occurred: government prioritization of security over civil liberties. 


\section{CHAPTER III}

Research Design

For this project I will be analyzing democratic decline by specifically examining how a government prioritization of security over civil liberties affects citizen support for democratic norms. Therefore, my independent variable will be government policy prioritizations, my dependent will be citizen support for norms and values, and my hypothesis will be as follows:

State prioritization of security policy over civil liberties causes citizen support for fundamental democratic norms to decline.

The main data in this analysis will be public opinion and I will utilize case studies and some simple time series analysis of public survey data collected over the past 20 years to examine this hypothesis. Specifically, I focus on states that have balanced this prioritization at different levels, either with security a higher priority, with freedom a higher priority, or an attempt to keep the two values somewhat equal. My design includes three cases: New Zealand, The United States, and Turkey. This will allow the project to take the form of a comparative case study as I examine the ways these three very different states have approached the same problem of terrorism. There are clearly many important differences between these cases, as will be expanded on below, which is why this research takes a method of agreement approach, recognizing that the states differ in most regards, but not in the fact they face a security threat from terrorism or that the health of their democracy has changed in the past 20 years, either for better or for worse.

This is primarily a qualitative analysis because its main focus is case studies and descriptive narrative, however I also include a little bit of quantitative work through some 
simple regression and time series analysis in order to test relationships between my variables and provide further strength to my argument. By including a time series analysis I will be able to better understand the role timing has in the security vs. freedom debate, for there has been considerable work done in the past to support the idea of a "rally around the flag" affect occurring immediately after national crises, such as terrorist attacks. The question is if this attitude persists as distance grows from the time of attack, or if perceptions of threat and general government confidence return to pre-attack levels.

This is deductive research because I am building off of ideas and theories of previous authors, in particular those such as Thomassen and van Ham and Norris who argue that democratic legitimacy is safe and claims of decline are exaggerated. In effect this means that I am testing an existing theory by claiming that variables or factors have changed that has altered or negated the arguments of these researchers. For instance, Weßels and Inglehart both argue that democratic legitimacy is not in danger because people still support norms, and thus it's ultimately just performance ratings that have decreased. Contrary to this, I am using more recent evidence to make an argument that people $d o n$ ' $t$ necessarily support these foundational norms anymore (but at one point they did) by examining the security environment as a potential cause. Thus, I am expanding improving upon these earlier theories of democracy, rather than attempting to disprove or negate them.

The conceptual foundation of this analysis is therefore based in democratic theory and, since the focus is on changes in public opinion, the data takes on an almost constructivist/interpretivist paradigm. In analyzing how government policy transitions affect citizen's views on democratic norms, I am essentially exploring how this reality or 
understanding of the world is created by individuals. With complex concepts such as "democracy" and "legitimacy" it all comes down to how they are defined and understood, and thus they have different meanings for different people at different times. For this analysis I'm exploring one possible method by which that understood meaning changes and the effects this change might have on the broader idea of democratic survival.

Data:

As previously mentioned, my data will primarily be found in public opinion surveys, and thus my main sources will be existing public databases, in particular the World Values Survey, European Social Survey, and various regional Democracy Barometers. As I am examining public opinion, the level of analysis will predominantly be individual or micro level, although my units of comparison are going to be the states in my case study. Even though my comparison is about states, the data I'm concerned with is public support for democracy, and thus the analysis will remain on the individual level.

While these public databases are a fantastic resource, there are numerous measurement pitfalls inherent in these sorts of analyses that must be noted. Particularly when looking at a variable such as public opinion, there are often gaps across time and space, making it tricky to work with multiple data sets at once. For instance, for confirmation of his analysis on public support for democratic norms, Bernhard Weßels (2015) used the ESS wave 6 dataset which measures normative elements of liberal democracy. While this is a great collection of data, there is the glaringly obvious issue that Greece, one of the key states in his analysis, was missing from the survey in both 
2006 and 2012, and 2012 was the only year the survey very specifically asked about the "meaning of democracy" (Weßels 2015, 99). This meant that, although he still produced interesting findings Weßels' conclusions were greatly weakened by the limited availability of the data he needed and the fact that a key state was missing from the public dataset.

There will always be issues like this in using public opinion survey datasets, and while this doesn't make them less useful or their results less valid, it is a potential problem that is worth recognizing so as to combat it and keep it from weakening the overall strength of the research. For this reason most researchers of public opinion will focus only on items collected by one survey project at one specific point in time, thereby creating a relatively smaller cross-national dataset. There are some, such as Christopher Claassen (2020), who have recently created dynamic Bayesian latent trait models which permit for a smoother combination and measurement of all available data, however due to time and resource constraints, I will not be utilizing these, and instead will rely on a smaller dataset but be very cautious of the compatibility of various data.

Furthermore, many of these public datasets have received various criticism over the years, especially those used to measure democracy. Complex concepts such as "democracy" require complex measurement and there is no set or agreed upon way to do so, resulting in over 10 different datasets in existence. Of these the three most widely used are the democracy-autocracy index from Polity IV, the Freedom House Index, and the Przeworski et al dichotomous democracy-dictatorship indicators. However, both Polity and the dichotomous indicators have been criticized for neglecting to account for the extent to which participation in the political process is a widespread and important 
feature of democracy, and the dichotomous indicators have been found to lead to lower validity. Both Polity and Freedom House have been found to have fairly high levels of measurement error in some instances and to cluster at extreme values which raises concern that they are not fine-grained enough to pick up variation in highly democratic or highly autocratic countries. Finally, criticism has also been directed at the lack of clarity by which scores are assigned to indicators and the two datasets use of generalists rather than country specialists to assign these scores (Claassen 2020). Again however, despite these criticisms, these datasets remain the most frequently used and trusted, and thus I will also be using them, but must remain vigilant and careful in understanding their specific measurements and indicators so as to keep my analysis valid.

\section{Measurements:}

There are several possible ways to measure the level or strength of democracy, but one of the most straightforward involves analyzing the legitimacy of the regime. A legitimate regime is one in which political authority rests on the consent of the governed, meaning that the citizens think the political authority has the right to rule, and, unlike in nondemocratic regimes, a democracy will fail if the people don't see this authority as legitimate. The best approach to measuring legitimacy is thus to measure the level of political support for the regime and its principles. Drawing on formative works by Easton (1965, 1975), Dalton (1999), and Norris (1999), political support is most often measured through a series of "levels" or categories. Easton $(1965,1975)$ originally identified three levels of political support: the community, the regime, and the authorities. Due to the some of the inherent difficulties in conceptualizing "regime," this level was further 
specified by Dalton (1999) and Norris (1999) into regime principles, regime performance, and regime institutions (Thomassen and van Ham 2017, 19). This ultimately provides us with a five-fold classification of political support which I will be utilizing to explore public opinion survey data in regard to government prioritization of security policy (See Table 1 below).

There are a number of ways to measure each of these levels of support, but to keep my analysis consistent with previous works of a similar nature, I will be using some of the more common indicators for each level, as laid out by Thomassen and van Ham (2017). Support for the political community is therefore measured as national pride. Support for regime principals is measured as support for democratic political regimes versus alternative types (i.e., citizen evaluations of democracy as a regime).

\section{Measuring Political Support}

\begin{tabular}{|c|c|c|c|}
\hline Level & Indicator & WVS Measurement & WVS Scoring \\
\hline $\begin{array}{l}\text { Political } \\
\text { Community }\end{array}$ & $\begin{array}{l}\text { Affective attachment } \\
\text { to political } \\
\text { community }\end{array}$ & National Pride & $\begin{array}{l}\text { "Very Proud," "Quite } \\
\text { Proud," "Not Very Proud," } \\
\text { "Not at all Proud" }\end{array}$ \\
\hline $\begin{array}{l}\text { Political } \\
\text { Regime: } \\
\text { Principles }\end{array}$ & $\begin{array}{l}\text { Evaluation of } \\
\text { democracy as a } \\
\text { political system }\end{array}$ & $\begin{array}{l}\text { Importance of } \\
\text { Democracy }\end{array}$ & $\begin{array}{l}1 \text { ("not at all important") - } \\
10 \text { ("absolutely } \\
\text { important") }\end{array}$ \\
\hline $\begin{array}{l}\text { Political } \\
\text { Regime: } \\
\text { Performance }\end{array}$ & $\begin{array}{l}\text { Evaluation of } \\
\text { performance of own } \\
\text { democratic system }\end{array}$ & $\begin{array}{l}\text { Democraticness in } \\
\text { Own Country }\end{array}$ & $\begin{array}{l}1 \text { ("not at all democratic") - } \\
10 \text { ("completely } \\
\text { democratic") }\end{array}$ \\
\hline $\begin{array}{l}\text { Political } \\
\text { Regime: } \\
\text { Institutions }\end{array}$ & $\begin{array}{l}\text { confidence/trust in } \\
\text { institutions }\end{array}$ & $\begin{array}{l}\text { Confidence in } \\
\text { Parliament; } \\
\text { Confidence in Political } \\
\text { Parties }\end{array}$ & $\begin{array}{l}\text { "A Great Deal," "Quite a } \\
\text { Lot," "Not Very Much," } \\
\text { "None at All" }\end{array}$ \\
\hline $\begin{array}{l}\text { Political } \\
\text { Authorities }\end{array}$ & $\begin{array}{l}\text { confidence/trust in } \\
\text { political actors and } \\
\text { authorities }\end{array}$ & $\begin{array}{l}\text { Confidence in } \\
\text { Government }\end{array}$ & $\begin{array}{l}\text { "A Great Deal," "Quite a } \\
\text { Lot," "Not Very Much," } \\
\text { "None at All" }\end{array}$ \\
\hline
\end{tabular}

Table 1- Framework for Measuring Political Support 
Regime performance is measured as satisfaction with the functioning of democracy and support for regime institutions is measured by trust or confidence in a range of institutions, most often parliament and political parties. Finally, support for political authorities is measured by trust in the incumbent political leaders and evaluations of their performance (Thomassen and van Ham 19, 2017).

To measure this public opinion and support I will primarily be using the World Values Survey due to its accessibility and the wide range of questions it asks respondents. In particular, the WVS has questions on national pride, citizen support for democratic ideals, citizen evaluation of their own regime, trust in institutions, and confidence in government, parliament, and parties, allowing me to address all 5 aspects of measuring political support, per Thomassen and van Ham. Most of these questions have also been asked over a number of different waves of the WVS, allowing for a better understanding of how they have changed over time. Beyond these core indicators, the WVS also has more specific questions focusing on important components of democracy, such as civil rights, free and fair elections, and gender equality, all of which will be utilized to form a more complete picture of the state of democracy in each of my test cases. Importantly as well, the range of questions asked also provide for a differentiation between how citizens view democracy in the abstract or ideal, and how they view its performance in practice within their country, which is a key distinction that must be recognized, as explained by Weßels (2015), Ferrín and Kriesi (2016), and many others.

Most of the existing survey datasets I will use organize responses ordinally and thus the data I examine will mostly fall into this category. For instance, The World Values Survey asks respondents how important democracy is to them, with 1 being "not 
at all important" and 10 being "absolutely important" with each number in between indicating it is a fraction more important than the previous one. This allows them to take the somewhat vague concept of democratic importance and build concrete categories out of levels of support, providing an easy and observable measurement. The majority of WVS questions are answered on a 10-point scale such as this and for simplicity's sake, as well as graphing purposes, in the analysis below I have condensed the responses into 3 categories: those responding 1-3, 4-7, and 8-10.

I will primarily be using Freedom House and The Economists Intelligent Unit's Democracy Index to measure the current standing of democracy in each country because, despite the criticisms these sources may have received, they remain very valuable tools for exploring the overall levels of democracy in a state, particularly in terms of restricting civil liberties. Although we lack a general consensus on the precise definition of democracy, most scholars would agree that, at a minimum, the fundamental features of democracy include government based on majority rule and the consent of the governed, the existence of free and fair elections, a level of government accountability, and respect for basic human rights. No two democracies are exactly the same, and the "best" balance of these various ideals is relatively context dependent, based on a wide range of statespecific factors, such as historical, social, and cultural considerations (Clucas and Valdini 2014). Freedom House accounts for these possible variations by awarding a country 0 to 4 points for each of 10 political rights and 15 civil liberties indicators, giving each state an overall score of 0-100, with 0 meaning "not free," 34 to 71 meaning "partly free," and 100 meaning "free." Political rights questions are grouped into the subcategories of electoral process, political pluralism and participation, and the functioning of 
government, while indicators of "civil liberties" include freedom of expression and belief, associational and organizational rights, rule of law, and personal autonomy and individual rights. Each indicator includes a number of sub-measures looking at specific institutions and rights, such as freedom of assembly, an independent judiciary, and academic freedom, all of which together create a very comprehensive measurement of civil liberties and overall measure of democratic strength (Freedom House 2020).

The Democracy Index meanwhile is a report put together every year by the Economist Intelligence Unit based on five categories: electoral process and pluralism, the functioning of government, political participation, political culture, and civil liberties. Based on its scores on a range of indicators within these categories, each country is then itself classified as one of four types of regime: "full democracy", "flawed democracy", "hybrid regime" or "authoritarian regime," giving a little more breakdown and categorization than Freedom House. The EIU also uses a slightly more complex scoring system, combining a dichotomous and a three-point system for 60 indicators, resulting in a score of 1-10 for each category which is then averaged to produce the states' overall Index score (EIU 2020). Examining the scores given by both the EIU and Freedom House will allow a more in-depth understanding of the strength of democracy in each state, especially in regard to civil liberties.

Other measurements that will be used analyze the threat the state faces from terrorism and various data on the history of terror and government responses to it, most of which is available in the Global Terrorism Index annual reports which are published by the Institute for Economics and Peace (IEP) using the Global Terrorism Dataset. Measuring terrorism is inherently tricky, for each country has slight differences in how 
they define and understand a terrorist act, introducing the possibility of error in recognizing attacks. To limit this, I will understand terrorism as defined by the Global Terrorism Index, for their scores are the driving force of this analysis. They very simply define terrorism as "the threatened or actual use of illegal force and violence by a nonstate actor to attain a political, economic, religious, or social goal through fear, coercion, or intimidation" (GTI 2020,6). Importantly, this definition recognizes that terrorism is not only a physical act, but also the psychological impact it has on a society for many years afterwards, which is crucial for my analysis. They take their definition even further and state that, for an act to be included in their global ranking, it must meet three criteria: 1.) The incident must be intentional, 2.) It must entail some level of violence or threat of violence, including property damage, and 3.) The perpetrators must by sub-national actors (meaning this database does not include acts of state terrorism). There are also useful terrorism and security related data available on the US Department of State's Country Reports on Terrorism and in the CIA Factbook, but in using these I must be very aware of the inherent bias in using US government funded sources. Finally, I will also utilize various polls, such as Gallup and Pew, as well as country specific surveys, such as MetroPoll in Turkey, to form a fuller picture of a populations' general attitude towards terrorism and the government's response to these types of threats. 


\section{CHAPTER IV}

\section{Case Studies}

\section{Introduction-}

Before exploring the WVS data and how it works towards my argument, it's necessary to give a summary of each of my three cases and how they have approached the questions of security and freedom. By first building a foundation of each states' past relationship with both democracy and terrorism, the later analysis will have stronger ground to stand on and provide the reader with a better understanding of why the governments choice of prioritization had the effect it did. This comparative case study focuses on three states with very different regimes in terms of democratic strength in order to test my hypothesis. New Zealand, The United States, and Turkey were all chosen primarily for the simple reason that they all face a relatively high threat from terrorism (at least in comparison to most other democracies and hybrid regimes) and thus have all had to address this question of security vs. civil liberties in a very serious way. As is revealed below, they also serve as a clear example of best, middle, and worst-case scenario of what happens to democracy when civil liberties are no longer prioritized. New Zealand, despite an increased risk of terrorism, never put security over freedom, and remains one of the freest and most democratic countries in the world. Turkey meanwhile heavily prioritized security and restricted most civil liberties, especially for the Kurds and any others in society considered a threat by the government, and now they have lost nearly all semblance of democracy, drifting closer and closer to a full autocracy by the year. The United States falls between the two, initially implementing harsh rights-restricting security policy but rolling it back somewhat when met with protest; however still 
prioritizing security at the expense of rights, while creeping into hybridity and steadily away from the stable democracy it once was.

These three states were chosen in part because of just how different they are in most respects. In population, size, even in length of democratic experience, they differ, which allows me to focus specifically on where the similarities lie- the higher security threat the state faces. New Zealand has a population just under 5 million and is an island nation, meaning they already have a great deal of natural protection and a relatively small citizenry to keep safe. Turkey has a much larger population of 83.6 million, holds a crucial geopolitical position as the gateway between East and West, and is surrounded by states in conflict, from border disputes in the Caucuses, to brutal civil wars in Syria and Yemen, to political turmoil in Israel and Iraq, and thus faces high risk from all sides. Finally, the US has the largest population at 328.2 million and holds some natural protection by being bounded by oceans on two sides, however, is also a key political and economic player in global affairs, thereby making them a more high-profile target (Worldometer, “Countries by Population 2021").

While these differences are important and help explain why each country reacted exactly as they did, they don't change the basic fact that all three states faced this same decision between freedom and security and responded to it in varying degrees, resulting in citizen support for democratic norms changing in keyways. Thus, why it's perhaps understandable that Turkey responded to terrorism with harsher policies, given their precarious environment, it doesn't justify the fact that democracy suffered as a result. The way these government prioritizations affected public opinion and changed citizen support for fundamental norms by making them seem unnecessary or even risky to have is what's 
crucial to focus on here. In examining the broader picture of why democratic decline persists many variables are clearly at play, and these case studies reveal that changing public opinion towards democracy may be one of them by comparing three different states that approached the security vs. freedom debate differently and whose democracies have strengthened or declined as a result. This section will go over a brief summary of each case in terms of the history of their democracy, the threat they face from terrorism, and how exactly the government has responded, in order to draw a connection between this prioritization and how support for fundamental norms may have shifted.

\section{New Zealand-}

New Zealand presents an interesting case study, due to their isolation, relative "newness," and consistently high score across freedom and democracy indexes. The state remains part of the Commonwealth, only officially having gained their independence from England in 1947 with the Statute of Westminster, and in many aspects their political system reflects this British heritage. New Zealand's constitution is not codified, meaning it's a mixture of statute and convention, giving it a great deal of adaptability but also giving rise to occasional controversies over different understandings and meanings. Despite their isolation, New Zealand is an active member of a number of IGOs and remains heavily engaged in international affairs, often serving as a role model to other western democracies (for instance, in their current handling of the Covid-19 pandemic) (Oliver 2021).

New Zealand has a strong record of free and fair elections and safeguarding political and civil rights, resulting in the state consistently ranking at the top of a wide 
range of global freedom indexes. Freedom House gives them a rating of 99 out of 100, noting particularly their electoral rights and strong anticorruption record as well as the independent media. The only reason New Zealand isn't given a perfect score is due to the economic inequality still felt by members of the Maori population and some instances of discrimination felt in education and the workplace (Freedom House 2020). These high scores are confirmed further by the Economist Democracy Index, who rank New Zealand as $4^{\text {th }}$ in the world in terms of democratic strength, due especially to their protection of civil liberties and democratic electoral process. The EIU also discusses the high functionality of their current government under Prime Minister Jacinda Ardern and the ever-increasing political participation across all sectors of society as important factors in the state's persistent high score (EIU 2020). The only states that outrank New Zealand on most democratic index are the Nordic countries, who boast incredibly high political culture and participation, however in terms of civil liberties New Zealand ranks supreme. The World Liberty Index places them first out of 187, as does the Human Freedom Index, and Transparency International ranks them as the least corrupt country in the world. All this is to say that, comparatively, New Zealand is a very free state with strong protections of civil liberties, and thus serves as an important case study in the security vs. freedom debate.

Jacinda Ardern, leader of the social-democratic Labour Party, has served as New Zealand's Prime Minster since 2017 and has improved the state's already high democracy and freedom scores in nearly all categories. Upon her election she became the world's youngest female head of government at age 37 and since then has dealt with a number of crises and disasters with a skill and poise that has garnered her international praise as 
well as incredibly high support domestically. Just in the past few years, her handling of the Covid-19 pandemic, the 2019 Christchurch massacre, and the 2019 White Island volcanic eruption brought her worldwide endorsement and allowed her party to gain an outright majority of seats in Parliament in 2020, the first time this has happened since the country introduced proportional representation in the 90s (Vowels and Dalziel 2021). She has focused her government particularly on the New Zealand housing crisis, child poverty, and social inequality, emerging as a strong defender of civil liberties not only at home but also across the globe. It should be clear from even this brief summary that New Zealand's government is a very democratic one and one that continues to prioritize freedoms over most other concerns, with the strong support of the citizens (Ardern's current approval rating is $60 \%$, while the Labour Party's is $56 \%$ (BBC 2020)). It is, of course, worth noting that one of New Zealand's defining features is its relative isolation, perhaps giving the citizens an inherently greater sense of security than those residing somewhere like Turkey, where they are closely surrounded by numerous regional conflicts. This isolation has allowed the government to maintain its prioritization of freedoms over security regardless of international events, giving them a distinct advantage that they have clearly used to their benefit, and to the benefit of their citizens who enjoy greater civil liberties than their counterparts in most other states.

It follows then that, for most of their history, the primary conflict in New Zealand has been between the indigenous Maori population and the colonizers and their descendants, making terrorism never much of a threat or concern to the government. In fact, the $20^{\text {th }}$ century was almost entirely free of terrorism in New Zealand, other than a few smaller bombings and attempted bombings related to acts of anti-war protest and the 
sinking of the Rainbow Warrior in 1985. The Rainbow Warrior incident is a somewhat unusual case, as it involved the French foreign service bombing a Greenpeace vessel in a New Zealand harbor that was on its way to protest French nuclear testing in the Southern Pacific, and thus while it is clearly an act of state-sponsored terror, it differs greatly from the sort of jihadist and insurgency type terrorism Turkey was facing at the same time. In response to the Rainbow Warrior bombings the government passed the International Terrorism (Emergency Powers) Act in 1987, which essentially just conferred emergency powers on the police and armed forces in the event of a declaration of an "international terrorist emergency," but didn't change much else in terms of the government response (Small 2011). The perceived low threat throughout the $20^{\text {th }}$ century meant that terrorism ultimately "remained in the background rather than the forefront of national security priorities" and by the turn of the century New Zealand still had essentially no antiterrorism legislation on the books (Battersby 2018, 65).

Along with most of the western world, following the 9/11 attacks New Zealand finally implemented antiterrorism policy with the enactment of the Terrorism Suppression Act 2002. This act, like most others in this era, somewhat broadened the powers of the executive and "strengthened ties with like-minded states" in the fight against global terrorism, but the primary purpose of the legislation was to create a better definition and understanding of terrorism itself (Battersby 2018). It created more serious offenses for financing terrorism, joining or recruiting members for terrorist groups, and harboring terrorists, however until 2019 the act was never formally used. Following a lengthy surveillance operation in 2007 a small group of activists were arrested and, although law enforcement attempted to use this legislation as justification, ultimately no 
charges were laid under the Terrorism Suppression Act and the Attorney General went as far as to call it "unnecessarily complex" and "incoherent," leading to its slight amendment later that year (Battersby 2018, 67). Ultimately, police in New Zealand have chosen to rely on regular criminal legislation for offenses that could be claimed as terrorist in nature, and it's notable that this Act didn't add any new agencies or divisions to the security force, and only expanded the budget of the intelligence agency, but no other branch (Battersby 2018). Even as much of the world was hastily implementing new policy and empowering authorities to detain and arrest indiscriminately, New Zealand continued to prioritize freedoms, and considered the general threat level to remain low.

The New Zealand government, even while addressing societal fears and concerns, has consistently made sure to safeguard civil liberties as the highest priority, rather than allow fear to dictate restrictions. Compared to countries across the world in the wake of 9/11, New Zealand adopted an anti-terrorism regime that "effectively balances international demands, national needs, and individual rights," earning them high international praise (Smith 3, 2003). Not only did the Terrorism Suppression Act rely on a much narrower definition of terrorism than the rest of the world, thereby all but eliminating the possibility of protestors and others being unnecessarily brought in by its laws, but it also declared mere membership in a terrorist organization to not constitute a crime. This provision, while granted, somewhat controversial, allowed individuals to retain certain rights and freedoms and required more evidence than membership alone to consider someone suspect. Further, in contrast to antiterrorism legislation such as the Patriot Act, New Zealand's law did not permit detention without charge and included 
provisions for judicial review, to ensure even those suspected of terrorist acts received equal and fair treatment under the law (Small 2011).

Importantly, the desire for continued vigilance in protecting individual freedoms is not a partisan issue, and instead exists as a shared priority across the political spectrum. As Peter Dunne, the retired leader of the centrist United Future party, in addressing political repression in other countries due to antiterrorism policy, proudly noted- "the reality of this country has been that we have been blessed with governments and leaders over the years who have not so indulged. It is not part of the New Zealand character to become so involved to that degree in the repression of our own citizens" (Smith 57, 2003). Likewise, Phil Goff, the current mayor of Auckland and former leader of the Labour Party congratulated Parliament on "finding the balance," noting that the TSA "protects the proper civil liberties of New Zealanders, and at the same time [allows] for effective action to be taken against terrorism" (Smith 59, 2003). Many saw the key to this bill's perceived success at achieving this balance being Parliament's acceptance of submissions by any concerned civil or human rights organizations in the state, which were then incorporated into the final draft, in effect making sure all voices were heard (Small 2011). Thus, even while New Zealand implemented policy changes in the aftermath of the 9/11 attacks, they took a very measured and balanced response to the declaration of an international "War on Terror," taking care to always prioritize freedom and only take action proportional to the threat faced.

This perceived level of threat and sense of security changed quite suddenly and drastically in 2019 with the Christchurch Massacre. On March 15 Brenton Tarrant, an Australian white supremacist, shot up a mosque and an Islamic center in Christchurch, 
killing 51 people and injuring 40 . The attacker was motivated by far-right extremism and Islamophobia and for his actions received the first life sentence without parole ever handed down in New Zealand. He filmed the first half of his attack, streaming it live on Facebook, and prior to the incident published a manifesto detailing his anti-Muslim and anti-immigrant sentiments, both of which were quickly banned from possession or distribution. The manifesto has since reappeared in connection to a number of other mass shootings and terrorist attacks across the globe where perpetrators cited the document as inspiration and the Christchurch shooter as a "hero" or "saint" (Coaston 2019, BBC 2019)..$^{2}$

As both the worst mass shooting and the deadliest terrorist attack in New Zealand's history, this massacre deeply shook society and led to renewed calls for stronger gun and antiterrorism laws in the state. New Zealand is almost on par with the United States in terms of unregistered firearms, however, unlike the US which remains plagued by mass shootings with little restriction, within a month of the Christchurch attack, the Arms Amendment Act 2019 was passed. This Act required all legally obtained semiautomatic and military-grade firearms and their ammunition to be handed over to police in a buy-back scheme that has since been called both a success (over 50,000 firearms were collected) and a failure (there are most likely well over 100,000

\footnotetext{
${ }^{2}$ Interestingly, and very troublingly, footage of the event also showed up in Turkey as part of Erdoğan's campaign rallies in 2019, as he condemned the attacker and the west in general for not sentencing him to death for his viciously anti-Muslim actions. President Erdoğan likes to portray himself as a leader of the Muslim world and, because part of the manifesto directly called out Turks, he seized this opportunity to create an enemy (something he thrives on) and to depict Turkey "as under threat and himself as its savior" (BBC 2019). Erdoğan's actions in response to domestic terrorist attacks will be reviewed in more depth below, but it is incredibly noteworthy that he also uses international attacks as part of his effort to consolidate power and play off the fear of terrorism deeply engrained in Turkish society.
} 
unregistered firearms still at large) (Zraick 2019). The government also was quick to increase Human Rights Commission funding and propose updates to hate speech legislation, with Jacinda Ardern noting that "hate-fueled behavior" is "unacceptable, and totally against who we are, and what we aspire to be as a nation" (TVNZ 2020).

It's notable that even in the wake of such an unprecedented and brutal terrorist attack, New Zealand did not really pursue any new terrorism legislation. Rather than target the idea of terrorism and extremism, they very specifically targeted the weapons used in the attack, and the only restrictions on civil liberties implemented after the incident were those related to sharing or possessing the video or manifesto created by the attacker. While restrictions on hate speech were increased, the government made a conscious choice to not introduce harsher restrictions on any civil rights, including freedom of movement and association, preferring to keep the same terrorism policies in place despite the increase in threat level. Further, Ardern's government worked tirelessly to keep the rhetoric around the event from ever turning into an "us vs. them" debate, which, as Davis and Silver explained, served to increase fear and distrust in the United States. Instead, Ardern kept the conversation in New Zealand focused on tangible fixes, such as gun control, and on bringing the country together. In this way the government very clearly continued to prioritize freedoms over security, allowing New Zealand to maintain its top ranking across democracy indexes, even as it rose drastically up the Global Terrorism Index. Due to Christchurch and some smaller attempted attacks in the past five years, New Zealand ranks as number 42 on the GTI 2020, with a score of 4.37 out of 10 (GTI 2020). The country still rates its threat level as "medium," down from "high" immediately after the attack, yet it hasn't taken some of the more extreme policy 
actions that other nations have in response to terrorist attacks. In lamenting the western world's response to terrorism Australian author Christian Michaelsen noted that "a policy that does not respect human rights in the first place cannot legitimately claim to protect these rights against transnational security threats in times of emergency," and it seems New Zealand's government recognizes this balance more than most (Small 74, 2011).

\section{United States-}

The United States stands out when it comes to the security vs. freedom debate, due primarily to the seeming paradox it reveals to be present in society. A large majority of US citizens proclaim freedom to be the most important priority of the country, and yet, in the past two decades the government has passed a series of restrictive policies that overwhelmingly were accepted by the public, even as they were directly opposed to these same freedoms thought to be so crucial. This apparent contradiction, while visible in many states, seems perhaps the most extreme in the US, which is what makes it such a fascinating case study. The United States is highly developed, is the world's foremost military power and largest economy by GDP and is still considered by many to be the "leader of the free world," however there have been some troubling changes in the past decade or so (Harris 2021). Most notably, across many democracy and freedom indexes, the United States, a country that so long stood as the prime example and goal for developing states, no longer qualifies as a full democracy.

Since 2016 The Economist Democracy Index has ranked the United States as a "flawed democracy," due to ever-increasing erosion of public trust in institutions, a phenomenon that began well before the election of Donald Trump but was significantly 
accelerated under his administration (EIU 2020). Due to some positive developments in political engagement and political participation, the US maintained it's ranking of $25^{\text {th }}$ on the global scale, even while there were worrying decreases in a number of other categories. Further, the EIU warns that "the country exhibits a number of democratic deficits that could result in a further deterioration in its score and ranking in the near future," looking with particular worry at increasing threats to freedom of expression and the extreme polarization that exists within American society (EIU 2020, 43). For instance, a November 2020 poll conducted by the Pew Research Center found that voters saw the differences between the two candidates in the 2020 election as being about "fundamental, core American values," rather than politics and policies, indicating that Americans occupy two distinct and conflicting realities and casting doubt on any shortterm improvement in the strength of our democracy (Dimock and Wike 2020). It's also important to recognize that, while Trump's presidency certainly added fuel to the fire and intensified many tensions within society, these weaknesses in American democracy have been increasing steadily well before he took office and are part of a larger problem then just one administration.

Freedom House too has noted a steady decrease in score over the past decade, although they still rate the United States as a "free" country, albeit a very low "free" with a score of 83 out of 100. In the past five years Freedom House recorded a slow decline, from 89 , to 87 , to 86 , and now to 83 , and by their measurement the cut off between "free" and "partly free" lies at 72, a range we are creeping closely to by the year (Freedom House 2020). While most of the recognized decrease in score has been in the category of political rights, found especially in the erosion of democratic institutions, civil liberties 
have also been affected and internet freedom in particular is ranked at a 76 out of 100 and continues to decrease. As reflected in the literature review, countless factors have been pointed to as possible causes for this phenomenon of democratic decrease, and while there is certainly truth to be found in some of these explanations, many of them again focus especially on the political and wealthy elites in society, rather that the citizens themselves. If the citizens are willingly (or apathetically) turning away from foundational democratic norms, what could account for this? Again, it must be reiterated that this is a multifaceted issue, and no one answer will have all the solutions, rather they may all work together as pieces of the puzzle. And when it comes to US citizen support for democracy, a fascinating place to start is the security-freedom debate, and the intense fear of terrorism that exists among the American public.

The United States is the highest-ranking western democracy in terms of a threat from terrorism, coming in at number 29 on the GTI 2020 Index with a score of 5.26 out of 10. This places it significantly higher on the list than most European democracies, with the exception of the UK (who follows immediately behind at number 30), and France $\left(38^{\text {th }}\right)$, and above most global democracies in general, with the exception of the flawed democracies of India (which ranks 8th) and the Philippines (10th). The US is threatened by both domestic and international terrorism, and since the attacks of September 2001 this fear has been predominately directed at "al Qaeda inspired terrorism," even though in recent years the vast majority of attacks and attempted attacks were linked to right-wing extremist groups rather than Islamic terrorism (GTI 2020). In fact, according to the US Government Accountability Office, since September 2001, right-wing extremist have been responsible for $73 \%$ of terrorist incidents in the US, while radical Islamist 
extremists were responsible for around 25\% (GAO-17-300, Countering Violent Extremism 2017). As of 2020, right-wing extremist terrorism has killed more people in the continental US since 9/11 than Islamic terrorism, but this hasn't stopped the persistent anti-Islam and anti-immigration sentiment in the country.

Of course, when one considers both the devastation and the unprecedented nature of the 9/11 attacks, it's not all that surprising that this fear of Islamic terror has remained so persistent, even 20 years later. The hijacking of four domestic airliners by members of the al-Qaeda network resulted in the death of 2,507 civilians, 343 firefighters, 72 law enforcement officers, 55 military personnel and 19 perpetrators, and had permanent psychological and political affects that have fundamentally altered American society in countless ways (Bergen 2003). Responses were instantaneous following the attack, which still holds the infamy of being the deadliest attack in human history, and ranged from an immediate rise in Muslim targeted hate crimes to a government crackdown on fundamental freedoms. Within a week President George Bush's approval rating soared to $90 \%$, the highest of any American president, despite (or perhaps due in part to) the instigation of the US War on Terror and a massive restructuring of the US government, creating of the Department of Homeland Security and the strengthening of the NSA (Dempsey and Cole 2006). Most importantly for the context of this paper, within a month of the attacks, and with essentially no time for debate, Congress passed the USA PATRIOT Act.

The Patriot Act was enacted under extraordinary pressure from John Ashcroft, the Attorney General at the time, and within an environment of such intense fear that even supporters of the bill did not read it as they were in such a rush to pass counterterrorism 
policy. President Bush signed the Act on October 26, with widespread approval from the public and very little political debate. Very basically, the three main provisions of the act are: an expanded ability of law enforcement for surveillance of the public, eased interagency communication, and increased penalties for terrorism crimes and an expanded list of what qualifies as "terrorism" (Cole and Dempsey 2006). Some measures of the Patriot Act made perfect sense and were necessary to provide needed security, particularly interagency communication, however in many respects the Act reflected an extreme overreaction that "violated core constitutional principles" (197). Ultimately the Patriot Act significantly expanded the power of the authorities and "cast a cloak of secrecy over the exercise of government power" through its removal of limitations and judicial controls (197). Some of the more controversial provisions were those that imposed guilt by association on immigrants, authorized detention of anyone based on mere suspicion, expanded the government's ability to collect information on citizens in secret, reduced judicial oversight, and gave the Treasury Department authority to freeze property and assets with very little actual evidence (Cole and Dempsey 2006). As we now know, this act, along with other actions and policies taken as part of the so-called War on Terror, have led to ethnic profiling, data mining, and the unjust detention and torture of hundreds of people, as evidenced through the Abu Ghraib prison scandal, just to name one particularly heinous incident.

While human rights advocates were immediately opposed or cautiously against some of the provisions in the act, the American public were overwhelmingly supportive, even though it placed restrictions on some of their rights (Davis and Silver 2004). It seems that, when it comes to civil liberties and freedoms, Americans are more supportive 
of them in the abstract than in practice, and thus will say they favor freedom above all else, even while accepting restrictions imposed by the Patriot Act. Studies in the past have found that, overwhelmingly, when they feel threatened, "people who previously protected civil liberties and personal freedom may compromise on these values for greater security," as abstract ideals crumble when faced with harsh realities (Davis and Silver 2004, 38). Following the horrors of the $9 / 11$ attacks, it was hammered home how truly devastating terrorist acts could be, and this realization instilled a deep seeded fear in citizens across the country, allowing the government to enact freedom restricting policies without much complaint. Interestingly, this general attitude has persisted, despite the distance from these attacks, allowing the Patriot Act to be reauthorized a number of times, by both conservative and democratic presidents (Laperruque 2020). ${ }^{3}$ As will be discussed in more detail in the data analysis portion of this paper, there exists a fascinating trend in American society where the fear of terrorism increases every year, while the actual threat of terrorism has been decreasing, and poses essentially no risk compared to other much more prevalent threats such as gun violence (another security vs. civil liberties issue, but one where the "freedom" aspect always seems to win out).

This is not to discount the very real psychological damage the events of 9/11 had on American society or imply that terrorism poses no risk at all to the general public,

\footnotetext{
${ }^{3}$ The most recent of these was passed by the Senate on May 14, 2020 under the mantle of the USA FREEDOM Reauthorization Act which reauthorized the Patriot Act (or more accurately, reauthorized the 1978 Foreign Intelligence and Surveillance Act which the Patriot Act itself was an amendment of) through December 2023. While this Act ended the invasive call detail records program, it also extended a number of the most controversial provisions of the original Patriot Act including roving wiretaps, the "lone wolf" provision and Section 215 which gives the government immense power to demand records from companies for national security investigations (H.R. 6172, 2020; Laperruque 2020; Cole and Dempsey 2004)
} 
simply that when it's put into perspective, the prioritization that citizens have accepted is somewhat confusing. Of course, attacks and attempted attacks have continued to occur since 2001, with some of the most heinous being the Boston Marathon bombings in 2013, the Pulse nightclub attack in 2016, and the El Paso shooting in 2019, although there have been many more across the country and with all manner of motivations and targets (US Dept. Homeland Security: Terrorism Timeline 2021). Despite the changing nature of warfare and terrorism in general, the US has maintained relatively similar policies as the ones first enacted in 2001. The Patriot Act has been amended and reauthorized a number of times, with some particularly controversial provisions being removed, however ultimately the US counterterrorism approach has remained the same- surveillance and a lack of transparency, along with war and intervention in foreign countries to allegedly make the world a safer place. The rise of the Islamic State in the mid-2010s further encouraged this same sort of policy, with the United States eventually leading the coalition to stop ISIL and taking a very active role in global counterterrorism policy. With the rising threat of ISIL and high-profile attacks carried out across the globe attributed to splinter cells, fear of terrorism increased yet again and heavy US involvement abroad was considered acceptable and even "just."

Unlike in New Zealand, the government in the United States has wholeheartedly decided to embrace security at the cost of civil liberties and have received a clear green light to do so by the American public (Davis and Silver 2004). This prioritization can certainly be attributed in part to proportional differences in the size of the threat faced, not to mention the size of the country's themselves, and to their different roles in the international community, however the fundamental effect of this decision can't be 
overlooked. From its implementation the Patriot Act's mere existence ran contrary to a number of critical democratic rights, particularly freedom of speech, due process, and privacy, and while these provisions have been scaled back some since 2001, they remain disproportionate to the threat faced. Despite overwhelmingly supporting freedom in the abstract, when it comes down to practice, the American public have shown they are very willing to give up these civil liberties if it comes with the promise of security. In 2015 when a number of provisions of the Patriot Act were set to expire, including the measure that allowed the NSA to secretly collect phone data on its citizens, a full $61 \%$ of Americans approved renewal while only $31 \%$ were opposed (CNN 2015). These numbers were even more drastic when controlling for party affiliation (73\% of Republicans wanted renewal, $63 \%$ of Democrats), despite the fact that a number of these provisions clearly violated fundamental democratic norms. The question raised then is how this in turn affects the long-term strength of democracy. If people don't find civil liberties as important as safety, and their perception of threat is stable and high, will they begin to no longer support these values at all? Worryingly, and particularly in regard to the United States, it seems this may be true, indicating this trade-off is perhaps partly to blame for the gradual decrease of democracy in this country. Unlike in New Zealand, the US government, with the full support of the American people, tilted their prioritization towards security, and this has been detrimental to public support for democratic norms in the long run. 


\section{Turkey-}

Turkey exists in a different realm than either of the other two cases, as a hybrid regime with ever increasing authoritarian tendencies. However, less than 20 years ago they were lauded as the model democracy in the MENA region and positioned as a goal for every other country with aims of democratization and thus, their inclusion in this analysis could help shed some light on just exactly what went wrong. Following independence and the 1924 constitution, Turkey was technically defined as a parliamentary democracy, however in less than a year the country had transitioned to single-party rule under Mustafa Kemal Ataturk's Republican People's Party (CHP),which still exists as the main opposition party in the state. Single-party rule lasted until 1945 when the country held its first free and fair elections with viable opposition parties, ushering in a new era for the Turkish democratic experiment (Lewis 2002, 303). Since then, Turkish democracy has had a turbulent existence, with four military coups and four re-transitions to democracy, each accompanied by a rewriting or heavy revision of the constitution. The 1982 constitution was ratified in the wake of a military coup and is technically the one still in use today, however it has been altered and ratified a total of 19 times, in effect re-writing nearly two-thirds (113 of the 177 articles) of the original text (Eder 2020, 705).

All this is to show that Turkey's experiment with democracy has been ongoing since its independence, although it's been marred by a number of backtracks and interruptions. Despite all this, by the early 2000s, in large part due to the requirements of the EU accession process and the new government's willingness to follow them, Turkey was viewed by the world as a rising democracy and the model for the rest of the Middle 
East. Particularly in the aftermath of the Arab Uprisings in 2011, many in the Western world were pointing to Turkey as the ideal outcome for states experiencing unrest, a sentiment further encouraged by then-Prime Minster Recep Tayyip Erdoğan and the ruling AKP. Erdoğan and his Justice and Development Party (AKP) first rose to power in in 2002 in the wake of the devastating economic crisis of the late 90s, with promises of economic stability, the cultivation of greater ties to the west, and the strengthening of democracy. Although from their creation the AKP was clearly an Islamic party in the supposedly secular state of Turkey, they have retained relatively high support since their rise to power, with Erdoğan eventually becoming the country's first-time popularly elected president in 2014 (Eder 2020, 710). Since then, he has further consolidated power around himself and gradually increased his authoritarian tendencies, leaving the Turkey today a much different one politically than the one of fifteen years ago. Turkey was never close to a perfect democratic state and has certainly had its fair share of corruption scandals and human rights violations, yet it is inarguable that at a recent point in time they existed as, at the very least, a flawed democracy.

While gradual change started earlier, most point the attempted coup of 2016 and the two-year long state of emergency that followed as a true turning point in Turkey's transition away from democracy. The heightened security threat following the failed coup allowed the government to avoid institutional checks and balances in the vague name of public safety and set the stage for the transition into an executive presidency in 2017 (Eder 2020, 705). Turkey's gradual turn away from democracy has been accompanied by mass purges of opponents, increased Islamization of society, major crackdowns on the media, and growing charges of human rights abuses, particularly in the Southeast where 
the country remains embroiled in a brutal conflict with the PKK and other Kurdish rebel groups. It's not that surprising then that in 2016 Freedom House crowned Turkey as the state with the largest one-year decline in freedom, and then followed this up a year later in 2017 by reporting that Turkey also had the notoriety of the largest 10-year decline (Freedom House). Turkey maintained their Freedom House rating of "party free" until 2018 when reports of election fraud finally dropped them down to a score of 32 out of 100 , solidly in the "not free" range.

Despite the growing authoritarianism and human rights restrictions Erdoğan's approval rating has remained relatively high since he first came to power and, apart from a relatively small but very vocal opposition to the AKP, citizens retain high confidence in their government. Due to the economic impacts of the coronavirus pandemic Erdoğan's approval rating has recently dropped to $46 \%$ from $56 \%$ in early 2020 and from a high of 68\% in 2016 following the coup (MetroPoll). This essentially puts him in the same field as most American presidents, who average around the mid-40s, with some jumps in the wake of crisis (such as George Bush's 90\% shortly after 9/11) or falls in the wake of scandals (such as Nixon's 24\% during Watergate) (Gallup, "Presidential Approval Ratings"). What this goes to show is that Erdoğan's increasing authoritarianism hasn't really changed his approval all that much, and although there have been gradual decreases, ultimately Turks seem accepting of his leadership and the state of their democracy right now.

A large part of this confidence and approval of a nondemocratic regime seems to stem originally from Erdogan's harsh approach to terrorism and suspected terrorists. Due to historical grievances, ongoing regional conflicts, and Turkey’s key geopolitical 
position, over the past two decades they have faced terrorist threats from a wide range of groups with ties to ISIL, al-Qaeda, the Kurdistan Workers Party (PKK), and a number of radical Marxist-Leninist groups such as the Revolutionary People's Liberation Party Front (DHKP/C) and the Urgent Ones (Zeldin 2015). The PKK in particular has been involved in a tense conflict with the Turkish government since 1984 which, by some estimates, has killed over 60,000 people and displaced thousands (Unal 2011; Crisis Group 2021). ${ }^{4}$ It's crucial to recognize just how instrumental the PKK is in just about every decision the Turkish government makes. The PKK, and the fight for Kurdish separatism in general, is considered by many Turks to be an existential threat to their survival, and thus this attitude is incredibly influential in driving both their domestic and foreign policy.

The PKK conflict has been economically, socially, and psychologically costly and to cope with this violence the Turkish governments over the years have implemented numerous polices, ranging from micro-level adjustments in security related issues to macro-level social and political reform. To most political elites, especially the current Erdoğan administration, these groups are a threat to the Turkish identity, and thus they must be wiped out and forgotten, resulting in a trend of counterterrorism policies being very broad in their potential application to thwart terrorism. Because this conflict is ever going and ever changing, the government likes to have the leeway to apply terrorism

\footnotetext{
${ }^{4}$ It should be noted that, while the US and Turkey (as well as the EU and a number of other states) classify the PKK as a terrorist group, this is actually a somewhat controversial label and various NGOs have disputed this claim by contending that the PKK does not systematically target civilians and thus it is more accurate to consider them a "militant political organization" or an "armed guerilla movement" (Zeldin 2015)
} 
legislation against alleged perpetrators no matter how the overall situation may transition, and thus while most polices are seemingly extensive and aimed at terrorism in general, they often have been implemented thinking particularly about the PKK (Unal 2011).

This method of policy implementation is exactly opposite of that which transpired in New Zealand, as the bulk of the various policies focused solely on PKK members and those affiliated with them, rather than addressing the underlying grievances or causes of the violent opposition. While obviously the New Zealand government wasn't able to target the malicious existence of Islamophobia, which was the true cause of their attack, they were able to more closely focus on the tools and opportunities at the disposal of the attacker, rather than a specific group of like-minded people, and this perhaps plays a role in their comparative success. The intricacies of Turkish-Kurdish relations could fill an entire book, so what's key to note here is that this conflict has existed for decades, is recognized as especially brutal and often inhumane, and has left citizens on both sides living in a state of constant tension and fear.

In 2015 the tentative ceasefire between the Turkish government and the PKK fell apart and violence immediately escalated, rapidly spreading across the country and resulting in over 400 people being killed in terrorist attacks between July 2015 and early 2017 (Soliev 2017). At the same time, 2014 saw the rise of ISIL as a global threat, and the formation of the US-led international coalition intervening in the region to fight back, which caused even further tension within Turkey as Western states began to support the YPG troops Turkey saw as PKK affiliated. ISIL and related splinter groups began attacking civilian targets in Turkey, carrying out the deadliest attack in modern Turkish history in October 2015, when suicide bombers targeted a rally for peace in Ankara, 
killing 95 people and injuring 246 (Soliev 2017). This was the first in a near constant series of attacks over the next two years, with ISIL targeting civilians and the PKK targeting military and police, creating a tense environment of fear. In light of this, it's easy to see why the Global Terrorism Index ranks Turkey as 18th out of 135, firmly positioning them into the "high impact" category. Enter into this same two-year period the attempted coup of 2016 and the growing fear of domestic terror and violence, it's no wonder at all that in the most recent wave of the WVS Turks overwhelmingly prioritized security over freedom $(60 \%$ to $40 \%)$. The continuation of occasional sporadic attacks from multiple sources, combined with the government's constant use of us vs. them rhetoric keeps the perception of threat very high in the daily lives of Turks, and helps explain why many citizens remain overwhelmingly supportive of harsh counterterrorism laws.

This is easily illustrated in the lack of resistance Erdoğan and his government received when passing a number of vaguely worded, power enhancing, terrorism laws shortly following the attempted coup. These new laws enabled Turkish authorities to detain a wide range of people with very little evidence, enhanced police powers to conduct searchers, allowed the use weapons against persons suspected of terrorism, strengthened government control of the internet, and expanded the power of the National Intelligence Agency (MiT). The way all these new terrorism laws have affected the media is perhaps most striking, as journalists are now regularly detained for up to eight years for "spreading terrorist propaganda," often times in ways as seemingly innocuous as using a picture of a suspected terrorist or reporting on the activities of MiT (Zeldin 2015). In the purges following the attempted coup 16 television broadcasters and 45 newspapers were 
closed by the government and 160 journalists were imprisoned alongside over 77,000 judges, teachers, police, and civil servants (Eder 2020). Importantly, while there have certainly been protest and criticism directed at the government for their treatment of journalists and academics, no one is quite willing to sacrifice the sense of security most of these policies bring.

Even though the threat of terrorism has greatly decreased since the tense period of 2015/16, the government continues to use these terrorism laws to detain essentially anyone it sees fit, primarily now for alleged ties to the PKK and any of their affiliates, or connections with the Gülen Movement whom the government still believes was ultimately behind the coup (an accusation Gülen himself vehemently denies). Just this past December (2020) Turkey enacted the Law on Preventing Financing of Proliferation of WMDs which enables the Interior Minster to target the legitimate and lawful activities of NGOs it finds "suspect" (HRW 2020). While the stated aim is to prevent the financing of terrorist groups this new law essentially just allows the government to restrict and control the actions of NGOs or other groups it doesn't like for whatever reason, making it a very dangerous tool to limit the freedom of association. Added to the countless targeted laws already in existence, Turkey's terrorism legislation has helped to consolidate power around Erdoğan and allowed him to restrict rights as he sees fit by claiming this in some way keeps citizens safe. It's important here to also recognize that without the heightened sense of fear following the coup and the numerous deadly attacks in this two-year period, it's unlikely Erdoğan would have had as much success in gathering support to amend the Constitution and abolish the office of the Prime Minister in 2017. People were scared, Erdoğan had a very high approval rating and confidence he could solve the terrorist 
threat, and for many this was enough to grant the executive much greater power and reach; a decision that has had a significant impact on the failed democratic experiment. Further, and crucially to this thesis, despite the relative lack of major terrorist activity in recent years and despite the obvious authoritarianism of the government, the public remains generally supportive of these policies and their regime.

Clearly, Turkey is not a democracy. As noted above, Freedom House rates them as "not free" and has recorded decreases in electoral rights and civil liberties every year. Some see the situation a little more positively, such as the Economist Democracy Index which labels Turkey a "hybrid regime," but one that has seen significant electoral improvement over the past year, with stronger performing opposition parties, higher turnout rates, and increased citizen participation in demonstrations all serving as positive signs (EIU 2020). At the same time however, civil liberties scores remain dismally low by every index and the government remains engaged in actions that directly target freedoms, such as their withdrawal from the Istanbul Convention (also known as the Convention on Preventing and Combating Violence Against Women and Domestic Violence) on March 21, 2021. Whether we recognize Turkey as an autocracy or a hybrid regime, it's clear that it's no longer the model democracy it was just a decade ago, and while, of course, many factors are involved in this transition, the heightened security threat and the fear it evoked seem to be a crucial player.

Regional conflicts and the rise of ISIL generated a very real fear that has remained and fermented even as ISIL began to lose strength in the region, causing citizens to continue to prioritize safety above all else. This desire was eagerly met by Erdoğan's government, partly by necessity and partly due to the obvious advantages it 
gave them in consolidating power. As the government continues to crack down on terrorism and security threats in any form, citizens remain relatively supportive, all the while the belief that democracy is important continues to decline. Citizens care most about security and are willing to overlook restrictions on their freedoms (particularly free speech) to achieve it, and it seems this is further contributing to the general decline of democratic support in the state. The AKP's security policies, while somewhat draconian, also seem to have successfully decreased terrorist activity in the state, seeing as the last major terrorist attack occurred in 2017, and this certainly further fuels the belief that some of these restricted democratic values aren't all that necessary after all. Since the $80 \mathrm{~s}$ and the start of the Kurdish conflict, Turkey has consistently and, then aggressively, prioritized security above all else, leaving us with a former democratic regime where many of the citizens no longer seem to support the norms they once so highly valued. In the question of balance between freedom and security, Turkey leaned hard towards the latter, in a tend that has proven detrimental to democracy. 


\section{CHAPTER V}

Data Analysis

\section{Democracy and Freedom:}

With a solid foundation in place for each of these three regimes we can turn to an examination of some key WVS data to determine if these government policy choices truly have had an effect on the long-term strength of democracy. By measuring survey responses over successive waves of the WVS I can gain a better understanding of how public opinion towards democracy in both the abstract and in practice has shifted over the past 20 years. Simultaneously, I will examine indicators that address terrorism and security to better gauge how attitudes towards the current environment and security policy may have changed support for these norms. Many of the indicators have been asked over multiple waves of the World Values Survey and thus a time series analysis is possible, however this isn’t available for every question, as will be further explained below. As discussed by the likes of Ferrín and Kriesi (2016), most of these indicators, particularly when it comes to questions of democracy, ask either about the ideal/abstract or about the actual practice or evaluation of that measure. Thus, the question on "importance of democracy" deals with the abstract concept, whereas "democratization of own country" deals with how democratic the respondent views their own government. I will be analyzing both types of responses in order to get a better sense of the bigger picture of democratic strength in these three cases. I'll begin this analysis by examining indicators that address democracy and freedom before tying in responses related to terrorism and security. 
The measure of "importance of democracy," very specifically asks "how important is it for you to live in a country that is governed democratically?" and has respondents answer on a scale where 1 means "not at all important" and 10 means "absolutely important." This question is key to this analysis because it measures what Norris (2011), Weßels (2015), Thomassen and van Ham (2017), and Ferrín and Kriesi (2016) all refer to as the abstract or ideal understanding of democracy, rather than democracy in practice. This is why it's not all that surprising, reflecting on the findings of Shin and Kim (2018), that this indicator remains relatively high across most states, because many people still recognize democracy as the preferrable or ideal system. What's crucial to note however, is that this measure, while still overall relatively high, is gradually decreasing across a wide range of states. For instance, time series analysis indicates that the importance of democracy is steadily decreasing in Turkey, dropping from $87 \%$ in $2005-9$, to $77 \%$ in $2010-14$, and to $60 \%$ in $2017-20$ (see Figure 1 ). ${ }^{5}$ While not as extreme, the United States' scores have also dropped, from $74 \%$ in $2005-9$, to $72 \%$ in $2010-14$, and to $70 \%$ in $2017-20$. The change over time in the US is comparatively small, however it does still seem to indicate a declining trend in how people view democracy. Meanwhile, New Zealand stands out as one of the few countries that has increased on this indicator within the past decade, with scores rising from $80 \%$ in 2010 14 to $85 \%$ in 2017-20 (WVS data was not available in 2005-9). This indicator alone already provides evidence towards my argument, for the data taken together show the

\footnotetext{
${ }^{5}$ For clarities sake, the 1-10 scale in the WVS was further broken down into 3 categories based on respondents rating democracy 1-3, 4-7, and 8-10. A similar method has been used for other indicators that were answered on a 1-10 scale, see Appendix B for the full, un-collapsed data.
} 
belief in democracy's importance drastically declining in Turkey, slowly but steadily decreasing in the US, and steadily rising in New Zealand. Importantly, these responses from recent waves of the WVS seem to contradict some of the findings of previous scholars in this field, most of whom were utilizing various datasets that only collected responses until 2015, indicating that potentially important changes have occurred in the past five years.

Norris (2011), Weßels (2015), Thomassen and van Ham (2017), and Ferrín and Kriesi (2016) all ultimately found support for democratic norms and democracy to be stable across time, but it's possible this has begun to change, as a clear decrease is visible in a number of states. Besides Turkey and the US, Sweden, Australia, Chile, and South Korea all saw decreases in their scores as well, indicating this trend may be widespread.

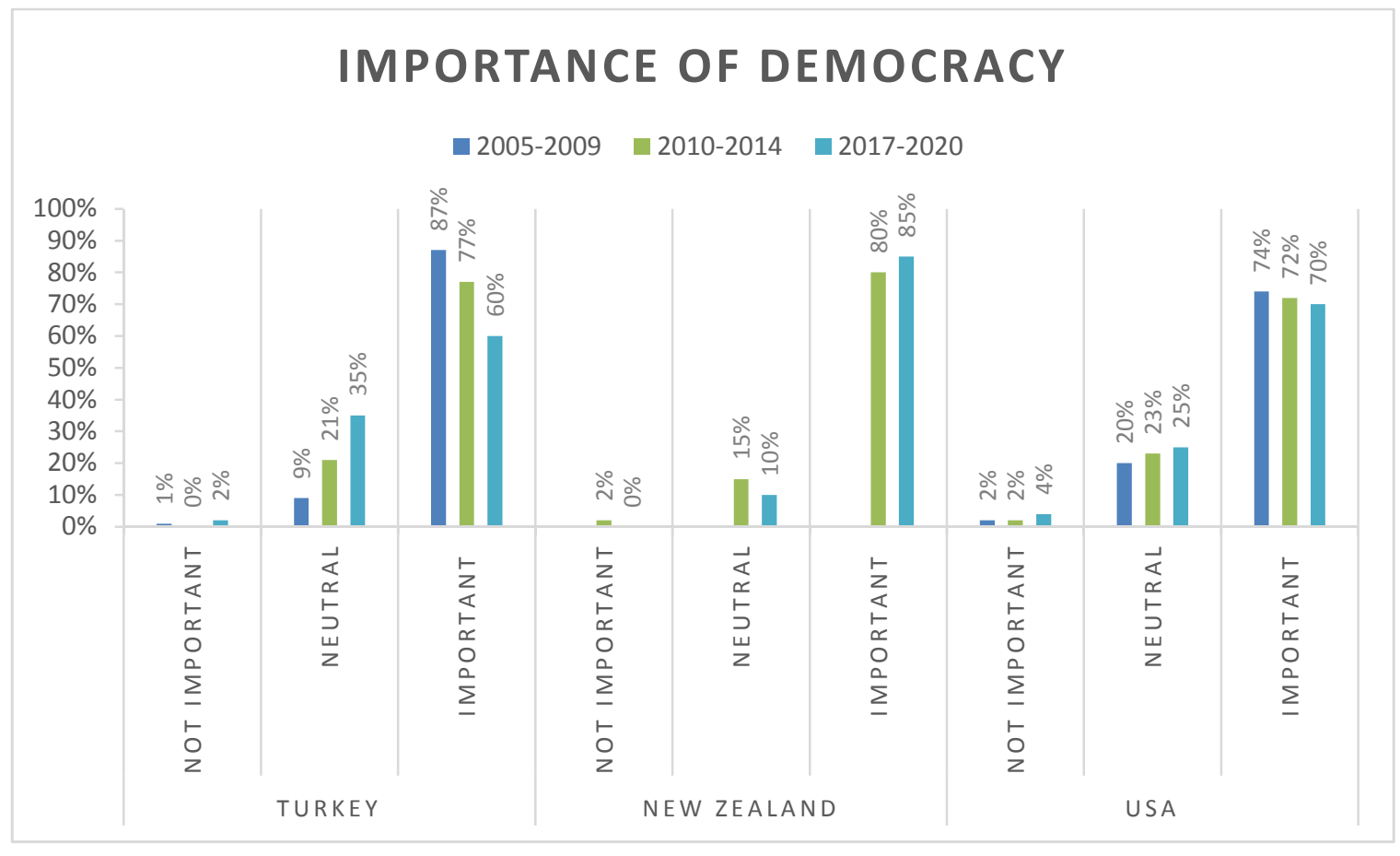

Figure 1- Importance of Democracy

Source: 2005-2020 World Values Survey 
It must be noted that a number of other states, including France, Germany, and Japan saw their scores increase slightly, so this slight variation by country echoes the worries that Thomassen and van Ham had over regional fluctuations. While it's true there is variation by country and this certainly demands further research, enough countries have seen steady decreases in recent years that we can't discount this as a "normal and unremarkable" fluctuation as doing so could be detrimental to long-term democratic survival.

Juxtaposing this indicator with an analysis of citizens evaluations of democracy in their own country adds another layer of complication, particularly in the case of Turkey. Weßels (2015) and Ferrín and Kriesi (2017) found citizens in Europe to ultimately see their democracies as performing negatively in a number of key regards (and found they

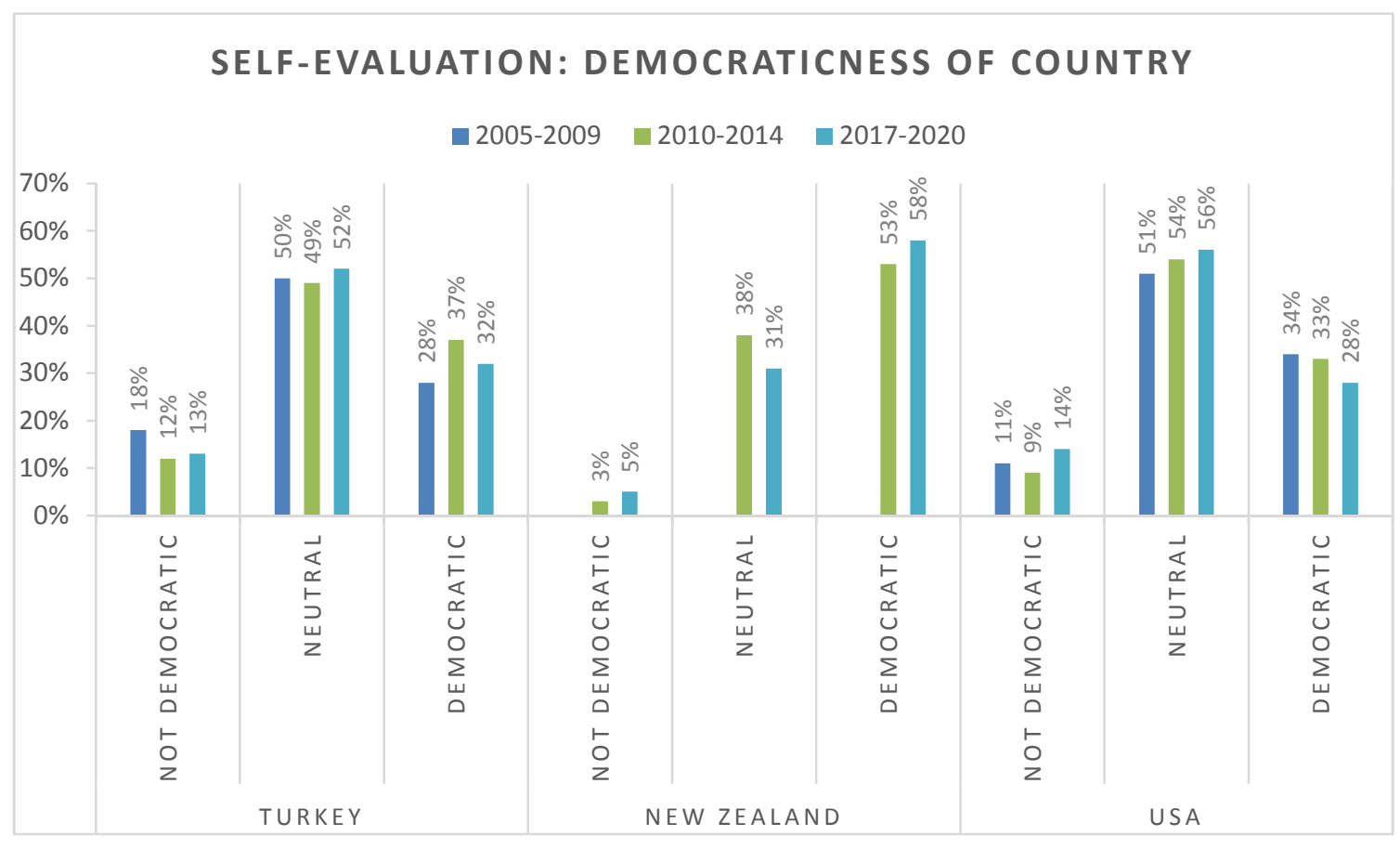

Figure 2- "Democraticness" of Own Country Source: 2005-2020 World Values Survey 
were often correct in these evaluations), yet this trend isn't as clear when looking at nonEuropean democracies. The WVS question asks respondents "how democratically is the country being run today" using a similar 10-point scale ranging from "not at all" to "completely." Using the same categorizations into three groups as I did with the importance of democracy measure, Turks rate the democratization of their country as fluctuating from $28 \%$ in $2005-9$, to $37 \%$ in $2010-14$, back down to $32 \%$ in $2017-20$ (see Figure 2 below, and Figure 2.5 in Appendix B). What's notable here is that, even to an outside observer relying purely on data from Freedom House and EIU, it would be clear that Turkey has gotten consistently less democratic under the AKP government, with 2015/6 arguably marking the true end of Turkish democracy. Yet, Turks still see their government as relatively democratic, in fact, more so than respondents in the US which scored $28 \%$ in $2017-20$ (down from $33 \%$ in $2010-14$ and $34 \%$ in $2005-9$ ). While the US certainly has had some major problems with their democracy these past few years, there isn't much of an argument to claim that it is less democratic than Turkey, but that's what the collective citizens seem to think.

Likewise, $28 \%$ of Turks were "completely satisfied" with the performance of their political system in 2020 , versus only $12 \%$ in the United States (and interestingly, only $18 \%$ in New Zealand). This is reminiscent of Shin and Kim's argument that, even though everyone can define democracy, most people are unable (or perhaps unwilling) to correctly identify their own regime. There is a clear disconnect between the way citizens understand the ideal of democracy and how the evaluate it in practice, which many previous studies have explored, and these two indicators seem to prove. Perhaps unsurprisingly, New Zealand again stands out with $58 \%$ of respondents recognizing the 
country as democratic in Wave 7, up from 53\% the previous wave (and again data was not available for wave 5: 2005-9). When one considers that New Zealand regularly ranks as one of the most democratic countries in the world, these numbers do feel a bit low, perhaps indicating that citizens are very harsh critics of their own regimes, yet comparatively they clearly recognize that they are doing better than either Turkey or the United States. This all indicates that the "democratic deficit" exists across all states, no matter how democratic they are, when citizens' ideals and evaluations differ, and so the real worry is that it seems to be growing.

Further evidence of a disconnect between reality and abstract can be found in the two indicators of "having a democratic political system" and "satisfaction with current system" (Figure 3 and Figure 4). In Turkey the idea of having a democratic political

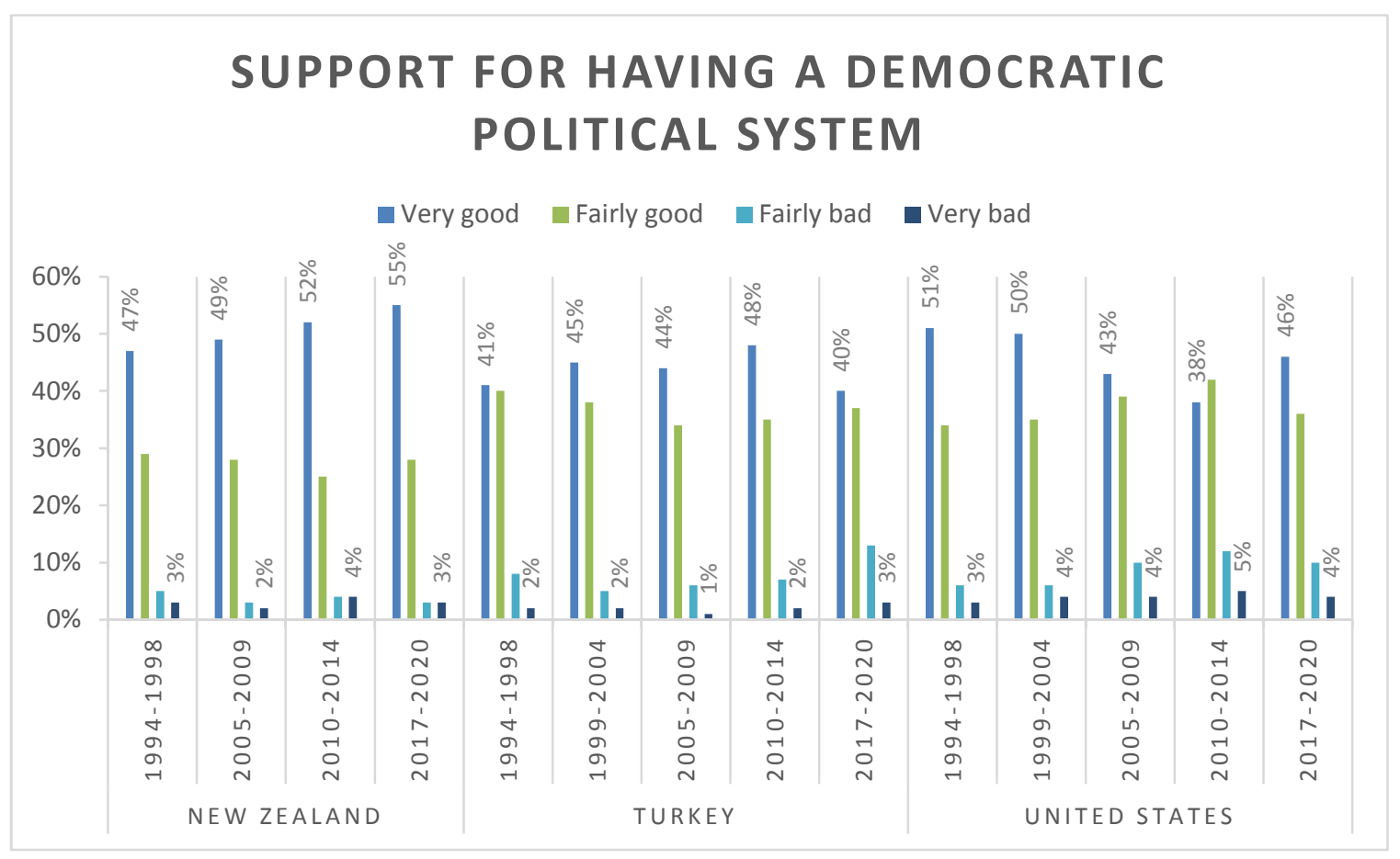

Figure 3- Support for Having a Democratic Political System

Source: 1994-2020 World Value Survey 
system is rated as "very good" or "fairly good" by $77 \%$ of respondents, and while this has decreased slightly over the past few waves, it remains comparatively very high. At the same time however, satisfaction with the current system (which is not a democracy) is also very high, with $28.6 \%$ of respondents saying they were "completely satisfied" with the political system (answered 8-10 on the scale). In comparison, only $12.2 \%$ of Americans and $18.9 \%$ of New Zealanders are "completely satisfied," despite very high percentages answering that a democratic system was "very good" or "fairly good" (82\% and $83 \%$ respectively). While one could argue this discrepancy makes some sense in the US, where democracy is clearly faltering and thus the performance of the system may be harshly judged, it makes less sense in New Zealand, clearly a strong democracy, or Turkey, clearly a growing autocracy. Yet again, it seems citizens have trouble connecting

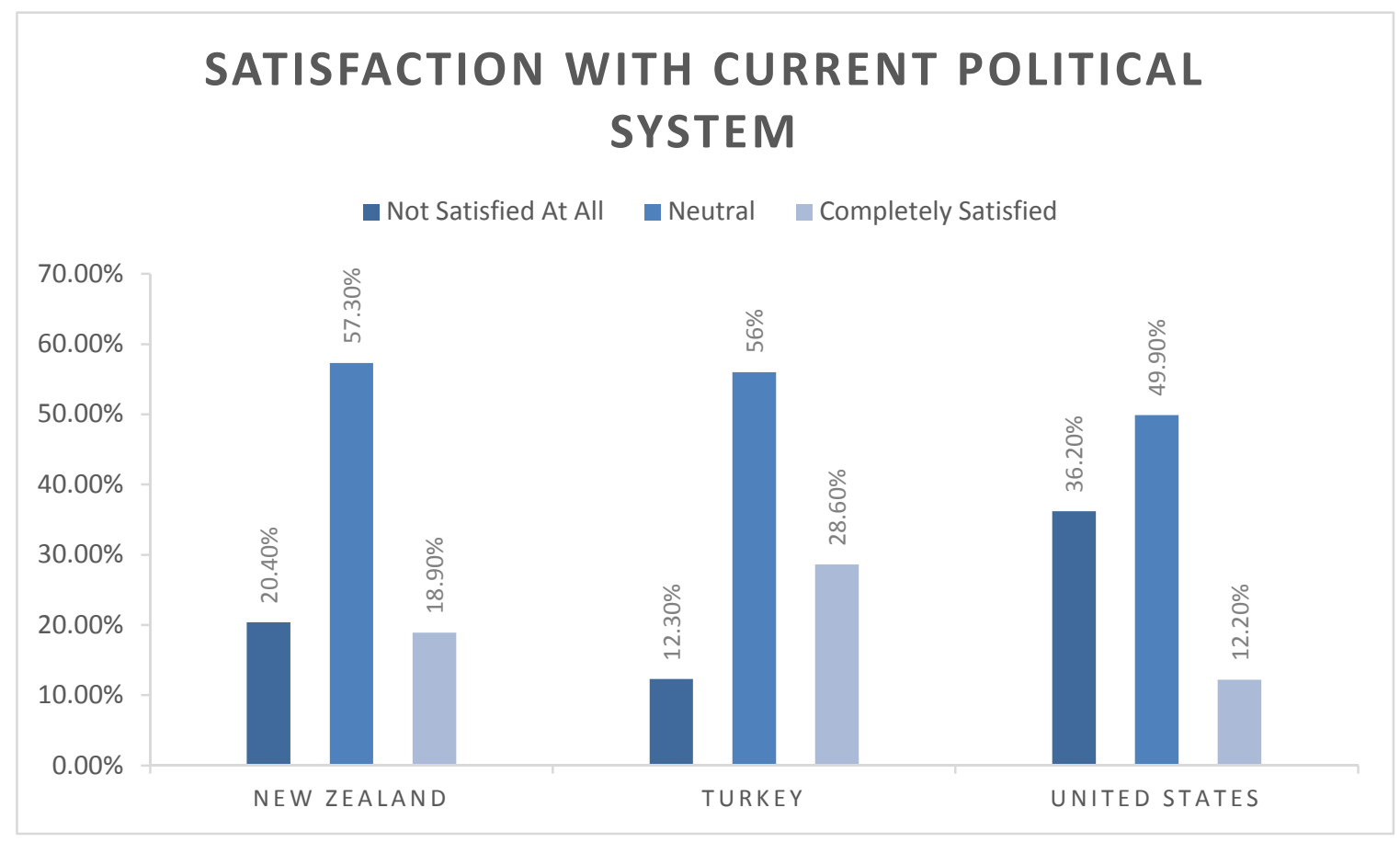

Figure 4- Satisfaction with Political System Source: 2017-2020 World Value Survey 
the abstract and the reality, and don't always recognize their own system for what it is. This also shows that performance ratings for these regimes are, in general, incredibly low, which is very worrying for long term legitimacy of the regimes. As Weßels (2015) cautioned, low performance ratings can quickly transition into decreasing support for fundamental norms, and if the WVS indicators for the importance of democracy are to be believed, this is already occurring. If citizens can't even recognize democracy when they have it, how would they even realize it was in danger of decline?

When we consider other factors that may play into overall democratic evaluations, based on Thomassen and van Ham's indicators for measuring political support, we can start to make better sense of how citizens of a country like Turkey evaluate their regime as more democratic than those in the United States. For instance, Turkey scores near the very top on the WVS question asking about national pride (61\% are "very proud" and $27 \%$ "quite proud" (see Figure 5)) and scores the highest of the three cases in terms of confidence in government ( $69 \%$ either have "a great deal" or "quite a lot" of confidence) and thus it's not that surprising that they still recognize their government and regime as ultimately democratic or "good." In comparison, in the United States only $46 \%$ of respondents said they were "very proud" of their country and only $8 \%$ have "a great deal" of confidence in the government, while only $25 \%$ have "quite a lot." Furthermore, confidence in the government has decreased slightly over time in the United States, with combined scores of "a great deal" and "quite a lot" dropping from 37\% in 2005-9 to 33\% in 2010-14, while the percentage saying they have no confidence at all jumped from $14 \%$ to $29 \%$ between 2014 and 2017 (See Figure 6 below). Likewise, feelings of national pride have also been steadily decreasing in the United States, from a high of $77 \%$ feeling "very 
proud" in $1994-98$ all the way down to $46 \%$ in the most recent wave. While this is, comparatively, still quite high, it's important to recognize how much this percentage has fallen and continues to decline every year. Meanwhile in Turkey feelings of national pride have remained steadily high since the WVS began asking this question, but they have fluctuated somewhat randomly, from a shocking high of $81 \%$ "very proud" of their country in 1994 , down to $62 \%$ the following wave, back up to $74 \%$ after that, and so on, with no real discernible pattern.

Again, unsurprisingly, New Zealanders' have the most national pride of the three cases in the most recent wave, scoring just above Turkey with $67.7 \%$ "very proud." Like Turkey there has been some mild fluctuation in percentage of respondents feeling "very

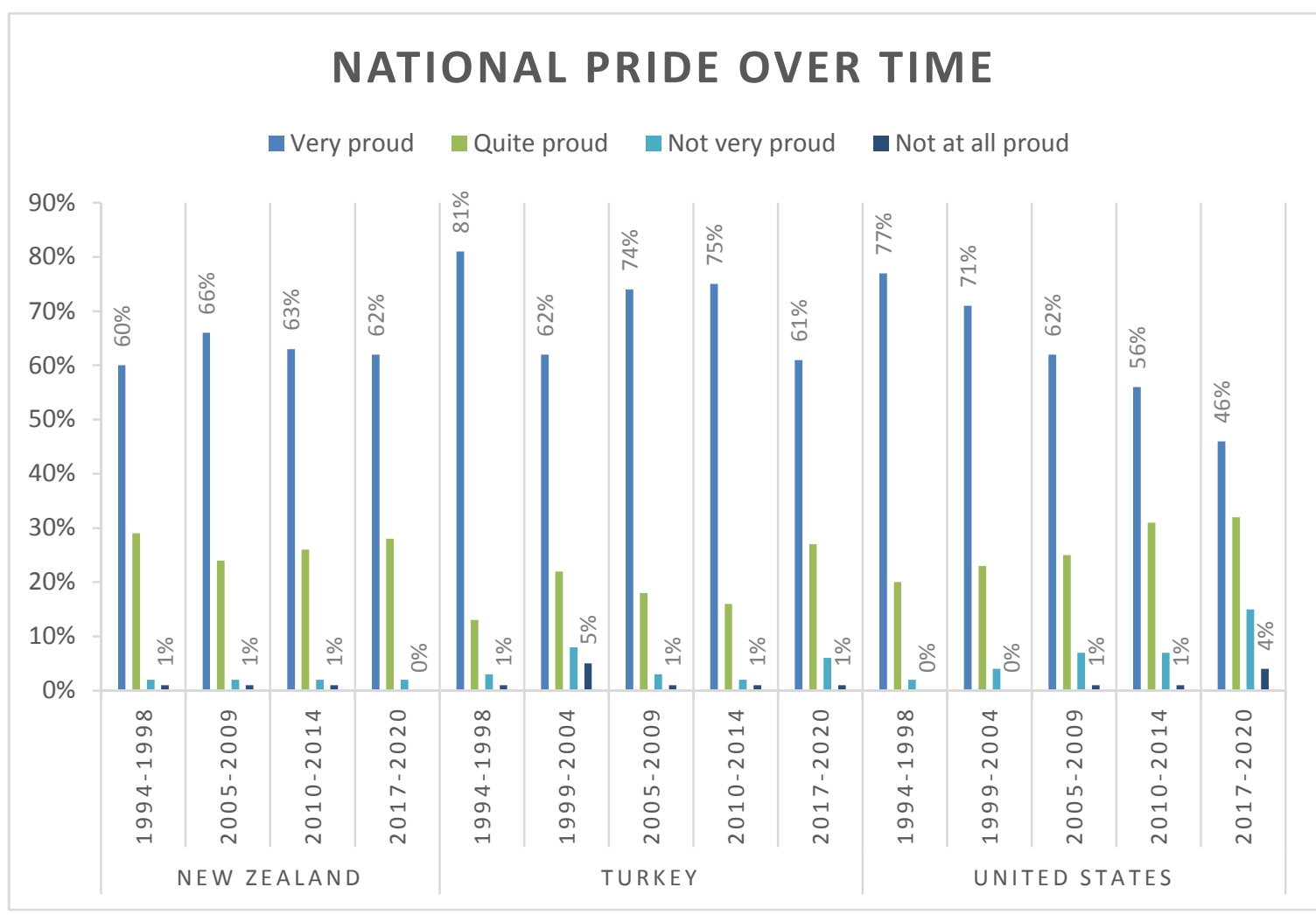

Figure 5- National Pride Over Time Source: 1994-2020 World Values Survey 
proud," however it has remained steadily between 60 and $70 \%$ since the $90 \mathrm{~s}$. New Zealanders also have very high levels of confidence in their government that continues to increase every year, with $38 \%$ either having "a great deal" or "quite a lot" of confidence in $2005-9$, up to $45 \%$ in $2010-14$, and to $50 \%$ in $2017-20$.

Even a country like New Zealand doesn't quite have the confidence levels seen in Turkey however, for, over this same time period, confidence in government has continued to rise, from $54 \%$ in 2009 to $59 \%$ in 2014 , to $69 \%$ in 2020 while simultaneously the percentage with no confidence has dropped from $20 \%$ to $15 \%$ to $8 \%$.

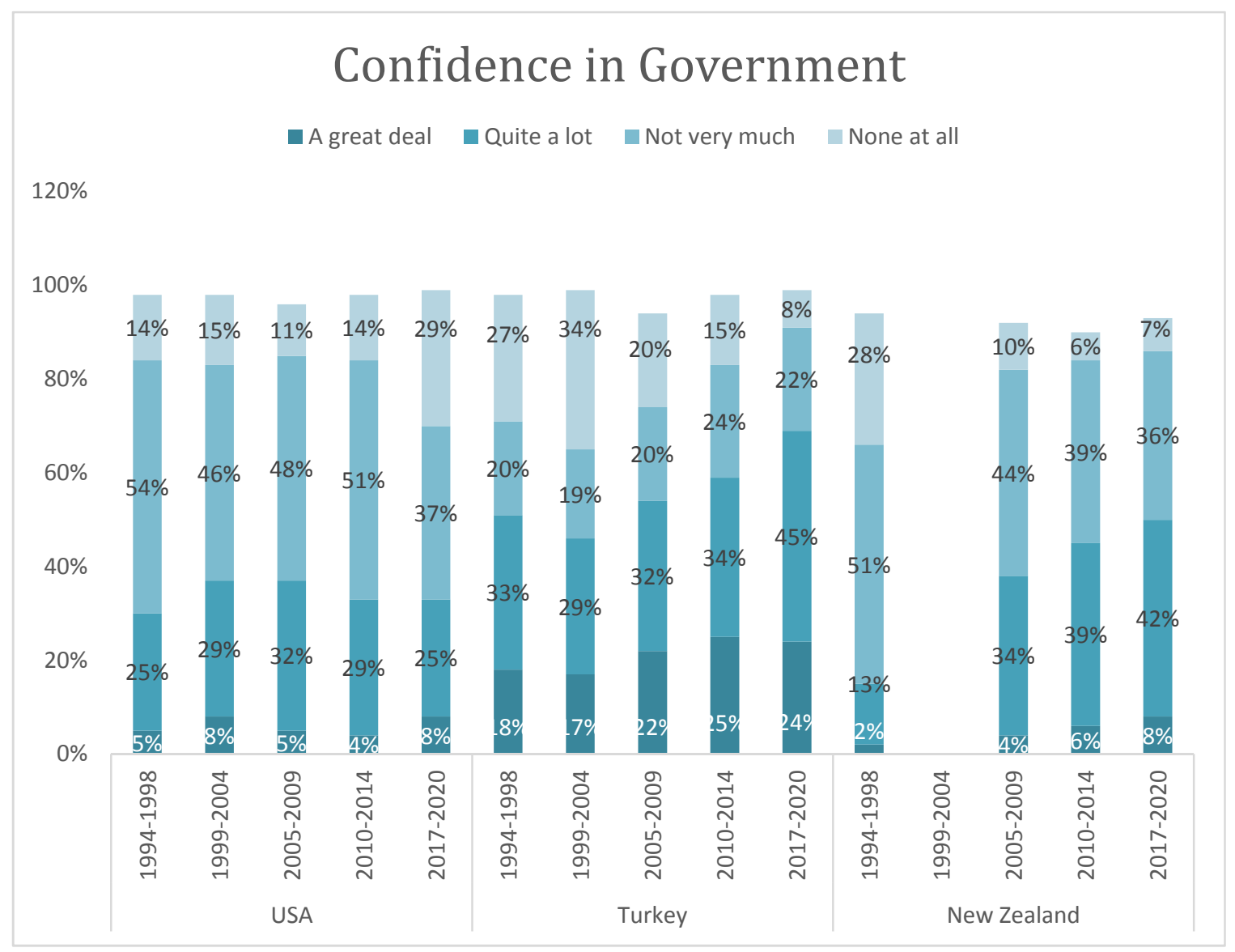

Figure 6- Confidence in Government Source: 1994-2020 World Values Survey 
This is particularly interesting because it shows that even in the face of events or situations we'd expect to decrease confidence in government, such as Erdoğan's crackdown on free speech post-2016, confidence has actually remained quite high in Turkey, and significantly higher than in the comparably more democratic United States. This seems counterintuitive at first glance, for while we know Erdoğan has many supporters, he also faces significant opposition so this high degree of confidence in the government seems misplaced or exaggerated. It seems possible that, despite intense criticism for human rights violations, citizens have a general approval for the government taking charge and not letting the west "push them around" anymore. It seems this takecharge attitude, combined with very real improvements to the economy, has resulted in a higher degree of confidence than an outside observer would expect, perhaps akin to the support and confidence Putin maintains in Russia even while the world knows he amounts to little more than a brutal dictator.

This is further enforced by the indicator measuring citizens preference for a strong leader who doesn't have to "bother with parliament or elections," essentially asking if they would support an authoritarian leaning leader who is largely unaccountable to other branches of government (Figure 7). Not that surprisingly, given their history, Turks are relatively accepting of a strongman style leader, and although the percentage responding this is "very good" has decreased slightly over the past 3 waves ( $21 \%$ to $17 \%$ to $15 \%$ ), when you also consider the percentage responding that this is "fairly good," the acceptance has remained steadily around $50 \%$ since 2004 . This is further evidence as to why Turks may remain confident in a government that is increasingly cracking down on rights and taking away freedoms, because, despite these things, the government is seen as 


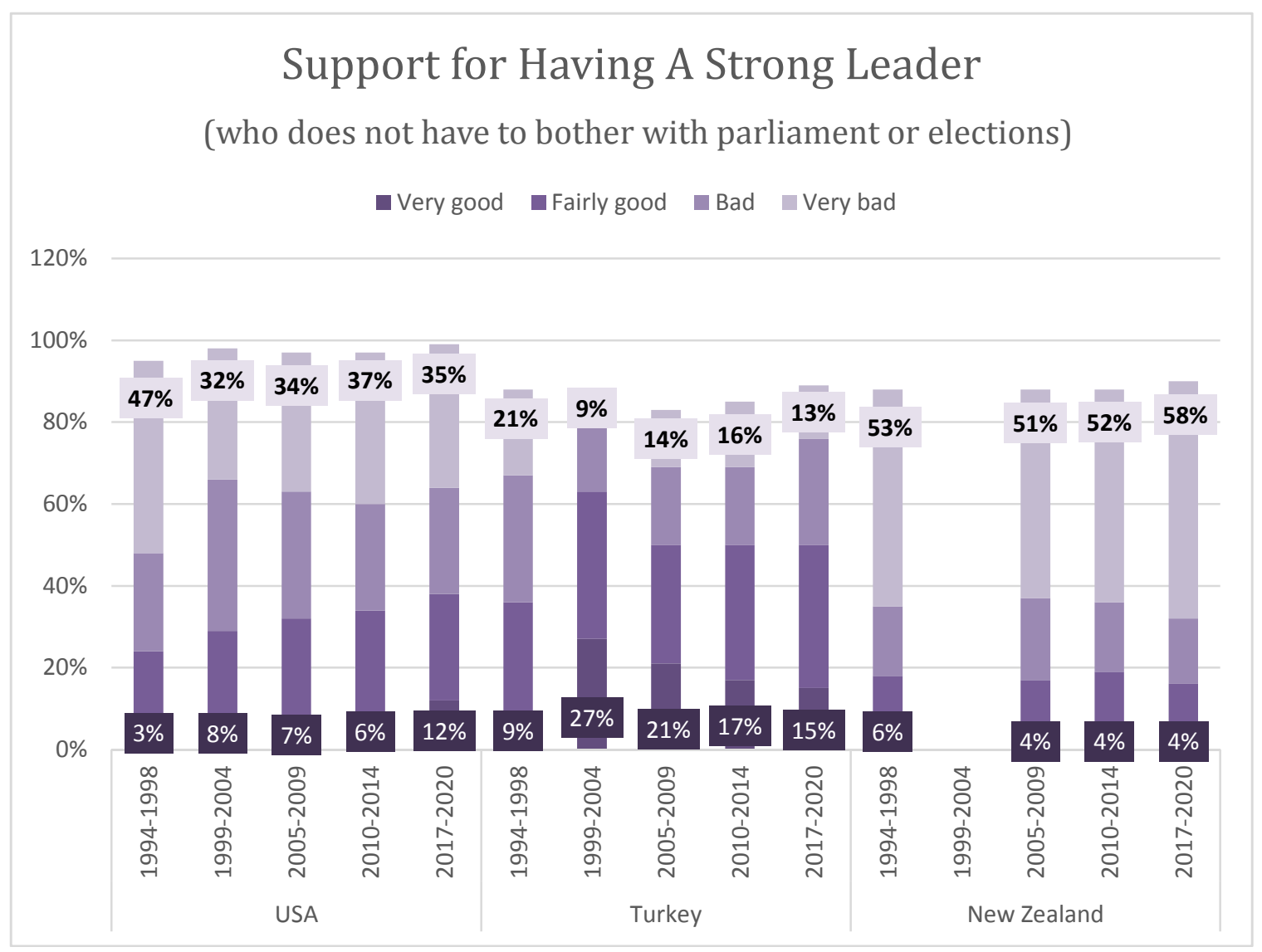

Figure 7- Support for Having a Strong Leader

Source: 1994-2020 World Values Survey

"strong," and a strong government offers the most protection. If people are seriously worried about their safety (as we'll see below they are in Turkey), it's understandable that a leader who can act immediately and forcefully and doesn't have potential to get bogged down by other branches and democratic processes would be appealing. Even those who recognize Erdoğan as an authoritarian may still believe he has brought greater safety to their lives and thus maintain a degree of confidence in his government in spite of the rights restrictions. This indicates as well that, in the grand scheme of things, these rights being restricted are not as important in performance and confidence assessments as 
security, and thus don't play as big of a role in how citizens evaluate their own regime and government.

Concerningly, on this same indicator of having a strong leader who doesn't have to bother with parliament or elections, the United States has steadily increased their approval every year. The percentage of Americans responding that a strongman style leader is "very good" or "fairly good" has risen from 32\% in 2005-9, to 34\% in 2010-14 and now with the most recent results from $2017-20$ indicating a worrying $38 \%$ are accepting of a semi-unaccountable leader. This seems to be a sharp contradiction to the $70 \%$ that state democracy is important and serves as further evidence of the falling position of certain democratic norms in American society. An unaccountable leader is antithesis to one of the core foundations of democracy and, although only $12 \%$ of Americans believe this is "very good," that's still too many, and the fact this number has been steadily increasing since the first wave this question was asked (1999-2004) is very worrying. Americans seem to value immediate action over democratic process, and this could perhaps partly be explained by the ever-present sense of threat they feel. When the Patriot Act was enacted within a month of the 9/11 attacks there was initially very little hesitation or protest from the general public, even though it was clear the legislators themselves didn't really know what they were passing (Cole and Dempsey 2006). When people are scared, their security takes precedent over democratic values, and thus they will willingly accept or even prefer, a semi-accountable leader who will "get things done" and help them feel safe. Contrary to both Turkey and the US, New Zealand has steadily maintained much lower scores on this indicator, with $4 \%$ responding a strong leader is "very good" in each of the past 3 waves, and the percentage stating it is "very bad" 
increasing from $51 \%$ to $58 \%$. This is perhaps partly due to the significantly lower level of threat they feel than either Turks or Americans, but also indicates how seriously both the citizens and the government prioritize freedoms and democratic values over all other concerns.

We can observe very similar patterns when we examine other confidence measures, particularly confidence in parliament (Figure 8) and confidence in political parties (Figure 9). Like government, confidence in the parliament in Turkey continues to rise, although at a more gradual rate, with $59 \%$ of respondents answering they had either "a great deal" or "quite a lot" in the most recent wave. The percentage of respondents with "a great deal" of confidence has decreased every year since 2005 , from $22 \%$, to $17 \%$ and now to $12 \%$, however those responding "quite a lot" has continued to increase while those with no confidence at all decreases steadily. Similarly, in New Zealand confidence in parliament also continues to increase gradually, with $39 \%$ answering they have "a great deal" or "quite a lot" in the 2017-20 wave, up from 14\% in 1994-8. Notably, of course, they still rank below Turkey in terms of confidence levels, despite the fact Turkey's parliament is considered relatively impotent and is the target of frequent corruption charges, while New Zealand's is generally considered to be strongly democratic. Meanwhile, just like with government, in the United States confidence continues to decline, with $20 \%$ of Americans responding they had no confidence at all in $2017-20$, combined with $60 \%$ responding "not very much," indicating a solid majority of the population has no trust or confidence in the legislature. Again, this isn't that surprising when one considers the growing polarization of American society and the complete gridlock this has caused in both houses, but it still is means for concern. 


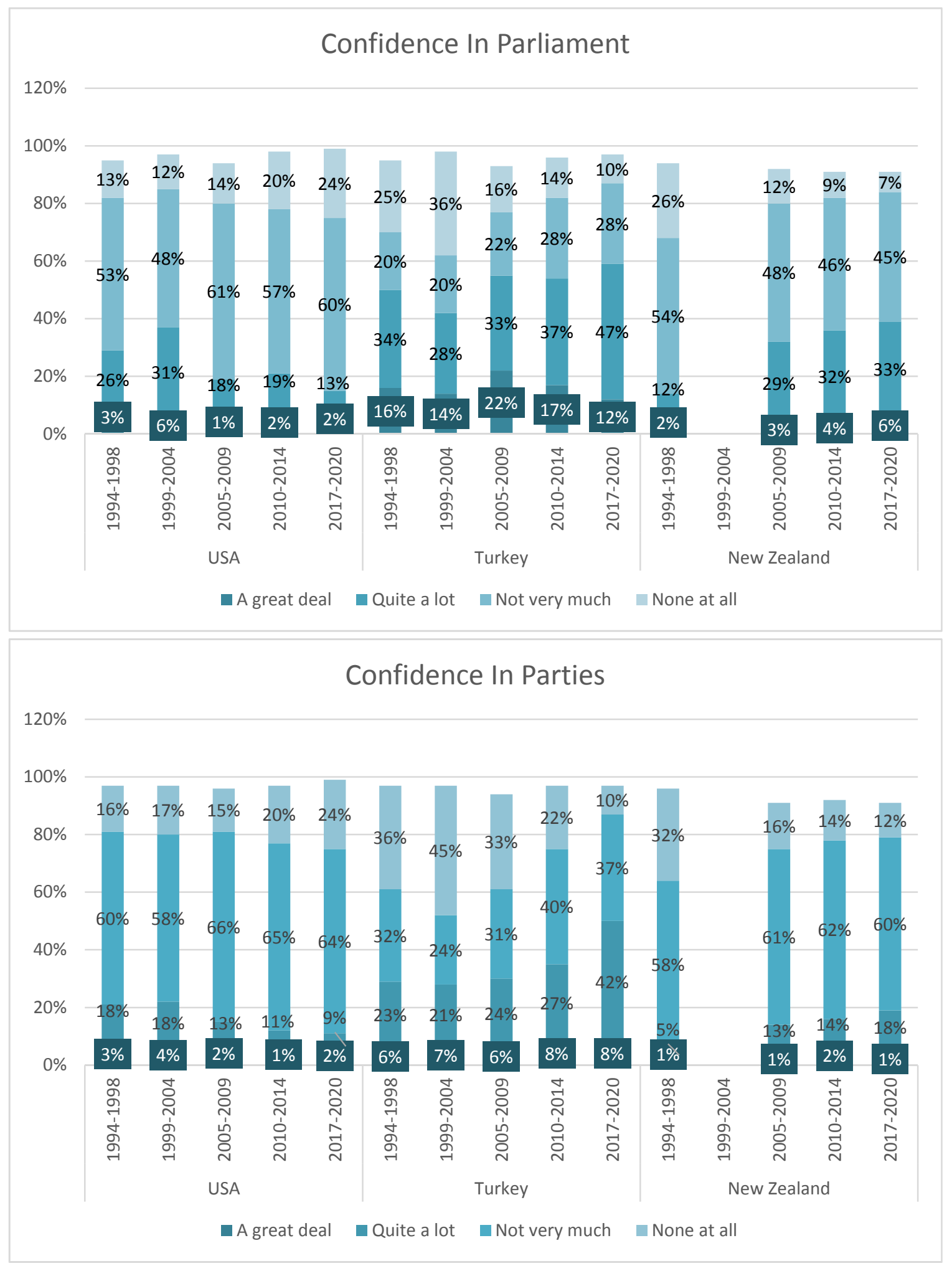

Figure 8- Confidence in Parliament and Figure 9-Confidence in Parties Source: 1994-2020 World Values Survey 
In looking at confidence in parties, we see a very similar trend, with the one difference being that none of the cases have all that much confidence in political parties to begin with. In the United States, there has certainly been a slight decline since the 90 s, with those with no confidence at all dropping from $16 \%$ in 1998 to $24 \%$ in 2020 ; however, when we factor in those with "not very much" confidence as well, this score has been consistently above $75 \%$ since 1994 . In Turkey there has been a bit more fluctuation, with 1999-2004 serving as a low point with $45 \%$ of respondents answering they had no confidence at all and scores slowly increasing from then, resulting in only $10 \%$ with no confidence and $50 \%$ having "a great deal" or "quite a lot" of confidence in the most recent wave.

This is perhaps most surprising out of all the confidence measures in the WVS due to well documented corruption and government control of parties in Turkey. Since the 90s there have been various laws in place to keep Kurdish affiliated parties or other groups unfavorable to the government from gaining any traction, including a shockingly high threshold of $10 \%$ to gain seats in the Grand National Assembly (HRW 2021). This has only intensified under Erdoğan, as indicated just last month (March 2021) by a case being brought against the People's Democratic Party (HDP), the third largest party in Turkey's parliament, accusing them of colluding with the PKK and attempting to ban the popular party entirely (BBC 2021). While actions like this speak more to the corruption of the government, the fact that it's clear parties only operate successfully with Erdoğan's approval raises questions over why citizens have so much confidence in the parties (unless of course this is the same confidence they have in the government in general, just transferred over to yet another arm of Erdoğan's). This incident also provides further 
evidence as to the public's acceptance of rights restrictions when done with a veil of security purposes, as Erdoğan linked the HDP to the terrorist group PKK to help control criticism or protest.

Finally, much like with the other confidence indicators, New Zealand has seen a steady increase in party confidence, albeit starting from a low point of $32 \%$ of citizens with none at all in 1994-8. In the $2017-20$ wave $12 \%$ of respondents had no confidence in parties and 19\% had either "a great deal" or "quite a lot," placing them in a better position than the US, but still nowhere near Turkey's level. Similarly as in a number of European countries, it seems there is a growing sense that, even though New Zealand is a multiparty system, the same few parties are always in control and these "traditional parties and politicians don't care about [me]" (Duncan 2018, 115). In New Zealand's case, although they switched from a First Past the Post to a Mixed Member Proportional electoral system in 1993 (modeled after the German system), their political system essentially remains a "Labour-or-National duopoly," with the inclusion of three other rotating parties in parliament (119).

While this has led some to warn of an eventual populist or nationalist uprising leading to the emergence of more radical outsider parties, as seen in Europe and the United States, most scholars of New Zealand's political system find there to be some dissatisfaction, but not a desire for full systemic change. Thus, their low (compared to Turkey) score of confidence in parties may be more of a reflection of this desire for minor change in the existing party structure, particularly in terms of greater inclusion of Maori interests, rather than a belief that the party system doesn't work at all, as is the case in the United States. On any international comparison, New Zealand's electoral and 
governmental systems are consistently rated very highly for observing values such as human rights, freedoms, and transparency, and survey evidence makes it abundantly clear that New Zealanders are more satisfied with democracy and parties now (and increasingly more so each year) than they were before MPP (Duncan 2018). A general distrust in political parties seems to be a universally shared sentiment, although when considered in relation to current events confidence can seem misplaced or arbitrarily decided. The intense gridlock and affective polarization in the United States may somewhat justify the low confidence in institutions, although it certainly seems to be a bit exaggerated. Meanwhile the opposite seems to be true in Turkey, where confidence is overly exaggerated for a government that frequently and aggressively cracks down on human rights, seemingly based primarily on economic and foreign policy concerns. Unlike Turkey, a clear autocracy, and the United States, a faltering hybrid regime, New Zealand remains consistently more committed to democracy and democratic principles, and this is apparent in nearly every indicator used by the WVS.

Particularly when we examine some of the WVS group of questions on the "essential characteristics of democracy" over time we can clearly see Turkey's fall away from democracy and New Zealand's continual rise, while the US fluctuates in the middle, presenting somewhat of an enigma. For instance, one of the questions asks if the respondent believes civil rights protect people's liberty against oppression, on a scale with 1 meaning they do not think it's an essential characteristic of democracy and 10 meaning it is (Figure 10). Again, since this is measuring the ideal rather than the practice, the numbers are high across the board, but there is a very obvious trend for both New Zealand and Turkey. In 2005-9 70\% of Turks responded that civil rights that protect 
people's liberty was an essential characteristic (answered 8-10), but this dropped to 57\% the following wave, and further still to $49 \%$ in 2017-20. Unfortunately for New Zealand we only have responses from two waves, but we can still see a significant increase from $54 \%$ saying they were essential in $2010-14$, to $64 \%$ in $2017-20$. Clearly, the concept of civil rights is being evaluated as increasingly less important in Turkey, which goes right along with their decreasing belief that democracy is important, while the exact opposite is true in New Zealand. There is less of a trend visible in the United States, where the percentage viewing civil rights as essential has fluctuated from $62 \%$ in $2005-9$, to $54 \%$ in 2010-14, back up to 57\% in 2017-20. All these numbers remain high, indicating that overall Americans still find civil rights to be an important component of democracy in the abstract, but the fluctuation does perhaps point to the insecurity and uncertainty Americans have with larger concept of democracy itself.

These same trends repeat themselves in other questions within this category of "essential characteristics," such as one that questions respondents on the importance of free elections. In New Zealand those believing free elections to be essential increased from $77 \%$ in $2010-14$ to $83 \%$ in $2017-20$, while in Turkey it steadily decreased from $76 \%$ in $2005-9$, to $70 \%$ in $2010-14$, to $54 \%$ in $2017-20$ (Figure 11). Interestingly, elections in Turkey have been increasingly evaluated by observers as corrupt and unfree, especially after the attempted coup in 2016 , so the large drop from $70 \%$ to $54 \%$ over this period is somewhat surprising. Instinctively you'd think that as the right to free and fair elections was taken away it would be viewed as more important, but instead it's seen as significantly less essential. This is perhaps indicative of Turks' desire to still see their country as a democracy, and thus they view some of the foundational democratic features 
as less essential so as to allow them to still convince themselves their regime fits the mold. Alternatively, this decreasing evaluation of election importance could also reflect the grim acceptance Turks have that their elections are corrupt and therefore potentially meaningless. Thus, this would indicate a growing apathy towards democratic norms rather than an outright willingness to turn away from them.

Likewise, for the question asking if women and men having the same rights is essential for democracy Turk's response dropped from 78\% saying this is essential in $2005-9$, to $67 \%$, to $58 \%$ in the most recent wave (Figure 12 ). Following the same trend, New Zealand's responses increased from $80 \%$ to $85 \%$ saying women and men having the same rights is essential, presenting still further evidence to democratic strengthening in New Zealand and weakening in Turkey. Again, for both the above questions responses in the United States fluctuated a bit but ultimately remained relatively steady, with 69$70 \%$ saying free elections are essential and $69-72 \%$ saying gender equality is. All of this together just goes to show how fundamental democratic norms are drastically losing support in Turkey while steadily gaining support in New Zealand, essentially confirming what we already knew about creeping authoritarianism under President Erdoğan and healthy democracy under Prime Minster Ardern. The United States meanwhile is harder to place fully following either trend, going right along with their current status as a weak democracy or even as a growing hybrid regime. Support for these fundamental norms in the US fluctuate but remain steadily in the middle of the two other cases, cementing their position as not quite a healthy democracy, but not yet an authoritarian regime either. This however is a precarious position as fluctuations can quickly turn into a downward trend if they receive the right catalyst. 

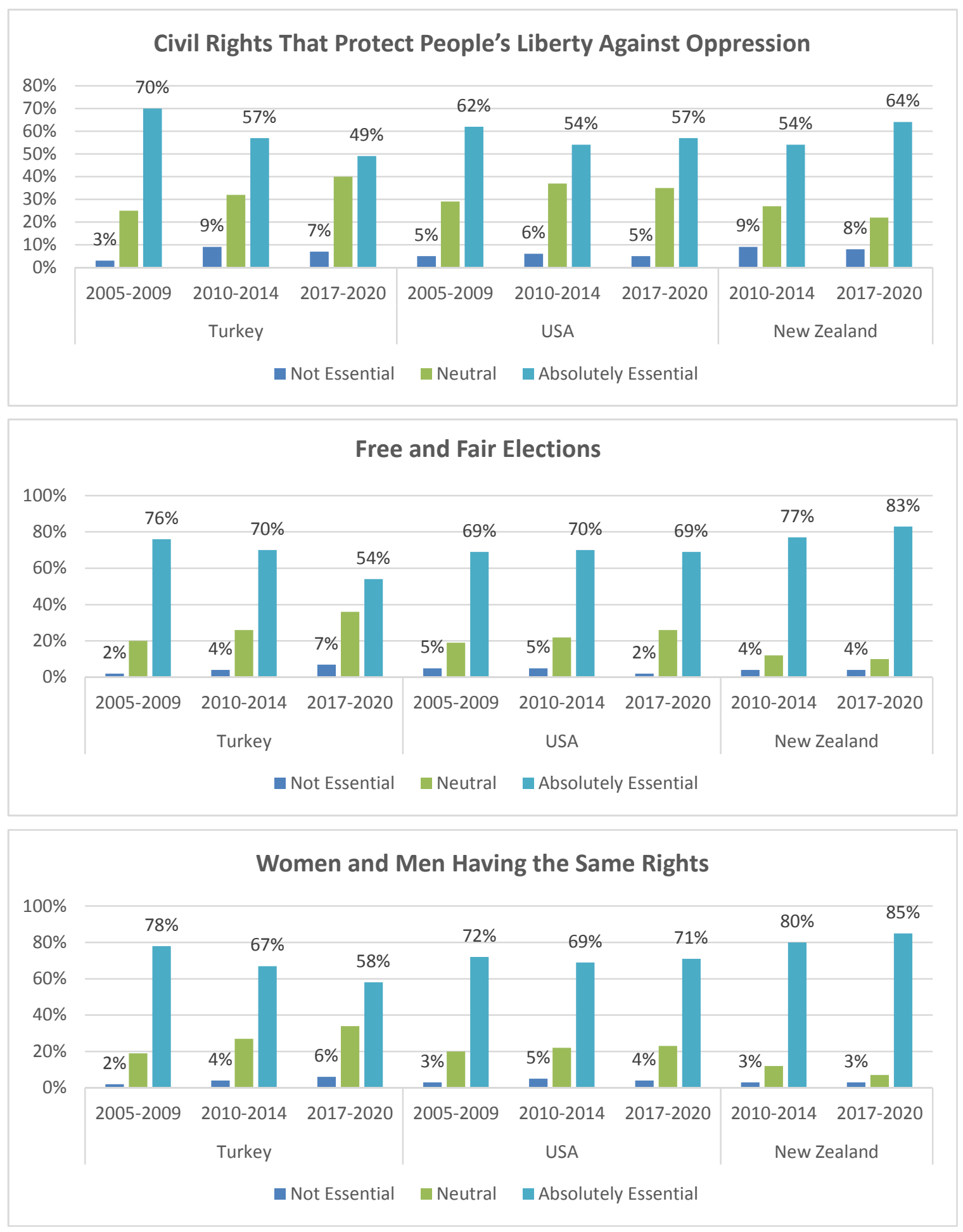

Figure 10- Essential Characteristics of Democracy: Civil Rights, Figure 11- Essential Characteristics of Democracy: Elections and Figure 12- Essential Characteristics of Democracy: Gender Equality Source: 2005-2020 World Values Survey 
While the analysis thus far has explored the strength of democracy and revealed some interesting trends, it hasn't really yet touched on evidence as to why these trends may be occurring and thus, I turn my attention now to measure of security and fears of terrorism.

\section{Terrorism and Security-}

In the post-9/11 environment most states quickly made moves to strengthen and update their counterterrorism policies and laws in an effort to be more prepared for this new type of terrorist threat. Unfortunately, as I've already touched on, freedom and security are most often thought of as a balance, wherein strengthening one detracts from the other. In an effort to explore how the general population feels about this balance, the most recent wave of the World Values Survey (2017-2020) asks very specifically if the respondent thinks security or freedom is more important and, while a time series analysis is unavailable because this question has only been asked once, the results are still worth examining. Crucially, they reveal that nearly every state, across the board, places security first. ${ }^{6}$ In fact, the only states in which respondents prioritized freedom were the United States (very highly at 69.5\%), Australia (at 51.2\%), and New Zealand (at 47.3\%, just barely over the $42 \%$ who responded freedom). Of the 49 states asked this question respondents in the majority of them significantly value security over freedom, unsurprisingly with the autocratic states ranking the highest (with Indonesia at the very

\footnotetext{
${ }^{6}$ It should be noted that a number of European countries were not asked this question, in either the WVS or any of the ESS of the same time range, and thus can't be included in this analysis (See Figure 13.5 in Appendix $B$ for all states included)
} 
top with $95 \%$ responding security). In Turkey respondents place security first at a rate of $59 \%$ versus $39 \%$ who said freedom, putting them in the same middle category of a general 60-40 split as the likes of Greece, South Korea, and Germany (Figure 13).

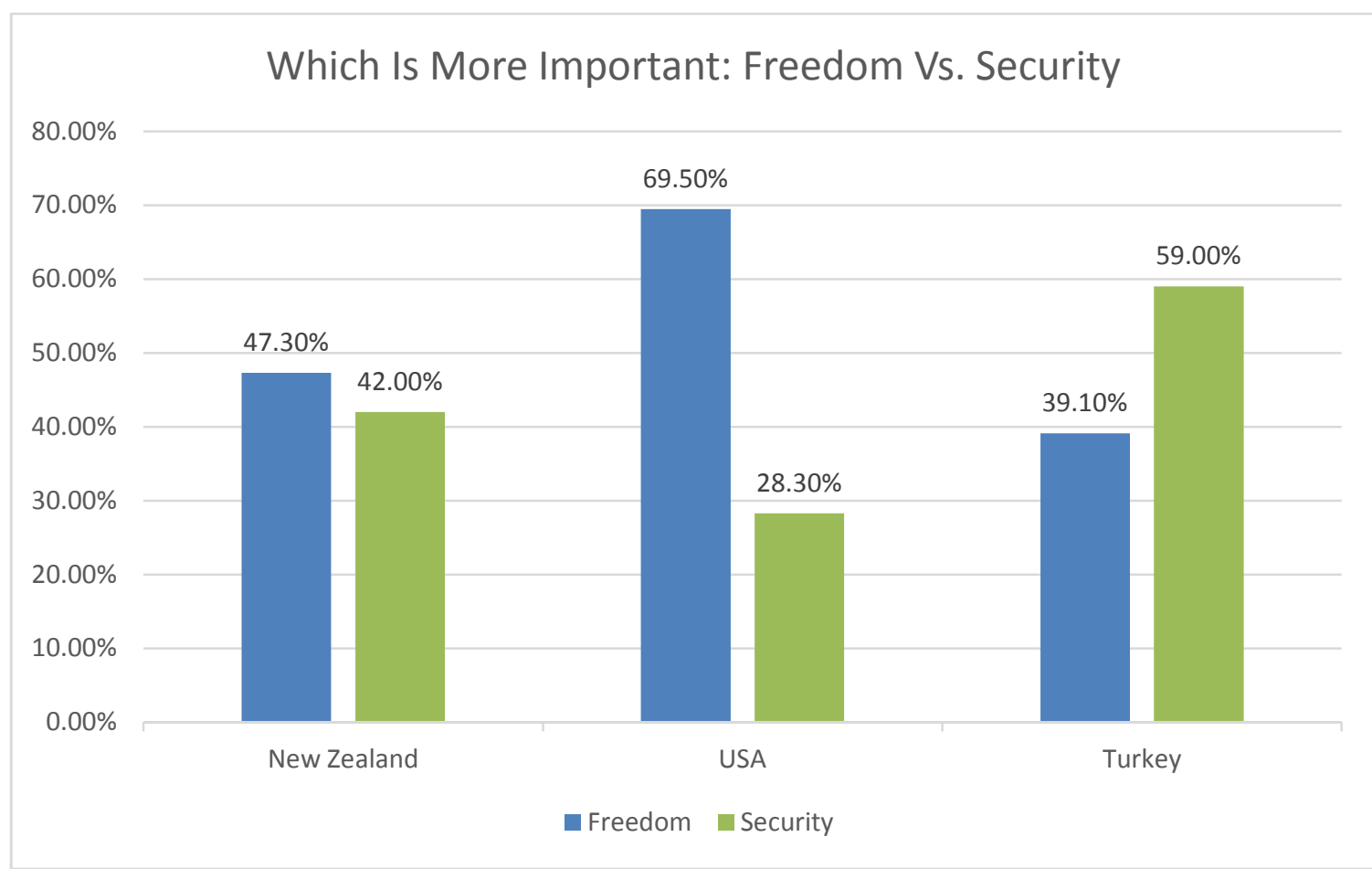

Figure 13- Which is More Important: Freedom vs. Security

Source: 2017-2020 World Values Survey

It is somewhat surprising that so many democracies place security first, when it's well acknowledged that prioritizing security often negatively affects freedom, providing strong evidence that civil liberties may be decreasing, but that people are ultimately accepting of this if it comes with a guarantee of safety. Of the states asked this question in Wave 7, over half qualify as either a "democracy" (7 of 49) or a "flawed democracy" (16 of 49) according to the EIU 2020, and thus while not as many states were asked this question as ideally hoped, we can still observe some interesting trends. Particularly when we combine this data with evidence gained from other indicators, it begins to help shed 
some light on a potential explanation for the decrease of support for democratic values in some key states.

As Silver and Davis found in their analysis of the US after 9/11, citizens were overwhelmingly okay with harsh security policy, even when it blatantly restricted their rights, because the fear of future terrorist attack was so high. It seems this tradeoff between security and freedom is an easy decision for many, and, if you ascribe to Maslow's hierarchy of needs, is to be expected as it's human nature to place safety and self-preservation above just about everything else (Silver and Davis 2004). One of the biggest questions raised here is thus: what explains the unusually high score in the United States? While I can't definitively conclude anything with only response from one wave of the WVS, it seems, similarly to questions of democracy, when respondents are evaluating freedom and security there is a discrepancy between what they see as the ideal and how they evaluate their own country, or even what they think is best for their country. It's also quite possible that, had this question been asked in the past few waves as well, it actually has been decreasing, but began from a higher starting point than some of the other states. I say this because, if we look at other indicators, such as fear of terrorism, or perceptions of security in their own neighborhood, the US has greatly been increasing, showing higher levels of fear and lower perceptions of safety, indicating that a desire for security may be growing. In terms of security in their own neighborhood, the percentage of Americans responding "very secure" dropped from 26\% in 2010-14 down to $12 \%$ in 2017-20, matching a general global trend in decreasing perceptions of security (Figure 14). For the same time period Turkey dropped from $25 \%$ down to $8 \%$, Germany dropped from $59 \%$ to $27 \%$, Australia from $29 \%$ to $16 \%$ and Japan from an already low $11 \%$ down 
to $3 \%$. New Zealand again is an outlier, increasing slightly from $27 \%$ to $33 \%$. It must be noted that this indicator is somewhat vague, and a change in perception of neighborhood security could be the result of violent acts such as terrorism but could also indicate if people are insecure due to more localized crime, gentrification, racism, etc. and thus we can't draw too many strict conclusions about terrorism based on this measure alone. That being said, it remains notable that this is a somewhat global phenomenon of decreased perceptions of security, matched by a high rate of prioritizing security over freedom, which seems to provide evidence to a bigger picture.

To measure terrorism more specifically, the WVS indicator of "fear of a terrorist attack" is much more telling and indicates that again, there has been a near universal

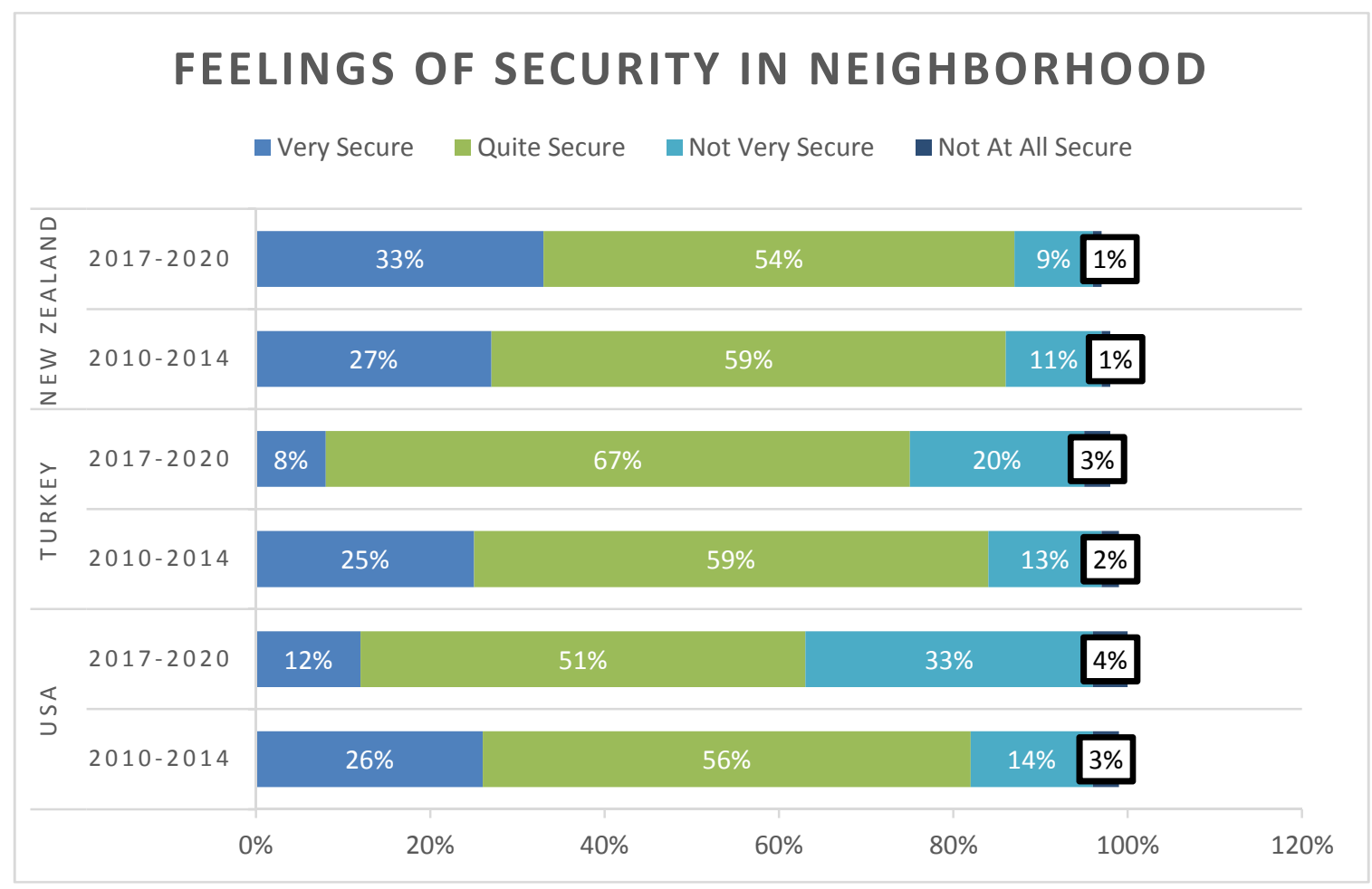

Figure 14-Feelings of Security in Neighborhood Source: 2017-2020 World Values Survey 
increase over the past ten years. In the United States the percentage responding they are "very much" afraid of a terrorist attack increased from $18 \%$ to $28 \%$, while those responding "a great deal" increased from $35 \%$ to $40 \%$, meaning over half the population now fears a terrorist attack (Figure 15). In Turkey meanwhile responses rose from $35 \%$ to $43 \%$ for "very much" and from $33 \%$ to $43 \%$ for "a great deal," indicating nearly $90 \%$ of Turkish citizens fear terrorism. Even New Zealand saw a slight increase, for while the percentage responding "very much" decreased by one point from $13 \%$ to $12 \%$, those responding "a great deal" increased from $9 \%$ to $20 \%$, putting the overall fear level at $32 \%$. It also is worth noting that, while the most recent wave ran from 2017-2020, responses for this question in New Zealand were gathered at an unspecified time in 2019.

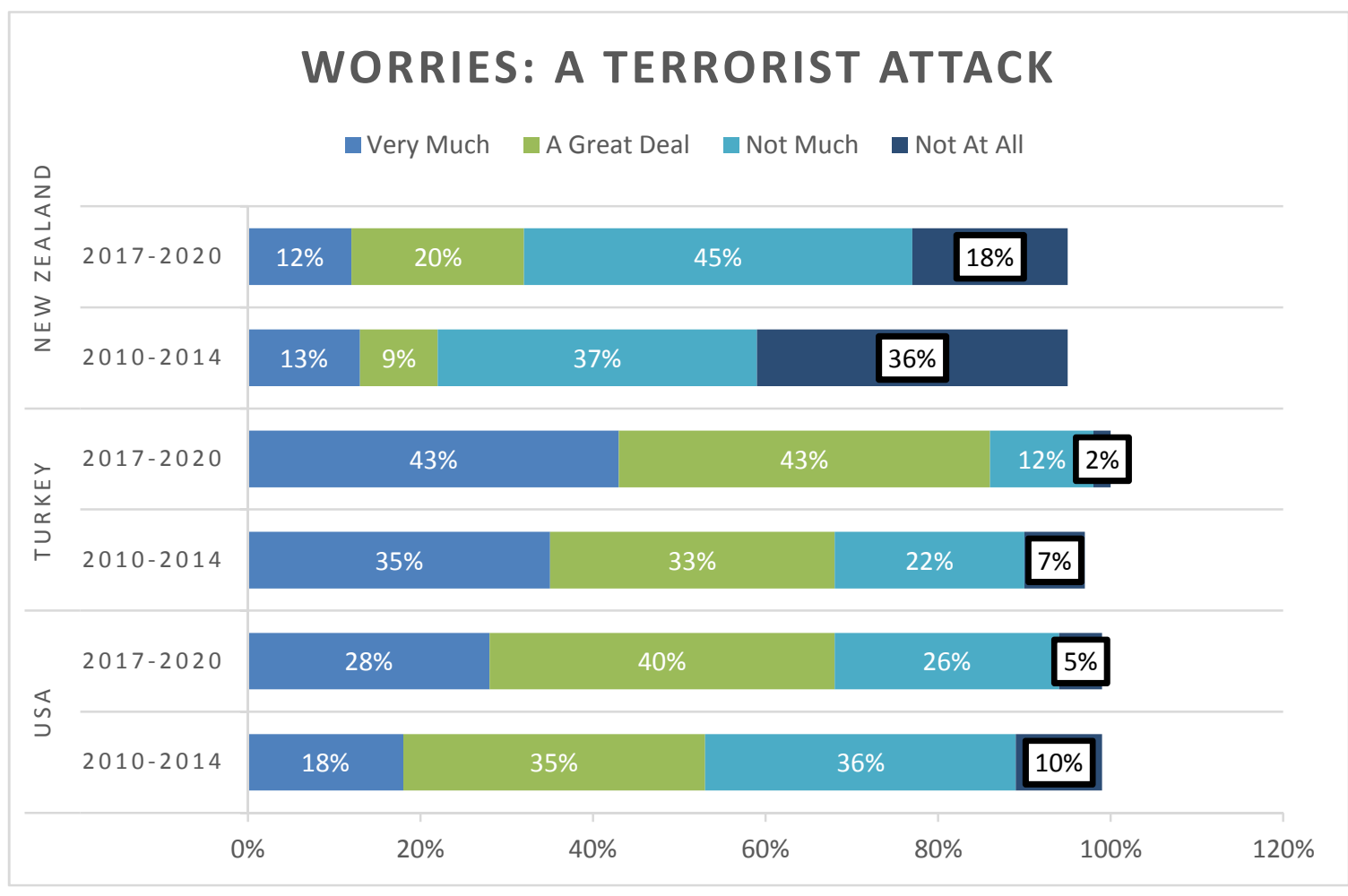

Figure 15- Worries of a Terrorist Attack Source: 2017-2020 World Values Survey 
This is important because the Christchurch Massacre, the greatest terrorist attack in New Zealand's history, occurred in late 2019 and thus, it's quite possible the responses were recorded before this event, meaning it's likely another increase followed this attack. These increases in fear are in many cases understandable based on events and current situations in these states and on a more global scale. For instance, Turkey's increase of almost 20 points lines up with an increase in both frequency and brutality of attacks in public places, both by ISIS and Kurdish separatist affiliated groups, making this drastic leap entirely warranted.

People are clearly scared, and increasingly growing more so, worried about terrorism, feeling unsafe in their neighborhoods and thus, perhaps justifiably, putting security interests above freedoms. Terrorism is of course a very real threat and has affected all three of these states in devastating ways, making this fear understandable, however, it's important to recognize the ways in which it may be exaggerated. It seems in many instances this heightened fear isn't due to any sort of change in risk, but rather due to changes in our perception of risk. For example, examining the annual Gallup poll measuring a similar question of American fears of terrorism reveals that the percentage of Americans very or somewhat concerned with being a victim of an attack hasn't gone below $40 \%$ since $9 / 11$. What's striking about this is the fact that, following the 1995 bombing in Oklahoma, this percentage was also at $42 \%$, however within just a couple of years dropped back down to the low 20 s, which had been the norm since the introduction of this question (Gallup, "Terrorism"). After 9/11 however there was no real drop and instead, as the WVS data indicates, there's actually been a steady increase in fear. 
This is despite the fact that there has actually been a decrease in the impact of terrorism in the United States (GTI 2020). The US State Department reported that, between 2001 and 2014 there were 3,412 deaths in the United States attributed to terrorism, which, while certainly still a tragedy, pales in comparison to the 440,095 deaths from firearms during that same period (Vox, 2017). This is not at all to discount these deaths or to belittle the fears people have over these acts, merely to point out that, while certainly a risk, terrorism exists as a much lower threat than many believe. There are, of course, countless explanations for this imbalance between fears and actual risk, with many pointing to the sensationalism of the media as the driving force behind this discrepancy, however this is a discussion for a later paper. For now, what's important to take away from this is the fact that fear of terrorism continues to rise while the actual risk remains relatively low, yet this fear outweighs most other concerns, resulting in acceptance of security policy even at a cost to personal freedoms.

It's also important to recognize that, while risk of terrorism is relatively low in the United States, comparatively, they are rather high on the Global Terrorism Index. The GTI uses the Global Terrorism Database to score each country on a scale from 0 to 10; where 0 represents no impact from terrorism and 10 represents the highest measurable impact of terrorism, considering economic, infrastructural, and societal effects. Unsurprisingly, Afghanistan has consistently ranked at the top of the list with a score of 9.59, followed closely by Iraq and Nigeria. The United States ranks number 29 with a score of 5.260, the highest of any western democracies (although it is closely followed by the UK with a score of 5.16). Turkey, meanwhile, with a score of 6.11 ranks number 18 , while New Zealand comes in at a surprising number 42 with a score of 4.33 (the 2019 
attacks significantly altered New Zealand's rank). The GTI also reports that 2019 was the fifth consecutive year of a decreased global impact of terrorism, so although all three cases rank relatively highly, it's important to reiterate that the threat of terrorism is decreasing. Despite this, the fact that all these states exist in the top 50 in terms of risk, accompanied by the growing fear globally, means that their respective governments have all continued to respond with security policies and counterterrorism initiatives.

These three states (and, realistically, nearly all states) have had to grapple with this growing fear and sense of insecurity, and all have responded with new laws and policies aimed at countering terrorism. These range from the extreme, such as the PATRIOT Act in the US, to the very targeted, such as the Law on Preventing Financing of Proliferation of WMDs in Turkey, to the much milder, such as the Terrorist Suppression Bill in New Zealand. There aren't any states that haven't responded to the growing real, and perceived, threats of terrorism in some form or another, yet the extent to which they respond may be key to the long-term effects of those actions. The argument here then is less that any government policy of security affects support for democratic norms, rather more that when they place it above freedoms there may be an impact on the health of the democracy. So, by these standards New Zealand exists as a sort of best-case scenario, with some protection but that which doesn't extend into infringement or restriction of rights. The US meanwhile seems to be crossing the line, so to speak, with security being placed too high above freedom and threat blown somewhat out of proportion, resulting in greater rights restriction and decreasing support for democracy. Turkey then serves as the worst-case scenario, as 20 years ago it was a democracy (albeit flawed) but harsh security policy and an intense crack-down on terrorism and suspected 
terrorist groups has led to a drastic decrease in support for norms and a complete erosion of democracy. Clearly security threats and government responses to them alone are not the only variable that matters or that may affect these changes, but it certainly has potential to be one of them. All these states have had terrorist attacks, all have responded differently, and all fall in very different places on the list of democratic strength today. These security policies aren't made in an attempt to curtail democracy or rights (usually), instead they are most often made out of a very real fear for the countries safety and often driven very strongly by popular support. The effect these policies may have on norms and values is seemingly unintended and perhaps has only become obvious in the long term but may pose a serious problem for the future of democracy.

Regression Analysis:

To further explore these results I used some simple regressions to test the relationship between various variables in order to see how (and if) they strengthened my hypothesis. Ultimately, regression analysis echoes the findings of Shin and Kim (2018), as the data strongly indicates a significant gap between the abstract and ideal and confirms the patterns that were emerging in the above section. The security indicators tested all have very high chi-squares when measured against "importance of democracy," which is further enhanced by p-values of 5.960e-17 for "freedom vs. security," $2.85 \mathrm{e}-146$ for "security in neighborhood," and 1.01e-187 for "worries of a terrorist attack." These very low p-values allow us to safely reject the null hypothesis, meaning that all these variables, when compared with the "importance of democracy" indicator, have a statistically significant relationship. 
Importantly, these significant relationships provide strong evidence for the inability or unwillingness of citizens to rectify their held ideals of democracy with the actual practice. For instance, there is very little difference between those rating freedom or security more important in relation to how crucial they view democracy, as there is roughly the same percentage of responses at each value, 1-10, of the perceived importance of democracy (see Table 2). For both choices the highest percentage of responses fall at 10 , meaning democracy is absolutely important, with $47 \%$ saying "security, and 49\% saying "freedom." This implies that citizens supporting the abstract ideal of democracy has very little weight on their support of security over freedom (and vice versa). Furthermore, this indicates that the decision to prioritize either one isn't connected to their belief in democracy's overall importance, despite the fact that the definition of democracy generally revolves around freedom. If people don't see prioritizing security as counter to their support for democracy, this could explain why they are so accepting of government policy that restricts rights. This again points towards findings of Shin and Kim that citizens can define democracy but don't recognize it in practice, and this phenomenon would explain why a clear restriction of rights isn't necessarily seen as antidemocratic by those living in the state, especially if they perceive of threat to their security to be high.

Likewise, there is very little difference in terms of either how worried people are about the threat of terrorism and how safe they feel in their neighborhood, and the importance they assign to democracy. The vast majority of responses rank 8 and above in abstract support of democracy across the spectrum of both worry over terrorism and perception of security (Table 3 and 4). Just like above, this implies that people don't 
connect how they feel about the ideal of democracy to other concepts that seem like they should change this evaluation. For instance, this explains how the average citizen in Turkey who's very worried about terrorism and believes democracy is important still overwhelmingly favors the harsh, rights restricting policies of their regime. Globally most people support the idea of democracy, whether or not they worry about terrorism and security, meaning they don't, for instance, think authoritarian regimes would be better at protecting them from terrorism or making them feel more secure in their neighborhood.

\begin{tabular}{|c|c|c|c|}
\hline \multirow[b]{2}{*}{ Importance of Democracy } & \multicolumn{3}{|c|}{$\begin{array}{l}\text { Which is More Important- Freedom or } \\
\text { Security? }\end{array}$} \\
\hline & Freedom & Security & Total \\
\hline Not at all Important & $1.67 \%$ & $1.95 \%$ & $1.87 \%$ \\
\hline 2 & $0.83 \%$ & $0.74 \%$ & $2.64 \%$ \\
\hline 3 & $1.15 \%$ & $1.14 \%$ & $3.87 \%$ \\
\hline 4 & $1.86 \%$ & $1.61 \%$ & $5.46 \%$ \\
\hline 5 & $7.50 \%$ & $6.87 \%$ & $12.51 \%$ \\
\hline 6 & $6.01 \%$ & $6.10 \%$ & $18.58 \%$ \\
\hline 7 & $8.00 \%$ & $7.96 \%$ & $26.55 \%$ \\
\hline 8 & $12.41 \%$ & $14.34 \%$ & $40.33 \%$ \\
\hline 9 & $10.70 \%$ & $11.95 \%$ & $51.92 \%$ \\
\hline Absolutely Important & $49.86 \%$ & $47.34 \%$ & $100.00 \%$ \\
\hline Total & $(19,889)$ & $(48,822)$ & $(68,711)$ \\
\hline Chi-Square: 97.1373 & P-Value: $<0.00$ & & \\
\hline
\end{tabular}

Table 2: Relationship Between Importance of Democracy and Security vs. Freedom 


\begin{tabular}{|c|c|c|c|c|c|}
\hline \multirow[b]{2}{*}{$\begin{array}{l}\text { Importance of } \\
\text { Democracy }\end{array}$} & \multicolumn{4}{|c|}{ Sense of Security in Neighborhood } & \multirow[b]{2}{*}{ Total } \\
\hline & $\begin{array}{l}\text { Very } \\
\text { Secure }\end{array}$ & $\begin{array}{l}\text { Quite } \\
\text { Secure }\end{array}$ & $\begin{array}{l}\text { Not Very } \\
\text { Secure }\end{array}$ & $\begin{array}{l}\text { Not at all } \\
\text { Secure }\end{array}$ & \\
\hline Not at all Important & $2.35 \%$ & $1.29 \%$ & $2.09 \%$ & $3.72 \%$ & $1.87 \%$ \\
\hline 2 & $0.79 \%$ & $0.66 \%$ & $0.84 \%$ & $1.28 \%$ & $2.64 \%$ \\
\hline 3 & $1.16 \%$ & $1.12 \%$ & $1.13 \%$ & $1.46 \%$ & $3.79 \%$ \\
\hline 4 & $1.47 \%$ & $1.72 \%$ & $1.96 \%$ & $1.98 \%$ & $5.50 \%$ \\
\hline 5 & $6.14 \%$ & $6.85 \%$ & $8.37 \%$ & $8.99 \%$ & $12.56 \%$ \\
\hline 6 & $4.94 \%$ & $6.46 \%$ & $6.80 \%$ & $5.27 \%$ & $18.60 \%$ \\
\hline 7 & $6.73 \%$ & $8.67 \%$ & $8.35 \%$ & $6.46 \%$ & $26.54 \%$ \\
\hline 8 & $12.14 \%$ & $15.32 \%$ & $13.45 \%$ & $9.33 \%$ & $40.28 \%$ \\
\hline 9 & $10.83 \%$ & $12.34 \%$ & $11.53 \%$ & $8.90 \%$ & $51.86 \%$ \\
\hline Absolutely Important & $53.46 \%$ & $45.57 \%$ & $45.46 \%$ & $52.59 \%$ & $100.00 \%$ \\
\hline Total & $(19,852)$ & $(31,925)$ & $(14,211)$ & $(3,280)$ & $(69,268)$ \\
\hline Chi-Square: 776.8551 & \multicolumn{2}{|c|}{ p-value: $<0.00$} & & & \\
\hline \multicolumn{5}{|c|}{ Source: World Values Survey- Wave 7 (2017-2020) } & \\
\hline
\end{tabular}

Table 3: Relationship Between Importance of Democracy and Security in Neighborhood

\begin{tabular}{|c|c|c|c|c|c|}
\hline \multirow[b]{2}{*}{ Importance of Democracy } & \multicolumn{3}{|c|}{ Worries of A Terrorist Attack } & \multirow[b]{2}{*}{$\begin{array}{l}\text { Not At } \\
\text { All }\end{array}$} & \multirow[b]{2}{*}{ Total } \\
\hline & $\begin{array}{l}\text { Very } \\
\text { Much }\end{array}$ & $\begin{array}{l}\text { A Great } \\
\text { Deal }\end{array}$ & $\begin{array}{l}\text { Not } \\
\text { Much }\end{array}$ & & \\
\hline Not at all Important & $2.28 \%$ & $1.51 \%$ & $1.33 \%$ & $2.33 \%$ & $1.90 \%$ \\
\hline 2 & $0.68 \%$ & $0.84 \%$ & $0.86 \%$ & $0.87 \%$ & $2.68 \%$ \\
\hline 3 & $1.00 \%$ & $1.31 \%$ & $1.32 \%$ & $1.21 \%$ & $3.85 \%$ \\
\hline 4 & $1.54 \%$ & $1.91 \%$ & $1.84 \%$ & $1.94 \%$ & $5.59 \%$ \\
\hline 5 & $6.76 \%$ & $7.77 \%$ & $7.08 \%$ & $7.39 \%$ & $12.75 \%$ \\
\hline 6 & $5.26 \%$ & $7.15 \%$ & $6.56 \%$ & $6.17 \%$ & $18.86 \%$ \\
\hline 7 & $6.50 \%$ & $9.17 \%$ & $9.40 \%$ & $7.93 \%$ & $26.79 \%$ \\
\hline 8 & $11.73 \%$ & $16.02 \%$ & $15.44 \%$ & $13.30 \%$ & $40.55 \%$ \\
\hline 9 & $10.62 \%$ & $12.58 \%$ & $12.90 \%$ & $10.89 \%$ & $52.16 \%$ \\
\hline Absolutely Important & $53.64 \%$ & $41.75 \%$ & $43.27 \%$ & $47.96 \%$ & $100.00 \%$ \\
\hline Total & $(29,042)$ & $(17,669)$ & $(13,346)$ & $(7,777)$ & $(67,834)$ \\
\hline Chi-Square: 973.3651 & \multicolumn{2}{|c|}{ P-Value: $<0.00$} & & & \\
\hline \multicolumn{5}{|c|}{ Source: World Values Survey- Wave 7 (2017-2020) } & \\
\hline
\end{tabular}

Table 4: Relationship Between Importance of Democracy and Worry of a Terrorist Attack 
Finally, these relationships remain significant even when controlling for a specific country, rather than looking at the dataset as a whole, providing further evidence that these variables are related within each of our three cases (See Appendix A). ${ }^{7}$

Similarly, when I take all these same variables and measure them against the perceived democraticness of the respondent's country (testing the practice rather than ideal) they remain significant. This means we can also conclude that a relationship exists between perceived democracy of one's own country and worries of a terrorist attack, security vs. freedom, or how secure they feel in their neighborhood (See Table 5, 6, and 7). Once again, the results are akin to measuring democracy in the abstract, in that there is not a huge degree of difference in percentage of respondents at each level, meaning overall citizens perceptions of how democratic their country is don't change all that much with greater fear of terrorism, more security, etc. This indicates that, again, citizens don't view increased security as opposed to their own democracy, as well as provides further evidence of their inability to connect the abstract ideal they have of democracy with the actual reality of their country.

This further goes to show the power that the abstract ideals people hold over a concept like democracy can have over a wide range of interrelated concepts, such as terrorism, civil liberties, and safety. While an expanded analysis that includes many

\footnotetext{
${ }^{7}$ The one notable exception to this is the relationship between "importance of democracy" and "worries of a terrorist attack," which becomes less significant when we isolate New Zealand. The regression when controlling for New Zealand gives us a chi2 statistic of 20.5143 and a p-value of .808, meaning we are unable to firmly state these two variables are related. When we consider how highly important new Zealanders believe democracy to be $(63 \%$ said it was "absolutely important" and $85 \%$ rated it 8 or above in the most recent WVS), and how relatively low their worry of terrorism is (only $13 \%$ are "very" worried), this is not all that surprising.
} 


\begin{tabular}{|c|c|c|c|}
\hline & \multicolumn{3}{|c|}{ Which is More Important- Freedom or Security? } \\
\hline $\begin{array}{l}\text { How Democratically is This } \\
\text { Country Being Run Today? }\end{array}$ & Freedom & Security & Total \\
\hline Not at all Democratic & $9.22 \%$ & $8.80 \%$ & $8.92 \%$ \\
\hline 2 & $3.50 \%$ & $3.22 \%$ & $12.22 \%$ \\
\hline 3 & $5.55 \%$ & $5.21 \%$ & $17.53 \%$ \\
\hline 4 & $6.99 \%$ & $6.04 \%$ & $23.85 \%$ \\
\hline 5 & $14.91 \%$ & $15.59 \%$ & $39.24 \%$ \\
\hline 6 & $11.90 \%$ & $12.48 \%$ & $51.55 \%$ \\
\hline 7 & $14.27 \%$ & $14.46 \%$ & $65.96 \%$ \\
\hline 8 & $14.34 \%$ & $14.41 \%$ & $80.35 \%$ \\
\hline 9 & $7.33 \%$ & $6.74 \%$ & $87.26 \%$ \\
\hline Completely Democratic & $12 \%$ & $13.04 \%$ & $100 \%$ \\
\hline Total & $(19,762)$ & $(48,363)$ & $(68,125)$ \\
\hline Chi-Square: 56.2553 & P-Value: $<0.00$ & & \\
\hline
\end{tabular}

Source: World Values Survey- Wave 7 (2017-2020)

Table 5: Relationship Between Perceived Democraticness of Country and Freedom vs. Security

\begin{tabular}{|c|c|c|c|c|c|}
\hline \multirow[b]{2}{*}{$\begin{array}{l}\text { How Democratically is } \\
\text { This Country Being Run } \\
\text { Today? }\end{array}$} & \multicolumn{4}{|c|}{ Sense of Security in Neighborhood } & \multirow[b]{2}{*}{ Total } \\
\hline & Very Secure & $\begin{array}{l}\text { Quite } \\
\text { Secure }\end{array}$ & $\begin{array}{l}\text { Not Very } \\
\text { Secure }\end{array}$ & $\begin{array}{l}\text { Not at all } \\
\text { Secure }\end{array}$ & \\
\hline Not at all Democratic & $7.93 \%$ & $6.53 \%$ & $11.86 \%$ & $25.15 \%$ & $8.91 \%$ \\
\hline 2 & $2.81 \%$ & $3.00 \%$ & $4.25 \%$ & $4.78 \%$ & $12.20 \%$ \\
\hline 3 & $4.34 \%$ & $5.17 \%$ & $6.63 \%$ & $6.88 \%$ & $17.52 \%$ \\
\hline 4 & $5.18 \%$ & $6.51 \%$ & $7.56 \%$ & $6.79 \%$ & $23.88 \%$ \\
\hline 5 & $14.11 \%$ & $15.45 \%$ & $17.10 \%$ & $15.64 \%$ & $39.29 \%$ \\
\hline 6 & $10.43 \%$ & $13.30 \%$ & $13.14 \%$ & $9.56 \%$ & $51.56 \%$ \\
\hline 7 & $12.80 \%$ & $16.67 \%$ & $12.95 \%$ & $8.58 \%$ & $65.97 \%$ \\
\hline 8 & $14.77 \%$ & $15.94 \%$ & $11.87 \%$ & $7.87 \%$ & $80.36 \%$ \\
\hline 9 & $8.14 \%$ & $7.24 \%$ & $5.36 \%$ & $4.20 \%$ & $87.33 \%$ \\
\hline Completely Democratic & $19.50 \%$ & $10.18 \%$ & $9.27 \%$ & $10.55 \%$ & $100.00 \%$ \\
\hline Total & $(19,565)$ & $(31,640)$ & $(14,114)$ & $(3,241)$ & $(68,651)$ \\
\hline Chi-Square: $3.3 e+03$ & $\begin{array}{l}\text { P-Value: } \\
<0.00\end{array}$ & & & & \\
\hline
\end{tabular}

Table 6: Relationship Between Perceived Democraticness of Country and Security in Neighborhood 


\begin{tabular}{|c|c|c|c|c|c|}
\hline \multirow[b]{2}{*}{$\begin{array}{l}\text { How Democratically is This } \\
\text { Country Being Run Today? }\end{array}$} & \multicolumn{3}{|c|}{ Worries of A Terrorist Attack } & \multirow[b]{2}{*}{ Not At All } & \multirow[b]{2}{*}{ Total } \\
\hline & Very Much & $\begin{array}{l}\text { A Great } \\
\text { Deal }\end{array}$ & Not Much & & \\
\hline Not at all Democratic & $11.01 \%$ & $7.05 \%$ & $6.03 \%$ & $9.23 \%$ & $8.79 \%$ \\
\hline 2 & $3.43 \%$ & $3.36 \%$ & $2.86 \%$ & $2.60 \%$ & $11.99 \%$ \\
\hline 3 & $5.08 \%$ & $5.18 \%$ & $5.50 \%$ & $5.16 \%$ & $17.19 \%$ \\
\hline 4 & $5.93 \%$ & $6.48 \%$ & $6.98 \%$ & $5.92 \%$ & $23.47 \%$ \\
\hline 5 & $15.86 \%$ & $15.49 \%$ & $14.15 \%$ & $14.47 \%$ & $38.77 \%$ \\
\hline 6 & $11.02 \%$ & $13.24 \%$ & $13.84 \%$ & $12.15 \%$ & $51.05 \%$ \\
\hline 7 & $12.41 \%$ & $16.26 \%$ & $16.95 \%$ & $14.56 \%$ & $65.61 \%$ \\
\hline 8 & $12.87 \%$ & $15.97 \%$ & $16.61 \%$ & $14.27 \%$ & $80.18 \%$ \\
\hline 9 & $6.57 \%$ & $7.32 \%$ & $7.57 \%$ & $7.42 \%$ & $87.24 \%$ \\
\hline Completely Democratic & $15.82 \%$ & $9.65 \%$ & $9.51 \%$ & $13.95 \%$ & $100.00 \%$ \\
\hline Total & $(28,805)$ & $(17,547)$ & $(13,290)$ & $(7,735)$ & $(67,377)$ \\
\hline Chi-Square: $1.3 e+03$ & $\begin{array}{l}\text { P-Value: } \\
<0.00\end{array}$ & & & & \\
\hline
\end{tabular}

Table 7: Relationship Between Perceived Democraticness of Country and Worry of a Terrorist Attack

more countries would be necessary to conclusively make any claims on this preliminary exploration of survey data, it does add further strength to our understanding of the importance and power of citizen evaluations of norms and values. The major finding gained from this analysis served to corroborate the findings of Shin and Kim (2018) in revealing that there is a significant gap between the abstract and reality, and that citizens aren't always able to connect concepts that realistically should be connected. This is incredibly important for this thesis, because it helps explain why citizens are so ready to accept rights restricting security policies, even when this prioritization of security may harm freedoms. Further, this evidence implies that citizens willing accept this trade off 
not only because they feel unsafe or perceive the threat level to be high, but also because they are unable to comprehend what this balance actually means for their regime. This disconnect between what democracy looks like in reality and the abstract is very worrying if it means people don't recognize the weakening of democratic norms that are fundamental to their regime's long-term survival. This dangerous behavior results in citizens not seeing an increase in security policy as counter to democracy, in either an abstract or practical sense, despite evidence that expanding security the way we as a global society have been is balanced out by a decrease in freedoms. The problem is not that citizens don't support democracy or think a different style of regime would provide them more safety, it's that they can't connect an increased sense of security with greater restriction of fundamental rights. Or, even more worryingly, perhaps they simply don't care. 


\section{CHAPTER VI}

\section{Discussion}

As previous authors have noted, survey data on public support for democracy reveals a murky, contradictory reality that changes based on the specific state and time period studied. However, I believe some real trends have emerged in recent years, indicating that the long-term effects of changing public opinion data perhaps were not yet as visible in 2015-16 when most of these prior studies were conducted. In the conclusion of their analysis Thomassen and van Ham stated that, even though they had seen a decrease in some key indicators, "decline is certainly not long-term, but rather trends of political support at these levels seem to follow patterns of fluctuation," ultimately blaming the global economic crisis for any observed changes (Thomassen and van Ham 2017, 31). However, in my analysis, using the same five-fold classification and indicators as they did, I saw significantly more decline than their research had revealed just five years earlier. As a reminder, the framework used to measure political support, and thereby the political legitimacy of a regime, includes measures for the political community, regime principles, regime performance, regime institutions, and political authorities. If all these indicators measure highly then a regime has considerable public political support and is thus viewed as legitimate by its citizens, while if they all measure poorly the opposite is true.

In applying this framework to my three cases some clear patterns began to emerge, indicating something more than normal fluctuation in the data. Granted, there was still some variation, particularly in the case of Turkey, but ultimately, there was observable steady decline in the United States and steady increase in New Zealand, which 
is a point of departure from these earlier studies. In measuring support for the political community I looked at national pride, which, although high in all three states, is visibly decreasing in both Turkey and the US, while remaining steady in New Zealand. In particular, the percentage of respondents "very proud" in the United States has dropped below $50 \%$ for the first time since this question was asked in 1981, showing clear signs of a steady downward trend. Likewise, and perhaps even more worryingly, support for regime principles (measured by "importance of democracy") is steadily decreasing in Turkey, gradually decreasing in the US, and just slightly increasing in New Zealand. Most concerning about this indicator is that, when viewed for all states included in the WVS, there is a consistent pattern of decline in over one-third of them, with significantly fewer citizens responding that democracy is "absolutely important." This runs contrary to many earlier studies that found the ideal of democracy to receive very high support globally, even if democracy in practice was favoring poorly, indicating that even democracy in the abstract is starting to decline. Again, when exploring regime performance (measured by "democraticness of own country"), New Zealand saw a slight increase, while the United States saw a steady decrease and Turkey remined somewhat steady around $30 \%$.

The measures of confidence, both of institutions and authorities, are a little less clear. In measuring institutional confidence I looked at both parliament and parties, and while support for parties shows some more obvious patterns, support for parliament fluctuates a bit more. Also, somewhat surprisingly, the trend for parties in Turkey goes opposite of what I expected, and support has actually been increasing, by even greater rates than in New Zealand. Support for parliament meanwhile fluctuates somewhat 
randomly in both the US and Turkey, while it steadily increases in New Zealand. If we look at those responding that they have "no trust at all" rather than those with "a great deal" and "quite a lot," there is a bit more of a trend to be found. On both indicators' citizens with no confidence at all is steadily decreasing in Turkey and steadily increasing in the United States, presenting us with yet another question. Finally, in terms of confidence in government we can similarly observe a significant increase in Turkey and New Zealand and a steady decrease in the United States. Taken altogether then, it seems very clear that public support across all measures of our framework is decreasing in the United States, indicating that democratic legitimacy is also in danger. Contrary to this, public support across all measures is increasing in New Zealand, revealing that they have a robust democracy with ever growing legitimacy. The real puzzle then is Turkey, that has both significant decreases (on political community and regime principles) and significant increases (on regime institutions and political authorities), indicating strong public support on some levels, and weak on other, leaving the question of legitimacy murky.

The fact that Turkey shows positive trends on a number of indicators seems to point towards the fact that they are not facing a legitimacy crisis, as public support remains high. However, when we consider this in light of the fact that, ten years ago, they were the model democracy of the region and now they are nearly a textbook autocracy, and yet people remain supportive of the regime, it raises some questions. Despite the gradual (and then not-so-gradual) and often very public destruction of democracy and democratic norms, these indicators imply that the overall legitimacy of the government remains intact, and is actually increasing, confusingly even while $60 \%$ of the population 
claims democracy is "absolutely important." Similarly, over $28 \%$ of the population is "completely satisfied" with the current regime (more than twice the number in the US), which serves as yet another contradiction to the supposed importance of democracy in the abstract. As many parts of this analysis have revealed, there is significant disconnect between democracy in the abstract and in practice in Turkey, with other concerns taking precedence over civil liberties when it really comes down to it. And, as Inglehart noted, just because public support exists doesn't mean democracy is healthy. All evidence in Turkey points to the fact that security and the economy are the highest priorities for most citizens and, as these were both maintained, and even improved upon, during Turkey's transition back to authoritarianism, the overall legitimacy of the regime didn't suffer much. Both physical and economic security have always been a top concern for Turkish citizens and thus even if rights are restricted this ultimately isn't as important a consideration to them if their primary goal has been accomplished. Therefore, the longterm constant prioritization of security has allowed support for democratic norms to gradually weaken as Turks remain willing to accept this tradeoff and, in turn, the importance of these values decreases.

While this would be worrying enough if Turkey were unique in this regard, it seems citizens in many other states have developed a very similar list of priorities. Recall here the findings from Shin and Kim's (2018) analysis of the Asia and Arab Barometers, wherein they examined responses to the close-ended question of which was the most important feature for democracy: elections, civil liberties/freedoms, economic equality, or economic security. They found that in both the Arab and Asian Barometers, respondents placed freedom as the least important, with economic concerns mattering nearly twice as 
much in both cases (Shin and Kim 2018). Unfortunately, this question didn't include physical security concerns as one of the features, however evidence from the WVS questions on security and fear indicate that this too is an important concern to most citizens. The point here is that, although global citizens all say democracy is important, when it comes down to actually ranking features that are considered essential to a regime, freedoms often fall in last place, with citizens willing to compromise on restricting these rights if it's accompanied by a promise of greater security.

It doesn't matter if citizens can define democracy if they aren't able to recognize or understand it in practice, and if they prioritize security and economic concerns first and foremost it's no wonder they support a government that does the same. Even while saying democracy is the best regime and supporting the democratic ideals behind it, in practice it seems most citizens are very willing to give up rights under certain conditions. This then indicates that it isn't apathy or alienation that has turned citizens away from supporting fundamental norms, but rather a willing acceptance. In other words, in most cases it seems citizens aren't frustrated or annoyed with a restriction on rights, but instead accept this as the best way to be provided the security they crave. And while we can see performance ratings decreasing in a number of states, WVS data indicates this has little to do with the status of civil liberties and much more to do with the values citizens more highly prioritize- security, the economy, rule of law, and government accountability (Ferrín and Kriesi 2016). Citizens remain highly critical of their own regimes, particularly those living in the strongest democracies, and yet they seem critical often of the wrong aspects of these regimes, focusing on worries of corruption and safety over the loss of fundamental civil liberties. This analysis has made it very clear that the way 
citizens understand, define, support, and recognize concepts like democracy, freedom and even terrorism, differs greatly in practice and in the abstract, creating an ever growing "democratic paradox." More worryingly, the data observed here indicates that this growing gap between norms and practice has helped encourage the spillover Weßels warned of, presenting us with a potentially serious problem if true.

Dahl and his democratic paradox, Norris and her democratic deficit, Ferrín and Kriesi and their recognition of a significant discrepancy between abstract and ideal, all share the similar conclusion that this is noteworthy, but not ultimately a threat to legitimacy. Some, like Weßels, note that this may become a problem in the future if a "spillover" occurs, however most of these earlier studies are more in line with Thomassen and van Ham's conclusion that the "crisis myth" has been greatly exaggerated and there is no clear evidence that democracy is truly in any danger. While these are all very strong, well supported arguments, it seems that the state of public support may have begun to shift since they were published, perhaps providing evidence that the fears of Weßels are coming true. I certainly still saw a bit of fluctuation in the WVS data observed in this analysis, particularly with the case of Turkey and their evaluation of democracy, and in the United States with some of their confidence indicators, however, it wasn't anywhere near as prevalent as when the same data was observed by Thomassen and van Ham and Ferrín and Kriesi just five years prior. Instead, there were much clearer trends visible of a general decline in democratic support in the United States and an increase in New Zealand, while Turkey provides some interesting puzzles for further analysis. While the various fluctuations in this data prevent me from drawing a strict conclusion on democratic decline, the emerging trends seem to indicate a general shift in 
the strength of democracy globally. As noted by Ferrín and Kriesi, part of the reason they couldn't conclude there was global democratic decline was that democratic strength varied somewhat by region and by state, which is exactly what I found. However, I wanted to take it further and examine a possible cause for this variation that might explain why only some states were seeing significant decline in recent years, and that is where the debate between security and freedom comes into play.

It's clear from the WVS data that democracy is fairing very differently in different states, but with somewhat consistent trends either of decline or growth- what could account for this discrepancy? Recognizing that there are likely multiple forces at work, I set out to explore a particularly tricky one that threatens all states, and thus they've all had to address in some way or another with policy changes. With globalization, rising nationalism, and the rising confidence of radical religious groups, the past few decades have seen international terrorism become a globally shared threat and a growing fear for most citizens. Despite the fact that terrorist acts have actually decreased since a peak in 2014/5 when ISIL was at their strongest, fear remains persistently high, further encouraged by heavy media coverage of any event that could be connected to terrorism. The attacks on 9/11 introduced a new era of fear, as they illustrated that no one, not even the strongest, most influential countries, were safe, and made terrorism an international issue, rather than something that only happened in impoverished or war-torn states abroad. Furthermore, the September $11^{\text {th }}$ attacks were the deadliest in human history and thus this devastation justifiably changed the way we understood and combatted the terrorist threat. 
This is made abundantly clear in the WVS analysis of terrorism and security issues discussed in the above section. Of the 49 states asked to choose between freedom and security, only three responded that freedom was more important, and two of them very narrowly (Australia and New Zealand). This is despite the fact that over half those included were states that are generally defined as either a "democracy" or a "flawed democracy" and the recognized fact that one of these principles most often comes at the cost of the other. There were numerous studies done immediately following $9 / 11$ that found Americans to be very willing to give up some civil liberties if it came with a promise of safety, and it seems this general "rally round the flag" sentiment has persisted long after that attack and is reflected in many other states besides. All three cases in my study have seen devastating terrorist attacks, and all are ranked in the top 50 of the Global Terrorism Index, and while a state like Turkey faces more consistent and everpresent risk than the other two, they've all had to deal with this trade-off, and all have done so differently.

In New Zealand, the government enacted new terrorism policy after 9/11, and then expanded it further after the 2019 Christchurch attacks, however they always maintained civil liberties as a top priority. In Turkey meanwhile the government cracked down harshly on most fundamental democratic freedoms in an effort to prevent further terror attacks, and eventually began using these restrictions as a targeted political tool. In the United State the government initially reacted to 9/11 with very intense anti-terrorism policy, which has since been softened somewhat, but still is too extreme and broad for the threat actually faced by the country. This is perhaps one of the biggest differences between these various state's terrorism policies: the scope and intended target. In both 
Turkey and the US the scope is broad and at times vaguely defined, so the laws can be stretched to cover a wide range of situations and individuals. They also have been used in a very individually targeted way, as anti-Kurdish policy in Turkey and anti-Muslim policy in the US (even though neither government would admit to this). Meanwhile in New Zealand, even in the wake of devastation following the Christchurch attack, the government responded very carefully, and rather than enacting broad sweeping terrorism reform, specifically targeted the weapon used. This allowed them to provide safety to their citizens without targeting a group of specific people and maintaining the freedoms the citizens enjoyed (although there was some minor protest by gun "rights" groups).

When it comes down to practice, people will nearly always prioritize safety over freedoms. At this fundamental level it's purely biology that makes us put survival and self-preservation first and foremost; the worry is how this may affect democracy in the long-term. If fear of terrorism isn't decreasing and citizens remain accepting of this compromise to their civil liberties, how does this change the way they view and support democracy over time? The analysis done here indicates that support for democratic norms is decreasing in states where security has been consistently prioritized, so much so that in states that have fully committed to security over freedoms, such as Turkey, support has started to increase again, despite the fact that the regime is no longer democratic at all. In this instance it seems the state has prioritized security so strongly, for so long, that the people, even while saying they believe democracy is the best regime and further, that they themselves have a strong democracy, no longer really support fundamental democratic values. This is clear in the rising support for an unaccountable leader and the steady decrease in their belief free elections are important, civil liberties protect them, 
and that women and men should have the same rights, as well as in the overall decline in the "importance of democracy" in the past 3 waves of the WVS. This also serves as further evidence that citizens decreasing support for democratic values isn't done out of apathy or frustration with the system, but rather it is a very willing and conscious choice made for the sake of security (or at least the perception of it).

Worryingly, a similar trend may be beginning to occur in the United States, as indicated by the steadily declining support for a wide range of democratic norms. As the available evidence makes clear, fear of terrorism remains very high in the United States, and has since the devastation of $9 / 11$, even while the actual threat of terrorism has decreased. During this same time period belief in the importance of democracy has also been gradually declining, accompanied by an even faster decline in the perceived democraticness of the United States by American citizens. Simultaneously feelings of national pride and confidence in both institutions and in the government have been decreasing, indicating that, when taken all together, the democratic legitimacy of the US is in danger. The regime doesn't have the full support of the citizens and the longer this persists the more of a danger to democratic survival it will be. Furthermore, the negative performance ratings of the government and institutions has indeed begun to spillover onto the way citizens evaluate fundamental norms, as most obviously observed in the decline in people answering that democracy is "absolutely essential." This is also apparent in the rising support for an unaccountable leader (38\% believe this to be "good" or "very good," whereas $24 \%$ believed this in 1998), which runs counter to a number of democratic values. Likewise, there has been a slight decline in belief that civil rights protect people from repression, with $57 \%$ now stating this is "absolutely essential," down from $62 \%$ in 
2009. Fortunately, on a number of other indicators- both free and fair elections and the belief that men and women are equal- response have remained steadily at $70 \%$ saying this is "essential" over the past three waves. This seems to indicate that, although a spillover onto norms has been realized, it hasn't yet reached every corner of democratic norms, as some values still remain supported, even as others are steadily declining. While this is certainly a positive, it does add a sense of urgency to "solving" this spillover before it sinks deeper into society and moves the United States further into hybridity.

Previous studies were indeed correct that democratic decline isn't a universally occurring phenomenon (yet), however it does seem to follow specific trends of increase and decrease depending on the state and their specific circumstance and, as this study indicates, their policy prioritization. In the aftermath of 9/11 the world reevaluated their approach to international terrorism and, with levels of fear drastically heightened across all sectors of society, began to more highly prioritize security over civil liberties. Terrorism is of course a very real threat and has affected all three of these states in devastating ways which is not a fact I'm trying to counter. Instead, I want to make clear that this changing environment, both literally and in citizens perceptions, may explain why people are open to rights being restricted. The degree to which this occurs then may in turn help explain why democracy is decreasing on a global scale. People are clearly scared, and increasingly growing more so in spite of evidence that the actual threat of terrorism has decreased, and thus put their security interests above freedom. The government in turn responds to citizen desire for safety and, due to the heightened perception of threat, even if they cross the line in restricting rights (whether intentional or unintentional), there will be little protest. The greatest danger here is the extent or degree 
to which governments choose to prioritize security seems to then have long-term effects on the strength of democratic norms as, over time, people accept that these rights are unnecessary or unimportant, particularly if they perceive their safety to be at risk. Furthermore, the above analysis also makes clear that, in general, people don't see this prioritization as in any way counter to their support of democracy and thus can justify this trade-off without compromising their belief in democracy's importance. It's not that citizens no longer view democracy as "the only game in town," it's that they have lost an ability to even explain what the rules of the game are. Over time it seems this has eroded support for fundamental democratic values in states that have more heavily placed security first and where the sense of threat is high, resulting in a gradual decline of democratic legitimacy and an increased support for autocracy in practice. 


\section{CHAPTER VII}

Conclusion

Taken as a whole this analysis makes several things clear. First, there is a growing gap between reality and ideal in citizens perception of democracy as a concept, as well as within a number of specific democratic norms. Secondly, both performance ratings and evaluations of democracy's overall importance are declining in many states, but not in all of them and not in all of them equally. In particular this analysis reveals that the United States is decreasing on nearly every indicator of democracy, while New Zealand is increasing and Turkey presents more of an enigma, with some decreases and some increases. More specifically, support for democratic norms such as free and fair elections and civil liberties is decreasing in Turkey, as is the overall importance of democracy (although it still remains relatively high), while confidence in institutions and satisfaction with the regime itself increase. Ultimately this data thus reveals three important relationships:

1. Support for all measures of democracy are decreasing in Turkey and support for the current (authoritarian) regime is increasing

2. Support for all measures of democracy are increasing in New Zealand and support for the current (democratic) regime is increasing

3. Support for all measures of democracy are slowly decreasing in the US and support for the current (democratic) regime is decreasing

What could explain this? How has the world changed in the past two decades that could be encouraging these trends? While certainly many factors are involved in this pattern, this analysis explored if the ongoing debate between security and freedom plays a 
role, particularly when it comes to prioritizing one at the expense of the other. If so, this could account for some of the variation by country and region that previous authors noted, as different states found a different balance of priorities. Furthermore, the growing gap between reality and ideal in citizens perception (the "democratic paradox") could then help explain why citizens may be accepting of rights restricting policy if they don't see it as opposed to their democratic ideal.

The evidence indicates that, rather than a global decline, we see some democracies weakening while others are strengthening, with enough regimes' fitting either condition that it is ill advised to overlook or to explain away by claiming it is "normal fluctuation" in the data. While not all democracies are declining, there is a very serious trend of decreasing support for the abstract ideal of democracy that could have much greater implications in the future. Furthermore, the growing gap between reality and democracy in the ideal is worrying. This discrepancy indicates that citizens have a picture or understanding of what democracy is that does not match the regime they have (or wish to have), and the more this grows the greater the impact on decreasing performance evaluations will be. As evaluations of regime performance continue to decline this begins to affect support for fundamental democratic norms as they too begin to lose support. This trend is then further exacerbated by the security environment and ever-present sense of threat felt by the majority of citizens that encourages a prioritization of security policy at the expense of civil liberties. Altogether this means that fundamental norms that provide a foundation to democracy are losing support both because citizens no longer view them as important and because they no longer support the regime that these values have built. 
The data examined reveals that fear of terrorism is very high and increasing in Turkey and this has led the government to aggressively prioritize security policy over freedoms. Meanwhile, fear of terrorism is lower in New Zealand and relatively stable, and the government has taken great effort to respond by strictly maintaining freedoms as a top priority and safety as a distant second. Finally, fear of terrorism is high, overexaggerated, and increasing in the United States and the government has, at least in the abstract, tried to balance security and freedom, but in practice leans much more heavily towards security. Connecting these facts together makes it therefore clear that this government decision of either freedom or security prioritization has had long term effects on citizen support for fundamental norms, both positive and negative. Thus, we see a state that aggressively pursued security and restricted civil rights experience a drastic decrease in support for democratic norms, to the extent that it no longer even qualifies as a democracy. Conversely, a state that carefully ensured freedoms were always a top priority has experienced an increase in support for democratic norms and now exists as one of the strongest and most stable democracies. Finally, we have a state that initially strongly prioritized security but then rolled it back some now experiencing a gradual decrease in support for some democratic norms (notably not all of them) and now exists as a flawed democracy, or potentially even a hybrid regime. We can safely conclude from this that, in terms of policy prioritization and democratic strength, Turkey exists as the worst-case scenario, New Zealand as the best, and the United States as risky mid-level scenario.

One of the most interesting surprises in the data was the fact that Turks have high degrees of confidence in their nondemocratic, increasingly corrupt system, even while 
they also say that democracy is important. It's true the percentage of respondents saying democracy is important has been steadily decreasing in Turkey, however it is still over $50 \%$ and more Turks think they live in a democracy than Americans do. It seems the state has prioritized security for so long that the people, even while claiming they believe democracy is the best regime and that they themselves have a strong democracy, no longer actually support fundamental democratic norms. While this is further powerful evidence of the disconnect between reality and ideals, it also reveals that legitimacy remains relatively high in Turkey despite the regime's transition away from democracy. This implies that, in the grand scheme of things, the restriction of rights is not as important in performance and confidence assessments as security, and thus doesn't play as much of a role in how citizens evaluate their own government and regime. This is crucial because it indicates that citizens are accepting of freedoms being restricted and, as a similar trend is visible in a number of states, provides evidence that citizens are perfectly willing to turn away from supporting democratic norms under the right conditions.

This idea has some very serious implications when thinking about policy making and how easily public opinion can be altered. No matter how important citizens say democracy is to them, this analysis reveals that they will very willingly turn away from these norms if they perceive it to be in their best interest to do so. The idea that citizens have an internalized list of priorities that rarely actually puts the democratic norms they claim to be crucial first is a troubling one indeed. Security and safety will always be a top priority for citizens, and thus, to an extent, any policy or act that claims to provide this is likely to be accepted, especially if introduced into an environment of fear, such as 
following a terrorist act or some other sort of crisis. While the implications of this are bad enough, particularly if this knowledge is used with ill will by political elites, even more worrying are the unintentional long-term effects. It seems that the longer and more aggressively a state prioritizes security, the greater the effect on democratic norms as citizens lose all support for these values, ultimately putting the democracy itself at risk. This is not to claim that these policy choices alone are what caused the failure of the Turkish democratic project, or other failed and flawed democracies like it, for obviously many factors are at play in these scenarios. What's most worrying about this prioritization however is the way that it makes these fundamental norms seem unimportant, or even dangerous for a state to have, thereby deeply impacting how citizens view and understand democracy in the long run.

This also makes it clear that the states we need to worry about are the "mid-level" scenario ones that fall somewhere in the middle of the balance and are the most at risk for experiencing further decline. States that have tried to balance this trade off in a middle gray area could too easily tip either way on the scale under the right conditions, leaving the state in a murky identity crisis of sorts as legitimacy straddles a very fine line. The US is of course a perfect example of this, as over time we have drifted further from a strong democracy and deeper into hybridity. As this analysis made clear, enough values are still supported in the United States that we aren't in immediate danger of legitimacy crisis, but there are some very worrying trends to look out for, particularly in terms of confidence in institutions. Furthermore, and very worryingly, the overexaggerated fear and sense of threat Americans feel make it far too easy for further rights restricting policy to be passed and accepted by the public. The US is somewhat unique in this regard, due particularly to 
the sensationalism of our news media, however a number of other states that have struggled with this balance may also be at risk of falling deeper into hybridity, as indicated by decreasing scores on the WVS indicator of democratic importance and dropping Freedom House scores. In particular, a number of Eastern European states (Poland, Bulgaria, Hungary) and Mediterranean states (Greece, Italy) have been seeing consistent decreases in recent years which could perhaps partly be explained by their struggle to balance security and freedom in regions facing various security threats. Further research into these states and the values they have prioritized would be fascinating and could provide even stronger evidence to support my argument. Meanwhile, states such as New Zealand and the Nordic states that have consistently and passionately prioritized freedom above all else exist as the best-case scenario in terms of democratic strength today. Even when faced with a serious security threat New Zealand maintained it's previous prioritization and only enacted new policy that very specifically targeted the weapons and hate speech used and avoided ever making it about "us vs. them." Even more interestingly, in terms of citizen perceptions of safety, New Zealand's approach seems to have been more successful when looking strictly at the numbers. In reflecting on feelings of security in their neighborhood, New Zealander's perception of safety has increased, in spite of the 2019 terrorist attack, while both Turks and Americans feelings of neighborhood security decreased by over $50 \%$ between the past two waves of the WVS. Like every other country asked the question in the WVS, New Zealand recorded an increase in the "fear of a terrorist attack" indicator over the past few waves, however the total responses for those either "very much" or "a 
great deal" afraid is still only around $30 \%$, while it is over $60 \%$ in the US, and over $90 \%$ in Turkey.

People everywhere are worried about terrorism, but even more so in the countries with harsher security policy, perhaps indicating that Cole and Dempsey's (2014) conclusion that security vs. freedom is a "false trade-off" may have some weight to it. They note that it's often unquestionably accepted that the threat of terrorism requires that we "alter the constitutional balance" that "antiterrorism measures infringing civil liberties will work," but that in reality there is little evidence to support this (Cole and Dempsey 2014, 240). Instead, many of these counterterrorism measures (in particular they discuss the Patriot Act) actually end up being counterproductive and doing much more harm than good because curtailing civil liberties doesn't necessarily enhance security. This is troubling, for whenever civil liberties groups raise concerns over provisions of security policy, it is most often justified by supporters saying some compromise is necessary in order for the state to be safe. However, if this is indeed a false trade-off, states are unnecessarily giving up freedoms they could have maintained, meaning much of the democratic decline attributed to this could have been avoided. Future research into how effective security policy such as the Patriot Act actually are in the long-term would be necessary to fully make this claim, however it remains a very interesting, and worrying, line of reasoning. It seems, either knowingly or subconsciously, the New Zealand government understood this, refusing to compromise on freedoms to provide safety, whereas governments in the US and Turkey were willing and even happy to do so.

The balance between security and freedom is not an easy one (and as Cole and Dempsey argue, it shouldn't have to be a balance at all) and these governments aren't 
entirely to blame for the long-term effects this decision had. As this analysis makes clear, in many instance citizens were happy to have rights restricted if it came with a promise of security, and thus human survival nature is just as much at fault as governmental policy makers. Further, the goal of this analysis is not to point the blame at anyone, but rather to explore what may account for the fluctuation and variation in support for democratic norms and, in turn, for the decline in democracy we can observe in select regions and states. It's also important to note that the argument here isn't that these security policy choices are "bad" or "good," rather they have had potentially unintended consequences on the overall health of democracy. Turkey has a serious problem with terrorism, there is no denying that, and they obviously have to take some sort of action against this with greater security policies. So, they haven’t necessarily made a mistake in doing so, however these choices may have had much more serious consequences in terms of support for democracy in the country. Likewise, the attacks on $9 / 11$ in the US were a national tragedy and there was huge support and push for the government to act against terrorism, so they weren't mistaken in trying to do something, but the reach of the Patriot Act went too far.

Responses to terrorism should be made in proportion to the risk the state faces, but also with a clear understanding that harsher security policy may go hand in hand with greater restrictions on civil liberties. New Zealand, like the rest of the world, responded to 9/11, and later the Christchurch attacks in their own country, with new and updated security policy, but they were very careful to keep from going overboard and maintained their prioritization of civil liberties throughout the legislation process. Meanwhile, the United States clearly overstepped, as indicated by the many attempts and successes to roll 
back the reach of PATRIOT in the following years, even though an amended form of the bill continues to exist. Likewise, Turkey, while certainly a high-risk state, fully committed to security over all else, and has even taken advantage of this risk, to make policy that sharply restricts rights and very specifically targets Kurdish citizens in response to PKK affiliated attacks.

When a government makes the choice to prioritize security, it's unlikely they do it knowing how support for fundamental democratic norms will change. In most instances this seems to be an unintended consequence of the fear and tension in society and an opportunity, or even need, for the government to pass stronger policy. There are of course situations like Turkey, wherein Erdoğan took advantage of the fear in society to further consolidate power around himself, but even then, it seems unlikely that his ultimate goal was to make Turkish citizens no longer even believe that these fundamental democratic norms were important. These findings are critical, for they show how easily public support can change over time within certain environments and how detrimental security prioritization is for the survival of democracy. If security policy and humankinds' inherent need for safety is inadvertently weakening democracy, it is an understatement to say we have a major problem on our hands. Although the global threat of terrorism has decreased since 2015/16 and the peak of ISIL's power, there's no knowing what we may face next. The world is a rapidly changing place, and new threats emerge every day that require governments to make a decision on priority. For instance, a particularly apt example is the coronavirus pandemic that we're only now starting to see the end of. In early 2020, as the world began to realize how serious this threat was, governments in every type of regime began to take away freedoms and suspend certain civil liberties in 
an effort to provide safety to their people. Freedom of movement and assembly were lost, states of emergency were imposed, elections were cancelled or postponed, educational and cultural establishments were closed, and public protests were prohibited, altogether creating what sounds like a very dystopian reality. This is in no way to argue these weren't right or necessary measures to take, or that they weren't met by protest from certain sectors of the population, just to point out that, in general, these harsh, rights restricting measures were willingly accepted by the public. It may seem odd to compare a global pandemic to the threat of terrorism, but I think both illustrate the point that citizens are going to put safety first, even if it comes at the expense of democratic norms. Now the policies enacted in response to the pandemic are, of course, temporary, and thus most likely won't have long-term effects on support for these values, but it would certainly be interesting to come back to this idea in a few years' time to fully examine what effect these pandemic measures have had.

Future research needs to focus on how public opinion changes over time, rather than looking at the immediate effect of a crisis or political event. The idea that a policy enacted 20 years ago can still have a role to play in how citizens understand what values are important in a democracy is a critical takeaway from this thesis. This theory has many potential applications in the field of political science, and I think a much larger study that focuses on more states and perhaps even more types of policy could strengthen these findings and introduce even more avenues for research. Public opinion is clearly a crucial component of democratic strength and can't be overlooked or just assumed in future studies. It plays a real role in legitimacy and in the long-term survival of democracy and we must understand this and take it into consideration when questioning 
why some democracies are surviving while so many others fail. Further, prioritizing security policy is clearly harmful to democracy, not only in that it comes at the cost of certain freedoms, but also in how it fundamentally affects how citizens understand these norms, increasing the risk of long-term damage. Especially if one follows Cole and Dempsey's line of reasoning, many of these harsh security policies are ultimately unnecessary and do more harm than good and thus we must recognize this risk before implementing ever increasing security measures.

Governments can't stop people from being afraid of terrorism, but they can do more to accurately convey the true level of threat a country faces and take more specific action against it, such as New Zealand and Australia have done with firearms. Furthermore, the media plays a significant role in sensationalizing terrorist acts and encouraging the spread of fear and, while any sort of media control is a gargantuan, if not impossible, task (not to mention potentially un-democratic), we must be better at recognizing fact and fiction. Future terrorism policy needs to be more carefully drafted in proportion to the threat the country actually faces and with consideration of what governments are asking citizens to give up in exchange for a perception of security, as well as a recognition of what the long-term consequences may be. Citizens themselves also need to be aware that this tradeoff exists and what the cost of the security they are demanding truly is. Of course, these are easy said than done, and in many countries the wounds run deep and will require a great deal of healing to strengthen support for democracy, however recognizing these facts is the first step to a cure. Global democracy as a whole is not yet at risk, but, in specific states that have made specific policy choices 
the threat is much more salient, particularly in the long-term. State security is key to state survival, but it shouldn't have to come at the expense of freedom. 
References

“2020 State of World Liberty Index.” n.d. J. Patrick Rhamey Jr. Accessed March 14, 2021. https://patrickrhamey.com/saturday-research/2020/4/21/2020-state-of-worldliberty-index.

"A Breakdown of the Patriot Act, Freedom Act, and FISA." 2018. Comparitech (blog). February 2, 2018. https://www.comparitech.com/it/blog/vpn-privacy/a-breakdownof-the-patriot-act-freedom-act-and-fisa/.

Ágh, Attila. 2016. "The Decline of Democracy in East-Central Europe: Hungary as the Worst-Case Scenario.” Problems of Post-Communism 63 (5-6): 277-87. https://doi.org/10.1080/10758216.2015.1113383.

Ahonen, Pertti. 2016. "A Weberian Study of Small, Prosperous Democracies: Comparing New Zealand and Finland.” SAGE Open 6 (4): 2158244016680685. https://doi.org/10.1177/2158244016680685.

Applebaum, Anne. 2020. Twilight of Democracy: The Seductive Lure of Authoritarianism. First edition. New York: Doubleday.

Baker, Nancy V. 2003. "National Security versus Civil Liberties.” Presidential Studies Quarterly 33 (3): 547-67. https://doi.org/10.1111/1741-5705.00006.

Battersby, John. 2018. “Terrorism Where Terror Is Not: Australian and New Zealand Terrorism Compared." Studies in Conflict \& Terrorism 41 (1): 59-76. https://doi.org/10.1080/1057610X.2017.1287501.

BBC News. 2019. "Christchurch Shootings: Why Turkey's Erdogan Uses Attack Video," March 20, 2019, sec. Europe. https://www.bbc.com/news/world-europe-47638936.

BBC News. 2020. “New Zealand Election: Jacinda Ardern's Labour Party Scores Landslide Win," October 17, 2020, sec. Asia. https://www.bbc.com/news/worldasia-54519628.

BBC News. 2021. "Turkey Moves to Ban Pro-Kurdish HDP Opposition Party," March 17, 2021, sec. Europe. https://www.bbc.com/news/world-europe-56438070.

Bergen, Peter. 2003. "September 11 Attacks | History, Summary, Timeline, Casualties, \& Facts | Britannica.” Encyclopedia Britannica. March 13, 2003. https://www.britannica.com/event/September-11-attacks.

Carlin, Ryan E., Gregory J. Love, and Elizabeth J. Zechmeister. 2014. "Natural Disaster and Democratic Legitimacy: The Public Opinion Consequences of Chile's 2010 Earthquake and Tsunami." Political Research Quarterly 67 (1): 3-15. https://doi.org/10.1177/1065912913495592. 
Çelik, Burçe. 2020. "Turkey’s Communicative Authoritarianism." Global Media and Communication 16 (1): 102-20. https://doi.org/10.1177/1742766519899123.

Claassen, Christopher. 2020. “Does Public Support Help Democracy Survive?” American Journal of Political Science 64 (1): 118-34. https://doi.org/10.1111/ajps.12452.

Clucas, Richard A and Melody Valdini. 2014. The Character of Democracy: How Institutions Shape Politics. New York: Oxford University Press.

Coaston, Jane. 2019. “The New Zealand Shooter's Manifesto Shows How White Nationalist Rhetoric Spreads." Vox. March 15, 2019. https://www.vox.com/identities/2019/3/15/18267163/new-zealand-shootingchristchurch-white-nationalism-racism-language.

Cole, David, and James X. Dempsey. 2006. Terrorism and the Constitution: Sacrificing Civil Liberties in the Name of National Security. 3rd ed. New York: New Press.

Dahl, Robert A. 2000. “A Democratic Paradox?” Political Science Quarterly 115 (1): 35-40. https://doi.org/10.2307/2658032.

Davis, Darren W., and Brian D. Silver. 2004. "Civil Liberties vs. Security: Public Opinion in the Context of the Terrorist Attacks on America." American Journal of Political Science 48 (1): 28-46. https://doi.org/10.2307/1519895.

Diamond, Larry, Marc F. Plattner, and Condoleezza Rice. 2015. Democracy in Decline? Baltimore: Johns Hopkins University Press. https://doi.org/10.1353/book.40891.

Diamond, Larry, Marc F. Plattner, and Christopher Walker. 2016. Authoritarianism Goes Global: The Challenge to Democracy. Baltimore: Johns Hopkins University Press. https://doi.org/10.1353/book.47469.

Dimock, Michael, and Richard Wike. 2020. "America Is Exceptional in the Nature of Its Political Divide." Pew Research Center (blog). November 13, 2020. https://www.pewresearch.org/fact-tank/2020/11/13/america-is-exceptional-in-thenature-of-its-political-divide/.

Douglas, Roger. 2014. Law, Liberty, and the Pursuit of Terrorism. University of Michigan Press. https://doi.org/10.1353/book.36854.

"Dropping the Democratic Facade." n.d. Freedom House. Accessed January 26, 2021. https://freedomhouse.org/report/nations-transit/2020/dropping-democratic-facade.

Duncan, Grant. 2018. "Trust, Distrust, and the End of Politics-as-We-Knew-It: The Mood of the Nation Prior to Election 2017." Kōtuitui: New Zealand Journal of Social Sciences Online 13 (2): 114-31. https://doi.org/10.1080/1177083X.2017.1355817. 
Eder, Mine. “Turkey.” In The Middle East, edited by Ellen Lust, 695-728. Fifteenth edition (Thousand Oaks, California: CQ Press, an imprint of SAGE Publications, 2020).

"Elites, Masses, and Democratic Decline in Indonesia." n.d. Accessed January 18, 2021. http://www.tandfonline.com/doi/epub/10.1080/13510347.2019.1680971?needAcces $\underline{\mathrm{s}=\text { true. }}$.

Farrell, Henry, and Abraham Newman. 2019. Of Privacy and Power: The Transatlantic Struggle over Freedom and Security. Princeton, New Jersey: Princeton University Press.

Ferrín, Mónica, and Hanspeter Kriesi, eds. 2016. How Europeans View and Evaluate Democracy. Oxford University Press. https://doi.org/10.1093/acprof:oso/9780198766902.001.0001.

“Gao-17-300.Pdf." n.d. Accessed April 23, 2021. https://www.gao.gov/assets/gao-17300.pdf.

Gerring, John. 2009. The Case Study: What It Is and What It Does. Edited by Carles Boix and Susan C. Stokes. Vol. 1. Oxford University Press. https://doi.org/10.1093/oxfordhb/9780199566020.003.0004.

Goldstone, Jack A., Robert H. Bates, David L. Epstein, Ted Robert Gurr, Michael B. Lustik, Monty G. Marshall, Jay Ulfelder, and Mark Woodward. 2010. "A Global Model for Forecasting Political Instability." American Journal of Political Science 54 (1): 190-208.

“GTI-2020-Web-1.Pdf.” n.d. Accessed February 14, 2021. https://www.visionofhumanity.org/wp-content/uploads/2020/11/GTI-2020-web$1 . \mathrm{pdf}$.

Hadenius, Axel, and Jan Teorell. 2005. "Cultural and Economic Prerequisites of Democracy: Reassessing Recent Evidence.” Studies in Comparative International Development 39(4): 87- 106. https://doi.org/10.1007/BF02686166.

Harris, James. n.d. "United States - Government and Security.” Encyclopedia Britannica. Accessed April 23, 2021. https://www.britannica.com/place/United-States.

Huysmans, Jef. 2006. The Politics of Insecurity: Fear, Migration, and Asylum in the EU. The New International Relations. London; New York: Routledge.

Inc, Gallup. 2007. “Terrorism.” Gallup.Com. September 14, 2007. https://news.gallup.com/poll/4909/Terrorism-United-States.aspx. 
Inc, Gallup. 2008. "Presidential Approval Ratings -- Gallup Historical Statistics and Trends." Gallup.Com. March 12, 2008. https://news.gallup.com/poll/116677/Presidential-Approval-Ratings-GallupHistorical-Statistics-Trends.aspx.

Inglehart, Ronald. 2003. "How Solid Is Mass Support for Democracy: And How Can We Measure It?" PS: Political Science and Politics 36 (1): 51-57.

Inglehart, Ronald, and Christian Welzel. 2005. Modernization, Cultural Change, and Democracy: The Human Development Sequence. Cambridge: Cambridge University Press.

Jackson, Richard. 2005. "Security, Democracy, and the Rhetoric of Counter-Terrorism." Democracy and Security 1 (2): 147-71. https://doi.org/10.1080/17419160500322517.

Klaas, Brian. 2017. The Despot's Accomplice: How the West Is Aiding and Abetting the Decline of Democracy. Oxford, UNITED STATES: Oxford University Press, Incorporated. http://ebookcentral.proquest.com/lib/psu/detail.action?docID=4803718.

Laperruque, Jake. 2020. "PATRIOT Act Morass: Gains and Stalled Reforms." Project On Government Oversight. March 17, 2020. https://www.pogo.org/analysis/2020/03/patriot-act-morass-gains-and-stalledreforms/.

Levitsky, Steven. 2018. "Democratic Survival and Weakness." Journal of Democracy 29 (4): 102-13. https://doi.org/10.1353/jod.2018.0066.

Levitsky, Steven, and Daniel Ziblatt. 2018. How Democracies Die. First edition. New York: Crown.

Lewis, Peirce. n.d. "United States | History, Map, Flag, \& Population." Encyclopedia Britannica. Accessed April 23, 2021. https://www.britannica.com/place/United$\underline{\text { States. }}$

Linz, Juan J. 1978. Crisis, Breakdown \& Reequilibration. The Breakdown of Democratic Regimes. Baltimore: Johns Hopkins University Press.

Lust, Ellen, ed. 2020. The Middle East. Fifteenth edition. Thousand Oaks, California: CQ Press, an imprint of SAGE Publications.

Miller, Doug, and John Elkington. 2017. Can the World Be Wrong?: Where Global Public Opinion Says We're Headed. https://search.ebscohost.com/login.aspx?direct=true \&scope $=$ site $\& \mathrm{db}=$ nlebk $\& \mathrm{db}=$ nla bk\&AN=1592386. 
Nadler, Jerrold. 2020. "H.R.6172 - 116th Congress (2019-2020): USA FREEDOM Reauthorization Act of 2020.” Webpage. 2019/2020. June 1, 2020. https://www.congress.gov/bill/116th-congress/house-bill/6172.

Norris, Pippa. 2011. Democratic Deficit: Critical Citizens Revisited. New York: Cambridge University Press.

“Norway Attack Suspect 'Inspired’ by Christchurch, El Paso Shootings: Report.” 2019. POLITICO. August 11, 2019. https://www.politico.eu/article/norway-attacksuspect-inspired-by-christchurch-el-paso-shootings-report/.

Oliver, William Hosking. n.d. "New Zealand | History, Map, Flag, Capital, Population, \& Facts.” Encyclopedia Britannica. Accessed April 23, 2021. https://www.britannica.com/place/New-Zealand.

Pavlović, Dušan. 2019. "When Do Neoliberal Economic Reforms Cause Democratic Decline? Evidence from the Post-Communist Southeast Europe." Post-Communist Economies 31 (5): 671-97. https://doi.org/10.1080/14631377.2019.1607436.

"Population by Country (2021) - Worldometer." n.d. Accessed April 23, 2021. https://www.worldometers.info/world-population/population-by-country/.

Przeworski, Adam. 2005. "Democracy as an Equilibrium.” Public Choice 123 (3/4): 25373.

Qi, Lingling, and Doh Chull Shin. 2011. "How Mass Political Attitudes Affect Democratization: Exploring the Facilitating Role Critical Democrats Play in the Process." International Political Science Review 32(3): 245-62. https://doi.org/10.1177/0192512110382029.

Raskin, Marcus G. 1976. "Democracy versus the National Security State." Law and Contemporary Problems 40 (3): 189-220. https://doi.org/10.2307/1191397.

Robbins, Michael D. H., and Mark Tessler. 2012. "The Effect of Elections on Public Opinion Toward Democracy: Evidence From Longitudinal Survey Research in Algeria." Comparative Political Studies 45 (10): 1255-76. https://doi.org/10.1177/0010414011434296.

Sarigil, Zeki. 2015. "Public Opinion and Attitude toward the Military and Democratic Consolidation in Turkey." Armed Forces \& Society 41 (2): 282-306. https://doi.org/10.1177/0095327X13504573.

Shin, Doh Chull, and Hannah June Kim. 2018. "How Global Citizenries Think about Democracy: An Evaluation and Synthesis of Recent Public Opinion Research." Japanese Journal of Political Science 19 (2): 222-49. https://doi.org/10.1017/S1468109918000063. 
Sidel, Mark. 2007. More Secure, Less Free?: Antiterrorism Policy \& Civil Liberties after September 11. Ann Arbor: University of Michigan Press. http://public.ebookcentral.proquest.com/choice/publicfullrecord.aspx?p=3414672.

Small, David. 2011. "The Uneasy Relationship between National Security and Personal Freedom: New Zealand and the 'War on Terror.'" International Journal of Law in Context 7 (4): 467-86. https://doi.org/10.1017/S1744552311000255.

Smith, J. E. 2003. "New Zealand's Anti-Terrorism Campaign: Balancing Civil Liberties, National Security and International Responsibilities." Ian Axford Fellowship Report. Washington, DC: US Department of Justice.

Soliev, Nodirbek. 2017. "The Terrorist Threat in Turkey: A Dangerous New Phase." Counter Terrorist Trends and Analyses 9 (4): 24-29.

Svolik, Milan W. 2015. "Which Democracies Will Last? Coups, Incumbent Takeovers, and the Dynamic of Democratic Consolidation." British Journal of Political Science 45 (4): 715-38. https://doi.org/10.1017/S0007123413000550.

Thomassen, Jacques, and Carolien van Ham. 2017. A Legitimacy Crisis of Representative Democracy? Vol. 1. Oxford University Press. https://doi.org/10.1093/oso/9780198793717.003.0001.

Tilly, Charles. 1978. From Mobilization to Revolution. Reading, Mass: Addison-Wesley Pub. Co.

Tilly, Charles. 2007. Democracy. Cambridge, [England] ; New York: Cambridge University Press.

“Timeline.” n.d. Homeland Security Digital Library (blog). Accessed April 23, 2021. https://www.hsdl.org/c/timeline/.

"Turkey: Draft Law Threatens Civil Society." 2020. Human Rights Watch. December 24, 2020. https://www.hrw.org/news/2020/12/24/turkey-draft-law-threatens-civilsociety.

“Turkey: Erdoğan's Onslaught on Rights and Democracy.” 2021. Human Rights Watch. March 24, 2021. https://www.hrw.org/news/2021/03/24/turkey-erdogans-onslaughtrights-and-democracy.

“Turkey’s PKK Conflict: A Visual Explainer.” 2019. Crisis Group. March 1, 2019. https://www.crisisgroup.org/content/turkeys-pkk-conflict-visual-explainer.

TVNZ. December 2020. "Full Statement: Jacinda Ardern Apologizes, Agrees to All Recommendations in Christchurch Attack Report.” Accessed May 24, 2021. 
https://www.tvnz.co.nz/one-news/new-zealand/full-statement-jacinda-ardernapologises-agrees-all-recommendations-in-christchurch-attack-report.

UN General Assembly. 1999. "International Convention for the Suppression of the Financing of Terrorism.” UN Resolution. December 9, 1999. https://www.un.org/law/cod/finterr.htm.

Unal, Mustafa Cosar, and Mustafa Cosar Eunal. 2011. Counterterrorism in Turkey: Policy Choices and Policy Effects Toward the Kurdistan Workers' Party (PKK). Abingdon, Oxon, UNITED STATES: Taylor \& Francis Group. http://ebookcentral.proquest.com/lib/psu/detail.action?docID=958724.

Vowles, Jack, and Raewyn Dalziel. n.d. "New Zealand - Government and Society." Encyclopedia Britannica. Accessed March 30, 2021. https://www.britannica.com/place/New-Zealand.

Vox. 2017. This Is Your Brain on Terrorism. https://www.youtube.com/watch?v=7ZohjYKGZJM\&ab_channel=Vox.

Weßels, Bernhard. 2015. "Political Culture, Political Satisfaction and the Rollback of Democracy." Global Policy 6 (June): 93-105. https://doi.org/10.1111/1758$\underline{5899.12232 .}$.

Welzel, Christian. 2007. "Are Levels of Democracy Affected by Mass Attitudes? Testing Attainment and Sustainment Effects on Democracy." International Political Science Review 28(4): 397-424. https://doi.org/10.1177/0192512107079640.

Zeldin, Wendy. 2015. “Turkey: Counterterrorism and Justice.” Web page. September 2015. https://www.loc.gov/law/help/counterterrorism/turkey.php.

Zraick, Karen. 2019. "New Zealand Ban on Most Semiautomatic Weapons Takes Effect." The New York Times, December 20, 2019, sec. World. https://www.nytimes.com/2019/12/20/world/australia/new-zealand-gun-ban.html. 


\section{Appendix A: Regressions and P-Values}

As noted in the regression analysis above, nearly all of the relationships explored remain significant when we control for country. Following are all the Chi2 Statistics by country for each relationship, and the associated $\mathrm{p}$-value.

If the $p$-value is less than or equal to .05 we can reject the null hypothesis that there is no relationship between the variables. P-values that we cannot reject, meaning we can't confirm that there is a relationship between variables, are highlighted.

Demimport $x$ fear_terror: $(p=1.01 e-187)$

- Turk: $273.9553 \quad[\mathrm{p}=1.066 \mathrm{e}-42]$

- Nwzld: $20.5143 \quad[p=.80849522]$

- USA: $82.7472 \quad[p=1.438 \mathrm{e}-07]$

Demimport x secure: $(p=2.85 e-146)$

- Turk: 110.3075 [p=4.925e-12]

- Nwzld: $109.3106 \quad[p=7.256 e-12]$

- USA: $90.8913 \quad[p=7.653 e-09]$

Demimport $x$ free_v_secure: $(p=5.96 e-17)$

- Turk: $44.2144 \quad[p=1.289 \mathrm{e}-06]$

- Nwzld: $12.9711 \quad[\mathrm{p}=.16391832]$

- USA: $84.7674 \quad[p=1.816 e-14]$

Demcntry $x$ fear_terror: $(p=4.42 e-257)$

- Turk: 138.1645 [p=6.950e-17]

- Nwzld: $44.7917 \quad[p=.01710244]$

- USA: $80.5039 \quad[p=3.167 e-07]$

Demcntry x secure: $\quad(p=<0.000)$

- Turk: 159.6445 [p=8.910e-21]

- Nwzld: $83.3470 \quad$ [p=1.163e-07]

- USA: $176.0887 \quad[p=8.017 e-24]$

Demcntry $x$ free_v_secure: $\quad(p=7.015 e-09)$

- Turk: $92.4798 \quad[p=5.171 e-16]$

- Nwzld: $14.2936 \quad[p=.1122579]$

- USA: $27.3806 \quad[p=.00120967]$ 
Country Isolation Regressions

Perceived Democraticness of Country x Sense of Security in Neighborhood:

\begin{tabular}{|c|c|c|c|c|c|}
\hline TURKEY & Sense o & Security & n Neighborl & lood & \\
\hline $\begin{array}{l}\text { How Democratically is This Country } \\
\text { Being Run Today? }\end{array}$ & $\begin{array}{l}\text { Very } \\
\text { Secure }\end{array}$ & $\begin{array}{l}\text { Quite } \\
\text { Secure }\end{array}$ & $\begin{array}{l}\text { Not Very } \\
\text { Secure }\end{array}$ & $\begin{array}{l}\text { Not at all } \\
\text { Secure }\end{array}$ & Total \\
\hline Not at all Democratic & $2.58 \%$ & $1.90 \%$ & $8.53 \%$ & $11.76 \%$ & $3.59 \%$ \\
\hline 2 & $3.09 \%$ & $2.02 \%$ & $4.05 \%$ & $7.35 \%$ & $6.27 \%$ \\
\hline 3 & $3.09 \%$ & $6.01 \%$ & $10.02 \%$ & $8.82 \%$ & $12.93 \%$ \\
\hline 4 & $4.12 \%$ & $9.86 \%$ & $8.53 \%$ & $11.76 \%$ & $22.10 \%$ \\
\hline 5 & $7.22 \%$ & $14.89 \%$ & $14.50 \%$ & $17.65 \%$ & $36.41 \%$ \\
\hline 6 & $9.79 \%$ & $13.53 \%$ & $16.20 \%$ & $10.29 \%$ & $50.07 \%$ \\
\hline 7 & $21.13 \%$ & $17.64 \%$ & $11.94 \%$ & $10.29 \%$ & $66.63 \%$ \\
\hline 8 & $18.04 \%$ & $19.22 \%$ & $12.15 \%$ & $10.29 \%$ & $84.05 \%$ \\
\hline 9 & $12.37 \%$ & $7.33 \%$ & $6.82 \%$ & $7.35 \%$ & $91.70 \%$ \\
\hline Completely Democratic & $18.56 \%$ & $7.52 \%$ & $7.25 \%$ & $4.41 \%$ & $100.00 \%$ \\
\hline Total & 194 & 1,582 & 469 & 68 & 2,313 \\
\hline Chi-Square: 159.6445 & P-Value & 0.00 & & & \\
\hline
\end{tabular}

\begin{tabular}{|c|c|c|c|c|c|}
\hline \multirow{2}{*}{$\begin{array}{l}\text { NEW ZEALAND } \\
\text { How Democratically is This Country } \\
\text { Being Run Today? }\end{array}$} & \multicolumn{4}{|c|}{ Sense of Security in Neighborhood } & \multirow[b]{2}{*}{ Total } \\
\hline & $\begin{array}{l}\text { Very } \\
\text { Secure }\end{array}$ & $\begin{array}{l}\text { Quite } \\
\text { Secure }\end{array}$ & $\begin{array}{l}\text { Not } \\
\text { Very } \\
\text { Secure }\end{array}$ & $\begin{array}{l}\text { Not at all } \\
\text { Secure }\end{array}$ & \\
\hline Not at all Democratic & $2.07 \%$ & $1.67 \%$ & $4.65 \%$ & $15.38 \%$ & $2.25 \%$ \\
\hline 2 & $0.30 \%$ & $0.74 \%$ & $1.16 \%$ & $0.00 \%$ & $2.86 \%$ \\
\hline 3 & $1.48 \%$ & $1.85 \%$ & $6.98 \%$ & $7.69 \%$ & $5.11 \%$ \\
\hline 4 & $1.48 \%$ & $2.78 \%$ & $2.33 \%$ & $7.69 \%$ & $7.46 \%$ \\
\hline 5 & $5.92 \%$ & $9.07 \%$ & $13.95 \%$ & $15.38 \%$ & $15.96 \%$ \\
\hline 6 & $3.55 \%$ & $8.33 \%$ & $10.47 \%$ & $7.69 \%$ & $22.82 \%$ \\
\hline 7 & $11.83 \%$ & $16.48 \%$ & $17.44 \%$ & $15.38 \%$ & $37.76 \%$ \\
\hline 8 & $28.70 \%$ & $30.74 \%$ & $26.74 \%$ & $15.38 \%$ & $67.24 \%$ \\
\hline 9 & $24.85 \%$ & $19.26 \%$ & $4.65 \%$ & $7.69 \%$ & $86.99 \%$ \\
\hline Completely Democratic & $19.82 \%$ & $9.07 \%$ & $11.63 \%$ & $1.69 \%$ & $100.00 \%$ \\
\hline Total & 338 & 540 & 86 & 13 & 977 \\
\hline Chi-Square: 83.3470 & \multicolumn{2}{|c|}{ P-Value: $<0.00$} & & & \\
\hline
\end{tabular}




\begin{tabular}{|c|c|c|c|c|c|}
\hline \multirow{2}{*}{$\begin{array}{l}\text { UNITED STATES } \\
\text { How Democratically is This } \\
\text { Country Being Run Today? }\end{array}$} & \multicolumn{4}{|c|}{ Sense of Security in Neighborhood } & \multirow[b]{2}{*}{ Total } \\
\hline & $\begin{array}{l}\text { Very } \\
\text { Secure }\end{array}$ & $\begin{array}{l}\text { Quite } \\
\text { Secure }\end{array}$ & $\begin{array}{l}\text { Not Very } \\
\text { Secure }\end{array}$ & $\begin{array}{l}\text { Not at all } \\
\text { Secure }\end{array}$ & \\
\hline Not at all Democratic & $5.96 \%$ & $3.02 \%$ & $5.61 \%$ & $17.39 \%$ & $4.69 \%$ \\
\hline & $1.32 \%$ & $2.65 \%$ & $3.82 \%$ & $2.17 \%$ & $7.53 \%$ \\
\hline & $5.63 \%$ & $4.79 \%$ & $7.26 \%$ & $15.22 \%$ & $13.57 \%$ \\
\hline & $4.97 \%$ & $7.60 \%$ & $9.81 \%$ & $7.61 \%$ & $21.54 \%$ \\
\hline & $10.60 \%$ & $16.81 \%$ & $23.31 \%$ & $22.83 \%$ & $39.84 \%$ \\
\hline & $1.92 \%$ & $13.86 \%$ & $13.38 \%$ & $5.43 \%$ & $53.02 \%$ \\
\hline & $22.85 \%$ & $21.31 \%$ & $15.41 \%$ & $9.78 \%$ & $72.27 \%$ \\
\hline & $13.91 \%$ & $19.10 \%$ & $11.85 \%$ & $8.70 \%$ & $88.13 \%$ \\
\hline & $10.26 \%$ & $6.05 \%$ & $4.97 \%$ & $5.43 \%$ & $94.32 \%$ \\
\hline Completely Democratic & $12.58 \%$ & $4.79 \%$ & $4.59 \%$ & $5.43 \%$ & $100.00 \%$ \\
\hline Total & 302 & 1,356 & 785 & 92 & 2,535 \\
\hline Chi-Square: 176.0887 & \multicolumn{2}{|c|}{ P-Value: $<0.00$} & & & \\
\hline Source: World Values Survey- & $7(2017$ & & & & \\
\hline
\end{tabular}

Perceived Democraticness of Country x Worry of a Terrorist Attack:

\begin{tabular}{|c|c|c|c|c|c|}
\hline \multirow{2}{*}{$\begin{array}{l}\text { TURKEY } \\
\text { How Democratically is This } \\
\text { Country Being Run Today? }\end{array}$} & \multicolumn{3}{|c|}{ Worries of A Terrorist Attack } & \multirow[b]{2}{*}{$\begin{array}{l}\text { Not At } \\
\text { All }\end{array}$} & \multirow[b]{2}{*}{ Total } \\
\hline & $\begin{array}{l}\text { Very } \\
\text { Much }\end{array}$ & $\begin{array}{l}\text { A Great } \\
\text { Deal }\end{array}$ & $\begin{array}{l}\text { Not } \\
\text { Much }\end{array}$ & & \\
\hline Not at all Democratic & $5.99 \%$ & $1.28 \%$ & $2.14 \%$ & $11.63 \%$ & $3.59 \%$ \\
\hline 2 & $3.40 \%$ & $2.36 \%$ & $1.43 \%$ & $0.00 \%$ & $6.24 \%$ \\
\hline 3 & $7.69 \%$ & $5.51 \%$ & $5.71 \%$ & $11.63 \%$ & $12.82 \%$ \\
\hline 4 & $6.89 \%$ & $10.33 \%$ & $13.21 \%$ & $2.33 \%$ & $21.88 \%$ \\
\hline 5 & $10.89 \%$ & $18.01 \%$ & $17.14 \%$ & $0.00 \%$ & $36.41 \%$ \\
\hline 6 & $12.49 \%$ & $14.96 \%$ & $13.57 \%$ & $11.63 \%$ & $50.09 \%$ \\
\hline 7 & $16.58 \%$ & $16.14 \%$ & $15.71 \%$ & $23.26 \%$ & $66.50 \%$ \\
\hline 8 & $16.68 \%$ & $19.29 \%$ & $14.64 \%$ & $9.30 \%$ & $83.94 \%$ \\
\hline 9 & $7.59 \%$ & $7.38 \%$ & $8.21 \%$ & $9.30 \%$ & $91.55 \%$ \\
\hline Completely Democratic & $11.79 \%$ & $4.72 \%$ & $8.21 \%$ & $20.93 \%$ & $\begin{array}{r}100.00 \\
\%\end{array}$ \\
\hline Total & 1,001 & 1,016 & 280 & 43 & 2,340 \\
\hline Chi-Square: 138.1645 & \multicolumn{2}{|c|}{ P-Value: $<0.00$} & & & \\
\hline \multicolumn{5}{|c|}{ Source: World Values Survey- Wave 7 (2017-2020) } & \\
\hline
\end{tabular}




\begin{tabular}{|c|c|c|c|c|c|}
\hline \multirow{2}{*}{$\begin{array}{l}\text { NEW ZEALAND } \\
\text { How Democratically is This } \\
\text { Country Being Run Today? }\end{array}$} & \multicolumn{3}{|c|}{ Worries of A Terrorist Attack } & \multirow[b]{2}{*}{$\begin{array}{l}\text { Not At } \\
\text { All }\end{array}$} & \multirow[b]{2}{*}{ Total } \\
\hline & Very Much & $\begin{array}{l}\text { A Great } \\
\text { Deal }\end{array}$ & $\begin{array}{l}\text { Not } \\
\text { Much }\end{array}$ & & \\
\hline Not at all Democratic & $5.51 \%$ & $2.03 \%$ & $1.10 \%$ & $3.24 \%$ & $2.28 \%$ \\
\hline & $0.79 \%$ & $1.02 \%$ & $0.66 \%$ & $0.54 \%$ & $3.01 \%$ \\
\hline & $0.79 \%$ & $4.06 \%$ & $2.41 \%$ & $1.62 \%$ & $5.39 \%$ \\
\hline & $3.15 \%$ & $2.54 \%$ & $2.19 \%$ & $2.16 \%$ & $7.77 \%$ \\
\hline & $15.75 \%$ & $7.61 \%$ & $6.14 \%$ & $9.19 \%$ & $16.06 \%$ \\
\hline & $7.09 \%$ & $8.63 \%$ & $5.70 \%$ & $7.03 \%$ & $22.80 \%$ \\
\hline & $11.02 \%$ & $19.29 \%$ & $14.91 \%$ & $12.43 \%$ & $37.62 \%$ \\
\hline & $22.05 \%$ & $29.95 \%$ & $33.11 \%$ & $28.65 \%$ & $67.78 \%$ \\
\hline tha & $17.32 \%$ & $14.72 \%$ & $22.15 \%$ & $19.46 \%$ & $87.26 \%$ \\
\hline Completely Democratic & $16.54 \%$ & $10.15 \%$ & $11.62 \%$ & $15.68 \%$ & $100.00 \%$ \\
\hline Total & 127 & 197 & 456 & 185 & 965 \\
\hline Chi-Square: 44.7917 & \multicolumn{2}{|c|}{ P-Value: 0.0171} & & & \\
\hline \multicolumn{5}{|c|}{ Source: World Values Survey- Wave 7 (2017-2020) } & \\
\hline
\end{tabular}

\begin{tabular}{|c|c|c|c|c|c|}
\hline \multirow{2}{*}{$\begin{array}{l}\text { UNITED STATES } \\
\text { How Democratically is This } \\
\text { Country Being Run Today? }\end{array}$} & \multicolumn{3}{|c|}{ Worries of A Terrorist Attack } & \multirow[b]{2}{*}{$\begin{array}{l}\text { Not At } \\
\text { All }\end{array}$} & \multirow[b]{2}{*}{ Total } \\
\hline & Very Much & $\begin{array}{l}\text { A Great } \\
\text { Deal }\end{array}$ & $\begin{array}{l}\text { Not } \\
\text { Much }\end{array}$ & & \\
\hline Not at all Democratic & $6.87 \%$ & $3.77 \%$ & $3.03 \%$ & $10.87 \%$ & $4.70 \%$ \\
\hline 2 & $2.72 \%$ & $2.28 \%$ & $3.43 \%$ & $3.62 \%$ & $7.51 \%$ \\
\hline 3 & $5.59 \%$ & $5.75 \%$ & $6.20 \%$ & $9.42 \%$ & $13.56 \%$ \\
\hline 4 & $6.55 \%$ & $8.72 \%$ & $8.18 \%$ & $7.97 \%$ & $21.54 \%$ \\
\hline 5 & $21.57 \%$ & $17.64 \%$ & $17.02 \%$ & $15.22 \%$ & $39.83 \%$ \\
\hline 6 & $11.82 \%$ & $12.09 \%$ & $15.57 \%$ & $12.32 \%$ & $52.91 \%$ \\
\hline 7 & $14.54 \%$ & $20.12 \%$ & $22.16 \%$ & $19.57 \%$ & $72.23 \%$ \\
\hline 8 & $14.70 \%$ & $18.24 \%$ & $14.64 \%$ & $10.87 \%$ & $88.11 \%$ \\
\hline 9 & $6.39 \%$ & $6.64 \%$ & $5.80 \%$ & $5.07 \%$ & $94.35 \%$ \\
\hline Completely Democratic & $9.27 \%$ & $4.76 \%$ & $3.96 \%$ & $5.07 \%$ & $100.00 \%$ \\
\hline Total & 626 & 1,009 & 758 & 138 & 2,531 \\
\hline Chi-Square: 80.5039 & \multicolumn{2}{|c|}{ P-Value: $<0.00$} & & & \\
\hline \multicolumn{5}{|c|}{ Source: World Values Survey- Wave 7 (2017-2020) } & \\
\hline
\end{tabular}




\section{Appendix B: Graphs of Full Data}

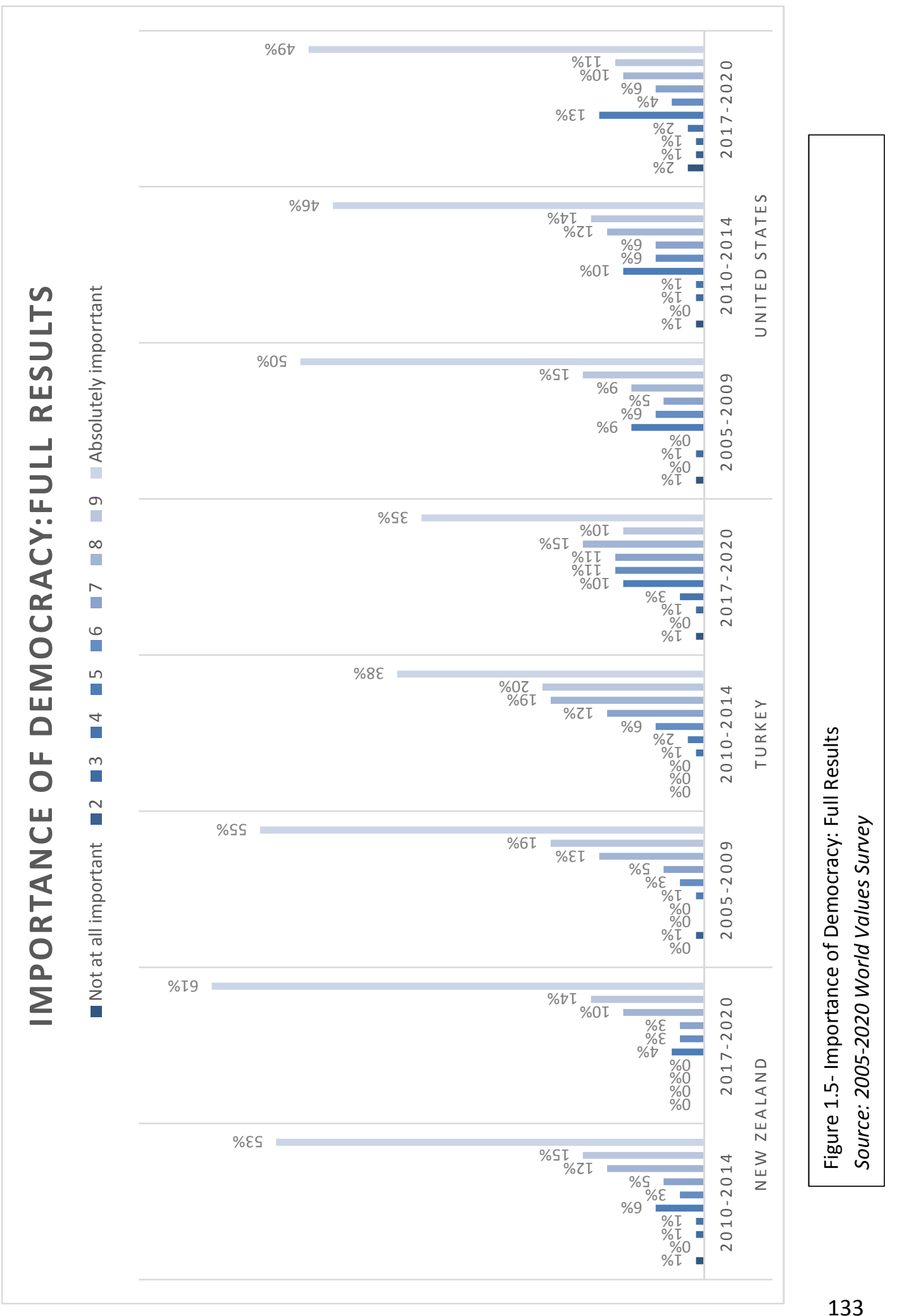




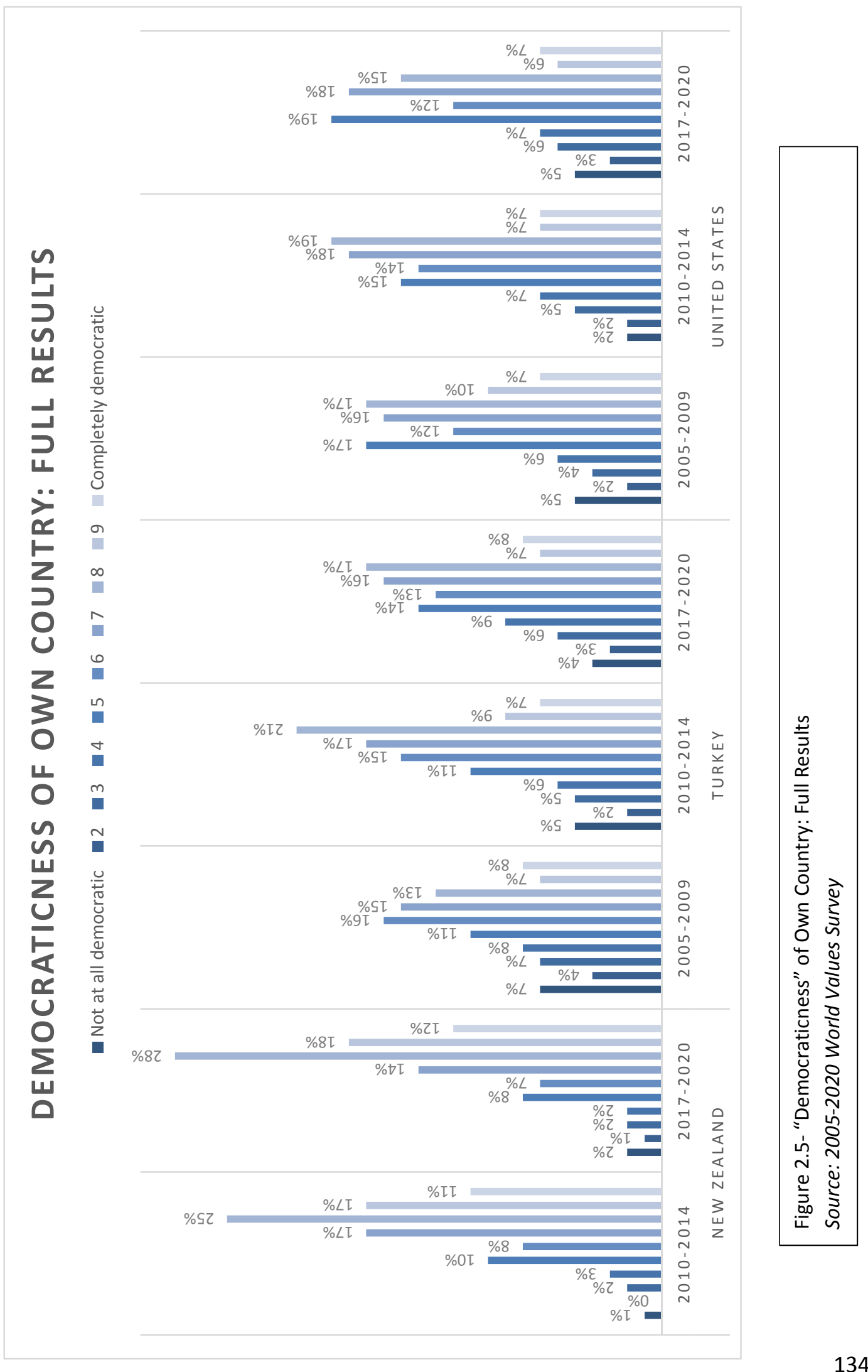




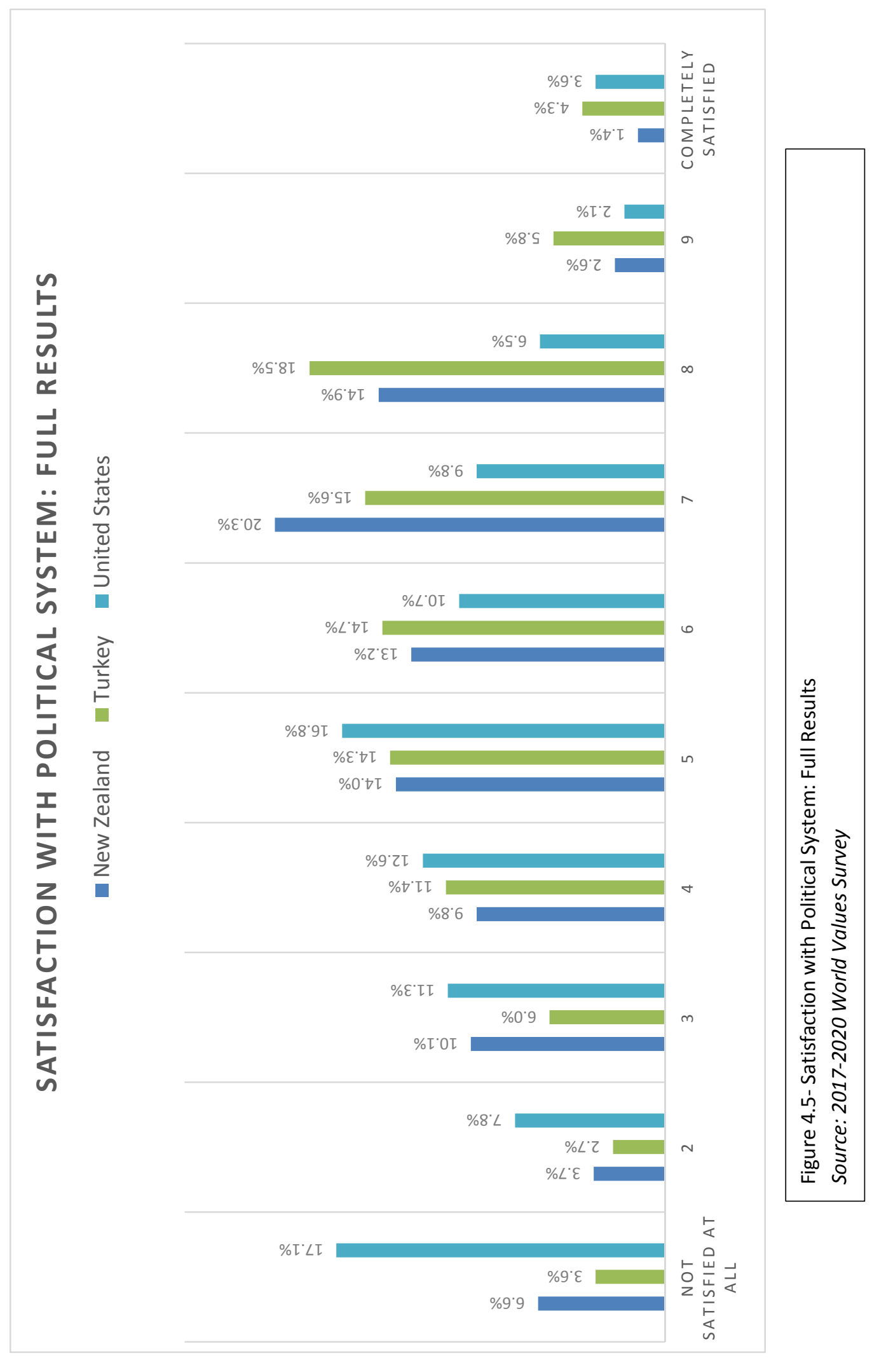




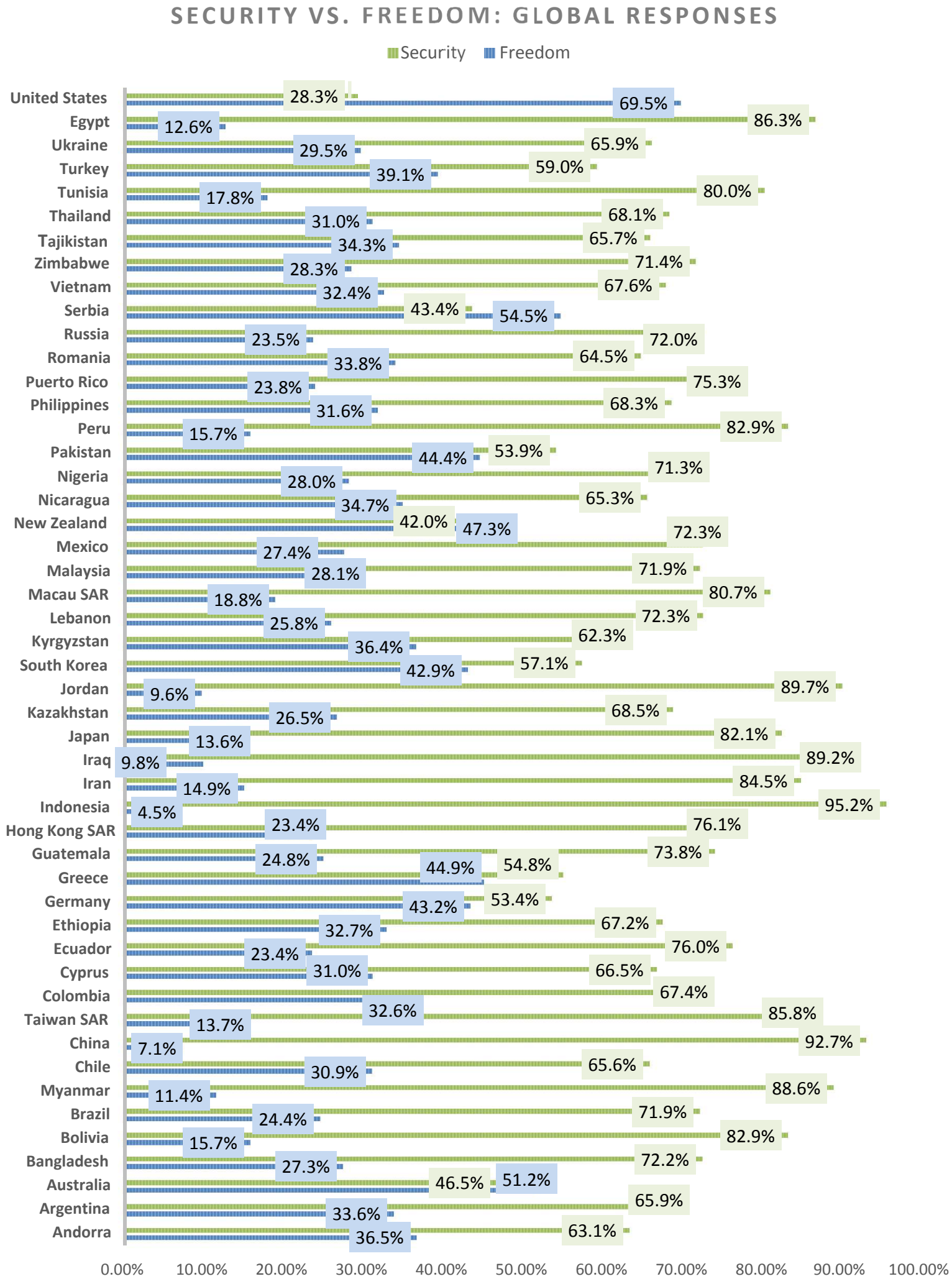

Figure 13.5- Freedom vs. Security: Global Responses; Source: 2017-2020 World Values Survey 